\title{
Dopant-Free All-Organic Small-Molecule HTMs for Perovskite Solar Cells: Concepts and Structure-Property Relationships
}

\author{
Mohamed M. H. Desoky ${ }^{1}\left(\mathbb{D}\right.$, Matteo Bonomo $^{1}{ }^{(\mathbb{D}}$, Roberto Buscaino $^{1}\left(\mathbb{D}\right.$, Andrea Fin $^{2}\left(\mathbb{D}\right.$, Guido Viscardi $^{1}(\mathbb{D}$, \\ Claudia Barolo ${ }^{1}$ (D) and Pierluigi Quagliotto ${ }^{1, *(D)}$ \\ 1 Department of Chemistry and NIS Interdepartmental Center and INSTM Reference Centre, \\ University of Torino, Via Pietro Giuria 7, 10125 Torino, Italy; \\ mohamedmagdyhassan.desoky@unito.it (M.M.H.D.); matteo.bonomo@unito.it (M.B.); \\ roberto.buscaino@unito.it (R.B.); guido.viscardi@unito.it (G.V.); claudia.barolo@unito.it (C.B.) \\ 2 Department of Drug Science and Technology, University of Torino, Via Pietro Giuria 9, 10125 Torino, Italy; \\ andrea.fin@unito.it \\ * Correspondence: pierluigi.quagliotto@unito.it; Tel.: +39-011-6707593
}

check for updates

Citation: Desoky, M.M.H.; Bonomo, M.; Buscaino, R.; Fin, A.; Viscardi, G.; Barolo, C.; Quagliotto, P. Dopant-Free All-Organic Small-Molecule HTMs for Perovskite Solar Cells: Concepts and Structure-Property Relationships. Energies 2021, 14, 2279. https:// doi.org/10.3390/en14082279

Academic Editor:

Emmanuel Kymakis

Received: 16 March 2021

Accepted: 9 April 2021

Published: 18 April 2021

Publisher's Note: MDPI stays neutral with regard to jurisdictional claims in published maps and institutional affiliations.

Copyright: (c) 2021 by the authors. Licensee MDPI, Basel, Switzerland. This article is an open access article distributed under the terms and conditions of the Creative Commons Attribution (CC BY) license (https:// creativecommons.org/licenses/by/ $4.0 /)$.

\begin{abstract}
Since the introduction of Perovskite Solar Cells, their photovoltaic efficiencies have grown impressively, reaching over $25 \%$. Besides the exceptional efficiencies, those solar cells need to be improved to overcome some concerns, such as their intrinsic instability when exposed to humidity. In this respect, the development of new and stable Hole Transporting Materials (HTMs) rose as a new hot topic. Since the doping agents for common HTM are hygroscopic, they bring water in contact with the perovskite layer, thus deteriorating it. In the last years, the research focused on "dopant-free" HTMs, which are inherently conductive without any addition of dopants. Dopant-free HTMs, being small molecules or polymers, have still been a relatively small set of compounds until now. This review collects almost all the relevant organic dopant-free small-molecule HTMs known so far. A general classification of HTMs is proposed, and structure analysis is used to identify structure-property relationships, to help researchers to build better-performing materials.
\end{abstract}

Keywords: Perovskite Solar Cells; Hole Transporting Materials; organic compounds; small molecules; photovoltaic devices; dopant-free

\section{Introduction}

The discovery that organic molecules, normally considered as insulating, were able to conduct electricity was a real breakthrough in the field of organic chemistry [1-3], and organic molecules' conductivity became a hot topic [2-5]. The application of conductive polymers grew rapidly, along with the comprehension of the conductivity phenomenon and charge recombination $[2,6]$. Another breakthrough was obtained by recognizing that electrical conductivity was not a property merely related to polymers but also to small organic molecules, which found great application in organic electronics [7]. While some concepts were recognized, several aspects have to be still studied and determined, since the conductive behavior of small organic molecules is related to both their chemical structure and their molecular arrangement in the solid-state film, when they are packing in amorphous or crystalline state [8]. One of the most interesting and intriguing application fields of small organic molecules involves the Perovskite Solar Cells (PSCs) [9], which recently reached the efficiency record of $25.2 \%[10,11]$.

PSCs always require the presence of both an Electron Transporting Layer (ETL) to drain efficiently electrons and a Hole Transporting Layer (HTL) able to lose electrons efficiently, thus accepting holes. In this manner, both electrons and holes are drained from the photoactive layer (i.e., the perovskite film) to the respective electrode, limiting the recombination phenomena. 
While inorganic Hole Transporting Materials (HTMs) are used in the PSCs with important performances, here they are only briefly mentioned, and some relevant references are given [12-14].

The organic HTMs are divided in two main classes: small-molecules [15,16] and polymeric HTMs [16,17]. In particular, small-molecules HTMs are interesting since they can be produced and easily purified by assembling different moieties, containing Donor and/or Acceptor functional groups tailoring and adapting their properties to the specific perovskite needs, based on the molecular structure and on the solid-state packing state.

Normally, the hole mobility of pristine organic HTM, no matter if small molecules or polymers, is low, in the range $10^{-4}-10^{-6} \mathrm{~cm}^{2} \mathrm{~V}^{-1} \mathrm{~s}^{-1}$. In order to work and perform well in a PSC, a HTM should have a hole mobility of at least $10^{-4} \mathrm{~cm}^{2} \mathrm{~V}^{-1} \mathrm{~s}^{-1}$ [18]; so, the required hole mobility can be usually obtained by doping $[2,19,20]$. So, spiro-OMeTAD (Figure 1) the standard reference small molecule for PSCs, reached a maximum of $21.6 \%$ Power Conversion Efficiency (PCE) in 2017 [21] from doping with t-butylpyridine (tBP) and lithium bis(trifluoromethanesulfonyl)imide (LiTFSI) [2,16,17]. These dopants, in particular the LiTFSI, are hygroscopic and help water to fill in the pores of the HTM layer. As a consequence, the perovskite layer becomes strongly sensitive to moisture and rapidly deteriorates [18].

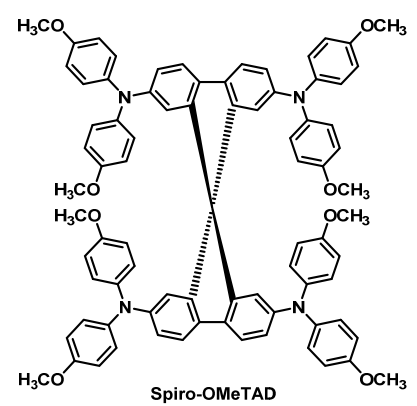

Figure 1. Structure of spiro-OMeTAD. The two moieties connected with the spiro atom are orthogonal to each other.

Alternatively, novel small organic molecules as HTMs being conductive by themselves have been proposed. The present review is focused on this last class of organic HTMs, known also as inherently conductive or dopant-free HTMs [15,16,22-24] The dopant-free HTMs show higher conductivity with respect to most classic HTMs, also in the undoped state. Sometimes the conductivity of dopant-free HTMs is higher in the undoped than if the doped state, and this makes them very attractive for both the fundamental and the applied point of view $[7,16]$. They are among the best candidates for upscaling the Perovskite Solar Cell technology, because of their facile synthesis for industrial production with high yield and purity as they have a distinct molecular weight and structure $[15,24]$.

The literature search was performed mainly on the SciFinder database, by using the combination of the following keywords: (1) dopant-free, Hole Transporting Material * and perovskite; (2) dopant-free, HTM, perovskite and solar cells; or the more general (3) dopant-free, perovskite and solar cells. We included papers from the earliest in 2014, up to April 2020, focusing mainly on HTMs reaching at least $15 \%$ of photovoltaic efficiency to limit the discussion to a reasonable number of papers, while taking into account all relevant papers to find structure-property relationships. We cannot exclude that we missed some articles, since the rate of publication in this hot-topic field is huge, but we made all efforts to cover all the available literature, and we apologize for any undesired omission.

The dopant-free HTMs are analyzed, keeping in mind their structure, to evidence structure-activity relationships that can guide the chemist to better comprehend the fascinating world of conductive organic materials and help towards the development of the novel generations of HTMs for Perovskite Solar Cells (PSCs). In particular, the HTMs are divided into classes based on their topology, e.g., 1D linear, 2D star-shaped, 3D spiro-like 
structures, which confers to them some specific characteristics, such as stacking, face-on orientation, etc. Careful analysis is also devoted to the main Donor and Acceptor cores and to the different coupling of those building blocks. When possible, similar molecules based on the same core are analyzed for the differences resulting from the subtle modifications due to the coupling with different substituents or inserted moieties, to evidence how they influence not only the final PCE but also the HTM whole properties and its structure in the solid-state film.

\section{Perovskite Solar Cells}

Starting from 2012, PSC has gained growing attention, becoming the most investigated emerging photovoltaic technology, approaching the efficiency of silicon-based devices $[10,11,25]$. As a matter of fact, PSCs will be the most exploited technology in the forthcoming years, both in single and in tandem configuration [26]. However, some criticisms are still present [27].

In PSCs, the photovoltaic activity is assured by the Pb-based perovskite films that allow us to effectively exploit the whole solar radiation in the range 350-800 $\mathrm{nm}$ [28]. In a working device, the perovskite (PSK) layer is sandwiched between a Hole Transporting Layer (HTL) and an Electron Transporting Layer (ETL), allowing an efficient charge extraction. The whole device is generally assembled by successive layer growths onto a Transparent Conductive Oxide (TCO) glass (usually indium tin oxide (ITO), playing the double role of support and front electrode) and closed (both physically and electronically) by a back electrode [9]. More recently, flexible devices (f-PSCs [29] have gained a growing attention especially for indoor and niche application; in this context, the glass is replaced by plastic substrates (e.g., polyethylene terephthalate (PET), polyethylene naphthalate (PEN), etc.).

Indeed, once the device is irradiated, one electron is promoted from the valence band (VB) to the conduction band (CB) of the perovskite. The electron is extracted by the ETL, whereas the neutrality of the active layer is re-established by the electron transfer of an electron from the HTL to the VB of the perovskite (Figure 2) [17,30]. Efficient HTL and ETL are mandatory to obtain high-performing devices. In fact, if the holes and the electrons are not properly and (sufficiently) fast extracted, they tend to recombine with each other, limiting the current powered by the device [30]. To minimize the recombination reactions and speed up charge transport processes, the charge extracting layer should possess some mandatory features: (i) From an energetic point of view, the frontier orbitals of the ETL and HTL should match the VB and CB of the photoactive layer, respectively; (ii) they should be enough conductive and preferentially transparent in order to not cause any parasitic light absorption; (iii) they should be homogeneously deposited and allow an effective covering of the PSK layer; and (iv) they should be thermally stable and not suffer prolonged light and air exposures [31]. Complying with the requirement (ii) for HTM is particularly meaningful when inverted architecture (vide infra) is designed being the Hole Transporting Layer the first the radiation passes through; therefore, any (even the lowest) absorption will dramatically reduce the portion of light could be absorbed and converted by the PSK layer. When dealing with PSCs one should always consider that the suitability of different materials to be employed as ETL or HTM strongly depends on the nature of the perovskite layer and to its energy level straightforwardly. On the other hand, the design of a proper HTM (the same is valid for Electron Transporting Material (ETM)) should also consider that, when the charge extractor material is deposited onto (or beneath) the perovskite layer, it could slightly modify the energetic level of its frontier molecular orbital via the band-bending effect. This will allow the most effective energetic coupling between the different layers, thus minimizing the losses and leading to an optimized efficiency.

From a structural point of view, PSCs could be divided into two classes: normal and inverted geometry (Figure 2) [32]. In the former, taking advantage of conventional Dye-Sensitized Solar Cells (DSSCs), the PSK layer is grown on the ETL, whereas in the latter, the substrate for the growth of the active layer is the HTL. Following on from the different structural role, some HTMs employed in inverted devices (e.g., NiO) could not be 
applied in conventional PSCs. Very interestingly, organic HTMs are suitable for both the architectures. Going deeper in the PSCs structure description, the "normal" geometry can be divided into two subclasses, the "mesoporous" (Figure 2d,e) and "planar" (Figure 2f,g) Perovskite Solar Cells. The former is a direct derivation of the typical DSSC structure, in which a mesoporous oxide (often $\mathrm{TiO}_{2}$ ) is deposited onto the ETL (a compact layer, mostly $\mathrm{TiO}_{2}$ but also $\mathrm{SnO}_{2}, \mathrm{ZnO}$, etc.) and the perovskite is deposited onto the mesoporous layer, just covering the nanoparticles surface (Figure $2 \mathrm{~d}$ ) or infiltrating it and ensuring a large contact surface for the electron transfer (Figure 2e) [28].

The latter is a simpler structure, in which the perovskite is directly deposited/grown on the compact ETL layer (Figure 2f) or the HTL layer (Figure 2g). All structures are completed by the conventional deposition of the HTM (Figure $2 \mathrm{~d}-\mathrm{f}$ ) or ETM (Figure 2g) layer and the metal electrode (mainly $\mathrm{Au}$ or Ag for normal cells and Al for inverted cells). The choice of a mesoporous or a planar structure leads to different advantages: The former allows for an easier perovskite growth and a better charge collection, as the active layer is physically mixed with the ETL; on the other hand, the production of planar PSCs drastically reduces the number of deposition steps and allows for the exploitation of low temperature throughout the fabrication process opening the way to flexible substrates. For further details on the different architectures, the reader is kindly directed to Reference [33].

All of those different approaches to the Perovskite Solar Cells showed excellent efficiencies (higher than 19\%, for mesoporous; $21 \%$ for planar and inverted PSCs) [8,34,35]. Attempts to simplify the PSCs structure were done, and both ETL and/or HTL-free PSCs were conceived [36]. While several concerns have to be overcome, due to the elimination of ETL and/or HTL, which normally help to tune the cell characteristics, the results are very encouraging, and high efficiencies were obtained (as high as 20\%) [36]. More work has still to be done to produce devices that are not only simpler and cost-effective, but also very stable. A further possible architecture is the triple-mesoscopic carbon PSC. This architecture is based on a TCO (Transparent Conductive Oxide) covered by a mesoscopic $\mathrm{TiO}_{2}$ layer, a second mesoscopic insulating layer, normally made of $\mathrm{ZrO}_{2}$, and a final conductive mesoscopic carbon layer. The perovskite infiltrates all the layers, instead to be packed between thin layers as in the more common architectures. This can exploit the ability of perovskite to transport charges, giving to the devices a chance to emerge as a possible alternative solution, obtaining so far a 17\% PCE and giving in general good stabilities [37].

Thoughtful choice of materials allows to tune the features of the resulting devices. For example, the perovskite structure could be modified, by changing both the cation and the anion, in order to tune the absorption of the layer, the energy level of its frontier molecular orbitals, as well as the charge transport properties of the photoactive layer itself. Similarly, the engineering of the extracting layer or the introduction of innovative materials could allow the tuning of the holes and the electrons transport kinetic, reducing the recombination reaction and the hysteresis experimented by the device and leading to mire performing and stable devices. Similarly, the back electrode could be selected to optimize the energy matching with the HTL or ETL in conventional or inverted geometry.

Up to date, PSCs are far to be proved stable for relatively long period, even properly encapsulated, suffering for both intrinsic and extrinsic instability [38-42]. Intrinsic instability is mainly due photo and thermal degradation reaction the active layer occurs in when exposed to sunlight [39]; on the other hand, extrinsic instability is due to external factors, such as moisture and/or oxygen, that tend to react with PSK layer leading to the formation of both $\mathrm{PbI}_{2}$ and hydrated perovskite phases that heavily jeopardize the photoactive features of the perovskite $[31,43,44]$. Instability due to external factors could be minimized by proper encapsulation of the device [45]. Indeed, barriers showing the Water Vapour Transmission Rate (WVTR) and Oxygen Transmission Rate (OTR) up to $10^{-5} \mathrm{~g} \mathrm{~m}^{-2} \mathrm{day}^{-1}$ and $10^{-4} \mathrm{~cm}^{3} \mathrm{~m}^{-2}$ day $^{-1} \mathrm{~atm}^{-1}$, respectively, have been proved to be able to effectively protect the device $[45,46]$. Intrinsic instability is more difficult to univocally avoid being dependent on the nature of the perovskite film, its interfaces with both the extracting layer and the eventual presence of doping molecules in the HTL [44,47]. 


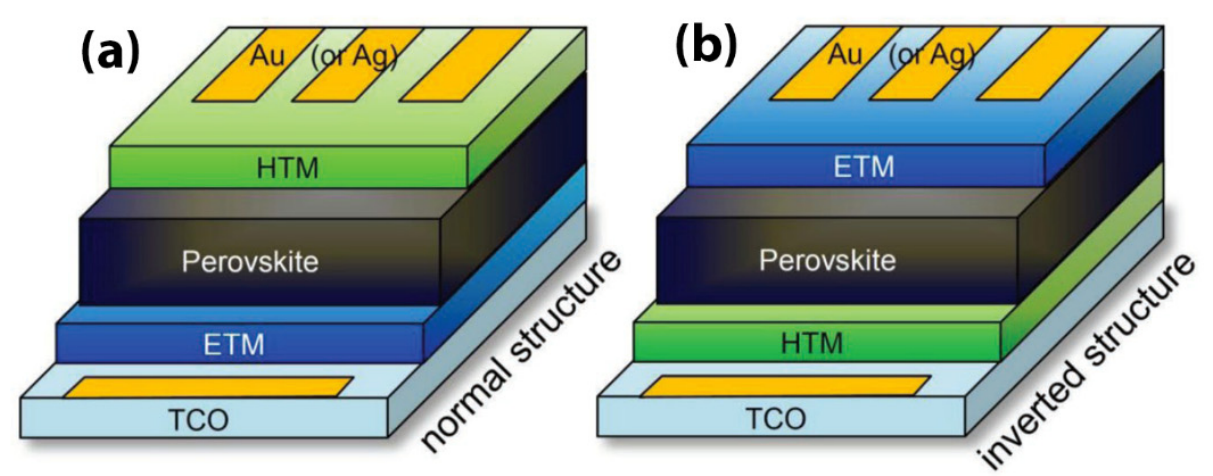

(c)

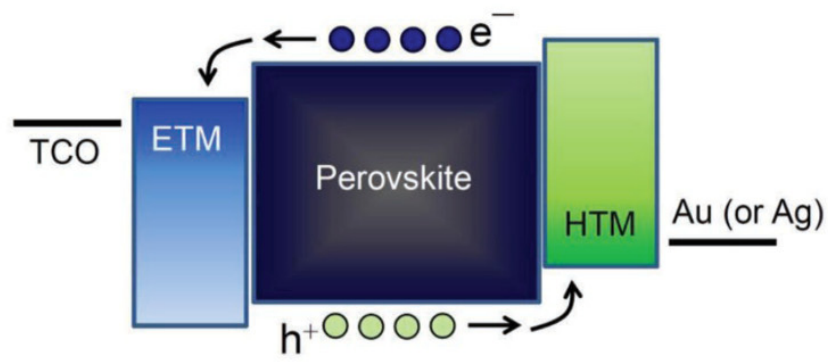

(d)

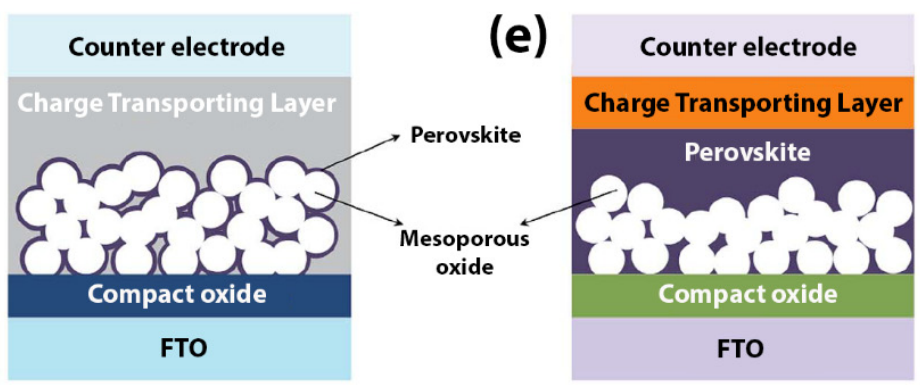

(f)

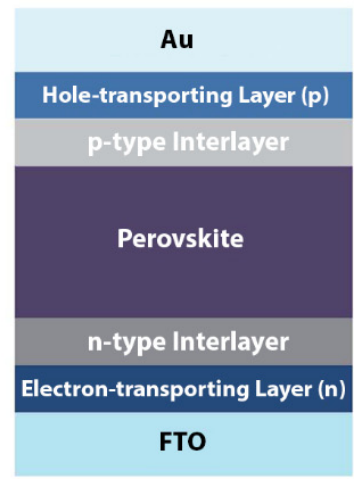

(g)

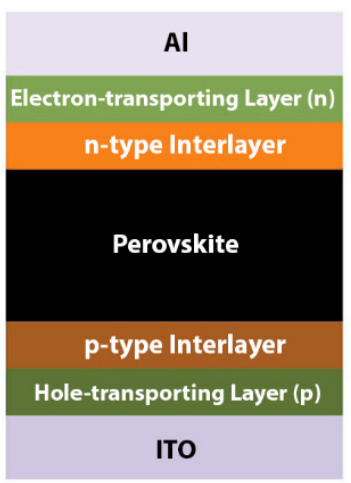

Figure 2. Schematically illustrated device structures depending on electrode polarity and lightabsorption direction: (a) normal structure with n-type Electron Transporting Material (ETM) facing incoming light and (b) inverted structure with p-type Hole Transporting Material (HTM) facing incoming light. (c) Energy level diagram showing carrier transport and injection. Different Perovskite Solar Cell structures: (d) mesoscopic structure with just a thin layer of perovskite over the nanoparticles, (e) mesoscopic structure with an overlayer of perovskite over the totally infiltrated mesoporous oxide, (f) planar conventional architecture and (g) inverted architecture. Reproduced with permission from Reference [6]. Copyright 2018, John Wiley and Sons. Reproduced from Reference [33], with permission from The Royal Society of Chemistry. 


\section{Figures of Merit of Dopant-Free HTMs}

The Power Conversion Efficiency (PCE) of a Perovskite Solar Cell depends on a few parameters: the open circuit voltage $\left(\mathrm{V}_{\mathrm{oc}}\right)$, the short-circuit current density $\left(\mathrm{J}_{\mathrm{sc}}\right)$ and the fill factor (FF). The $V_{o c}$ is the maximum potential could be established between the anode and the cathode when no current passes throughout the device; $\mathrm{J}_{\mathrm{sc}}$, on the other hand, is the maximum current powered by the cell in short circuit condition; finally, FF is an adimensional factor (between 0 and 1 ) accounting for the ideality of the device behavior.

Two main relationships are here reported to describe the mutual relation between these parameters:

$$
\begin{aligned}
\mathrm{FF} & =\mathrm{V}_{\mathrm{mp}} \mathrm{I}_{\mathrm{mp}} / \mathrm{V}_{\mathrm{oc}} \mathrm{J}_{\mathrm{sc}} \\
\mathrm{PCE} & =\eta=\mathrm{V}_{\mathrm{oc}} \mathrm{J}_{\mathrm{sc}} \mathrm{FF} / \mathrm{P}_{\mathrm{in}}
\end{aligned}
$$

where $V_{m p}$ and $I_{m p}$ are the potential $(V)$ and current $(\mathrm{I})$ at the point of maximum power; and $P_{\text {in }}$ is the incident power expressed as constant flux of photons. The PCE is directly depending on $\mathrm{V}_{\mathrm{OC}}, \mathrm{J}_{\mathrm{Sc}}$ and $\mathrm{FF}$; moreover, in this case for every parameter increase, the PCE increases.

Limiting the analyses to the role of HTM in maximizing PCE, the latter should have energy levels of both HOMO and LUMO correctly aligned with the ones of the other device components, namely the perovskite and the back electrode. Taking the vacuum condition as reference, the HTM should have the HOMO higher in energy than the perovskite VB, to be able to inject electrons into the perovskite or, in other words, accept holes from the perovskite. This quantitatively occurs when the HOMO of the HTM is about $0.2 \mathrm{eV}$ higher (i.e., less negative) than the perovskite CB. Secondly, the LUMO of the HTM should be as high as possible with respect to the perovskite $\mathrm{CB}$, since this energy misalignment would avoid electrons to come from the perovskite to the HTM, thus reducing the recombination exerting an electron-blocking effect. Moreover, the HOMO level of the HTM should lie just below the Fermi level of the back electrode in order to assure a fast charge collection. Indeed, all factors that reduce charge recombination contribute to increase the current density and straightforwardly the PCE. The photoactive element of the cell is the perovskite layer, which absorbs the radiation, causing an internal charge separation. Since the perovskite is essential an ambipolar semiconductor, it shows high values for both electron and hole mobility (for $\mathrm{MAPbI}_{3}$, ranging from 2 to $600 \mathrm{~cm}^{2} \mathrm{~V}^{-1} \mathrm{~s}^{-1}$, depending on the perovskite state and of the measurements technique) [48] and electron and hole diffusion lengths (around $100 \mathrm{~nm}$ for $\mathrm{MAPbI}_{3}$ and exceeding $1 \mu \mathrm{m}$ for $\mathrm{MAPbI}_{3-\mathrm{x}} \mathrm{Cl}_{\mathrm{x}}$ ), which means that the charges can travel fast into the perovskite layer and should be removed efficiently by the ETL and HTL, to minimize charge recombination. As an ideal goal, one should find an HTM with a hole mobility of the same order of magnitude. Far from this, the practical cases can afford good efficiencies even with lower hole mobilities but, as shown above, HTM doping is usually performed to improve the hole mobility. The hole transporting ability of small organic molecules is strongly related to the arrangement of the molecules in the solid-state film. This is depending on the HTM structure, on the minimum contact distances among molecules in the solid state, on the HTM wetting ability towards the perovskite surface (better contact between the HTM molecules and the perovskite), but also on the solvent used for the HTM deposition on the perovskite. An ideally performing HTM should met all of those conditions, and it is clear that one has to rely on the best compromise. Notwithstanding, a careful search for structure-activity relationships is opportune to make a rational discussion on how and why the HTM structure can affect the final photovoltaic performances.

\section{Organic Small-Molecule Dopant-Free HTMs: Structure-Activity Relationships}

As a premise to the following discussions, the HTMs whose structure is reported in the schemes and whose data are reported in the tables are marked in bold. Sometimes parent structures are cited (not shown in bold), since they were reported in the same relevant papers, even though they may be not relevant (e.g., their PCE is lower than the cutoff limit 
taken as a reference in this review). Those specific molecules are not shown in bold, but their data are reported in the text as useful remark for the discussion.

Han et al. introduced in 2014 the first dopant-free small-molecule HTM named TTF-1 and based on tetrathiafulvalene scaffold (Figure 3) [49]. The PSCs based on TTF-1 showed an efficiency of $11.03 \%$, close to the efficiency of PSCs based on the reference doped spiro-OMeTAD (11.4\%). Remarkably, the TTF-1 achieved a cell stability for over $500 \mathrm{~h}$, under $40 \%$ relative humidity at room temperature, while the doped spiro-OMeTAD survived only for $120 \mathrm{~h}$. This immediately demonstrated that the elimination of dopants and/or additives from the HTM layer improved the cell stability.

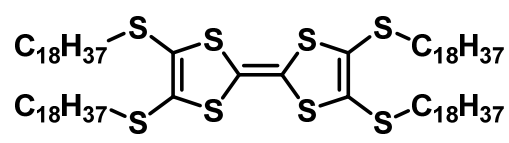

Figure 3. Structure of dopant-free small-molecule HTM named TTF-1.

After the pioneering work of Han et al., the huge work made about this topic caused the literature to "explode", with more than 500 papers published per year in the timeframe 2018-2020. More than 70 articles are here commented concerning only the more performing HTM, showing PCE exceeded $15.0 \%$, classified into families, to have some rough way to deduce structure-activity relationships.

From the chemical-structure point of view, the general structures one can identify are (i) the triarylamino-based structures and (ii) the $\mathrm{D}-\pi-\mathrm{A}$ (Donor- $\pi$-conjugated bridgeAcceptor) structures. The first ones are based on the triarylamino building block, which shows high Donor characteristics. While not being planar, this moiety gives normally high $\mathrm{HOMO}$ to the molecules in which contain it. It can be easily oxidized and so it is naturally prone to be a main constituent of a p-type organic material. Normally, triarylamino based molecules are not showing long conjugation pathway, because the nitrogen of the triarylamino group breaks the conjugation. They can be composed by Donor and Acceptor groups whose interaction is, however, not supported by conjugation.

The $\mathrm{D}-\pi-\mathrm{A}$ structures are well-known as a structural motif of dyes. When a conjugated chain is connected with a Donor group on one edge and an Acceptor group on the opposite edge, this causes an effective transfer of the charge along the chain and reduces consistently the HOMO-LUMO band gap. This results into a "polarization" of the molecule. The presence of unequally distributed charge in the molecule makes it able to accept and release electrons and this can be exploited to favor the charge flow into the material, while still having an organic nature.

From the "morphological/shape" point of view, the general structures one can identify are (i) the 1D linear structures, (ii) the 2D star-shaped structures (discotic) and (iii) 3D spiro-orthogonal structures.

\subsection{Linear 1D Structures}

One-dimensional linear structures are almost linear molecules and are nearly the most abundant in the field of HTMs (see Scheme 1 for the structures reported in this review and Table 1 for the relative performances in photovoltaic devices). They normally possess long and strong $\pi$ conjugation, giving important intermolecular interactions. TTF-1 (Figure 3) is an example of this kind of structures known as the first organic dopant-free HTM. TTF-1 is a simple dimeric molecule having a rigid central core which shows a strong $\pi-\pi$ stacking and S-S interactions. The octadecylthio chains enhance the solubility and create a fastener-effect in the film, which maintains the molecules in a stacked arrangement, giving an excellent hole mobility $\left(0.1 \mathrm{~cm}^{2} \mathrm{~V}^{-1} \mathrm{~s}^{-1}\right)$, while its high HOMO reduced a bit the photovoltage and the whole photovoltaic performances, which were however, higher than pristine and just below the doped spiro-OMeTAD [49]. 
Energies 2021, 14, 2279

8 of 49
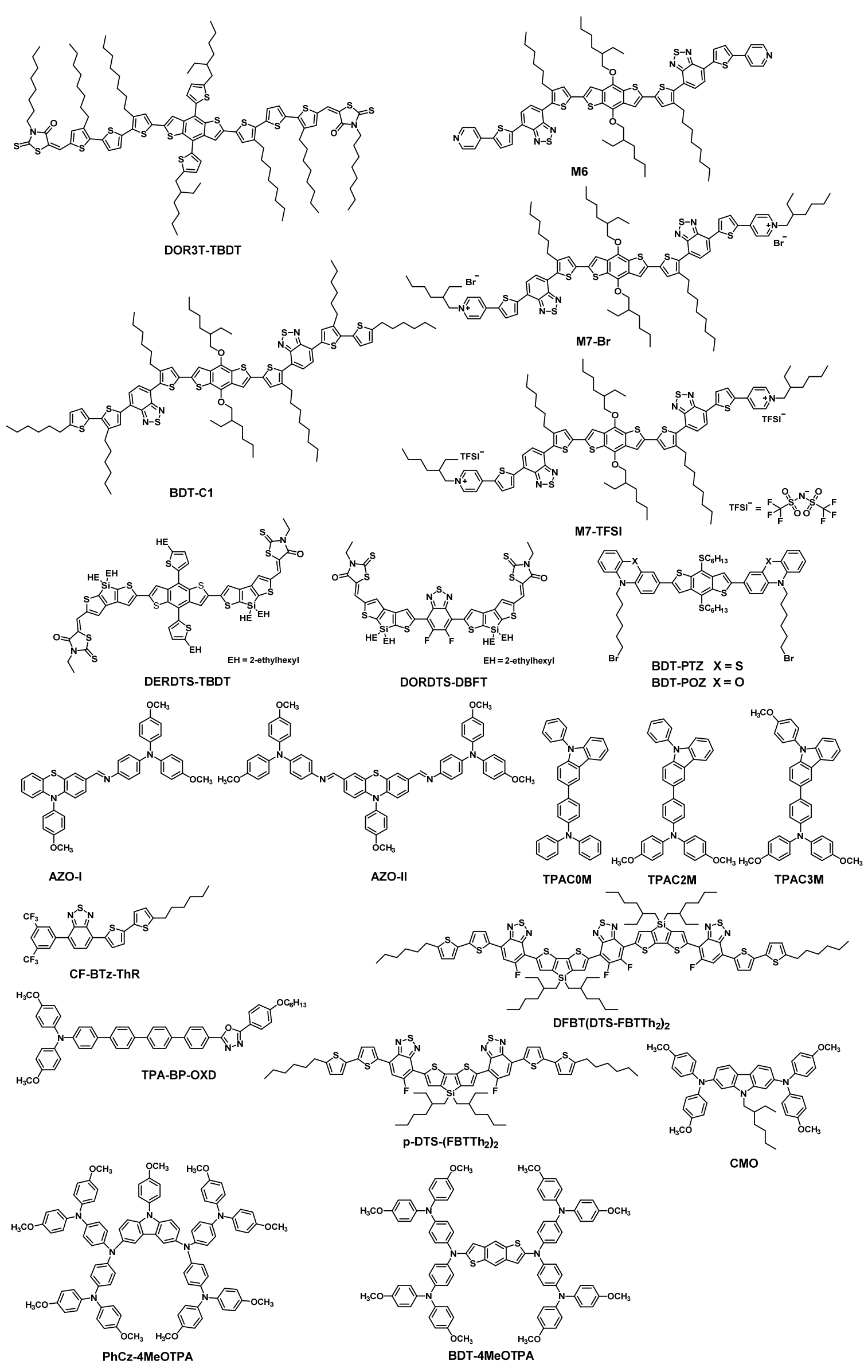

Scheme 1. Cont. 

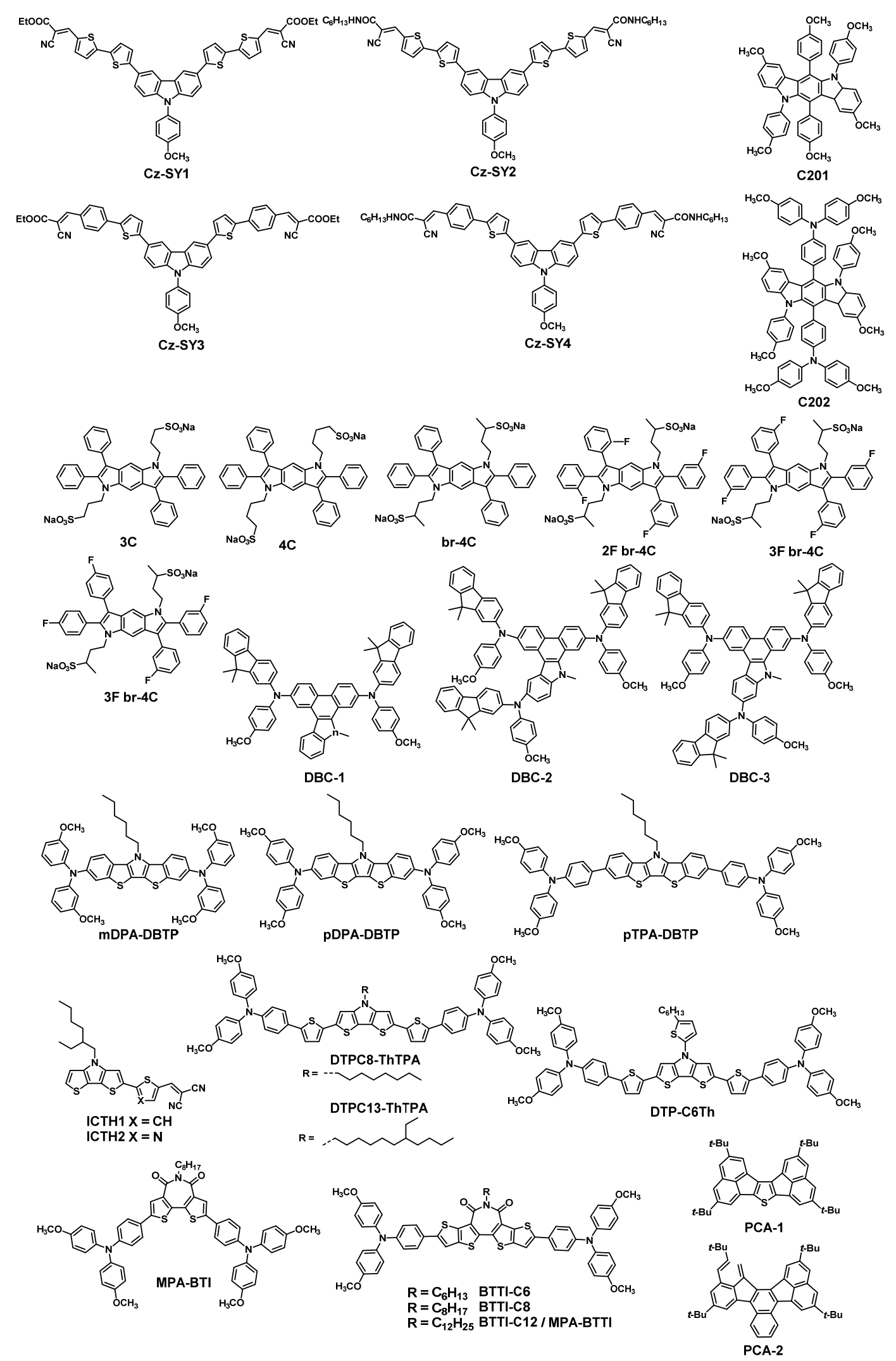

Scheme 1. Cont. 

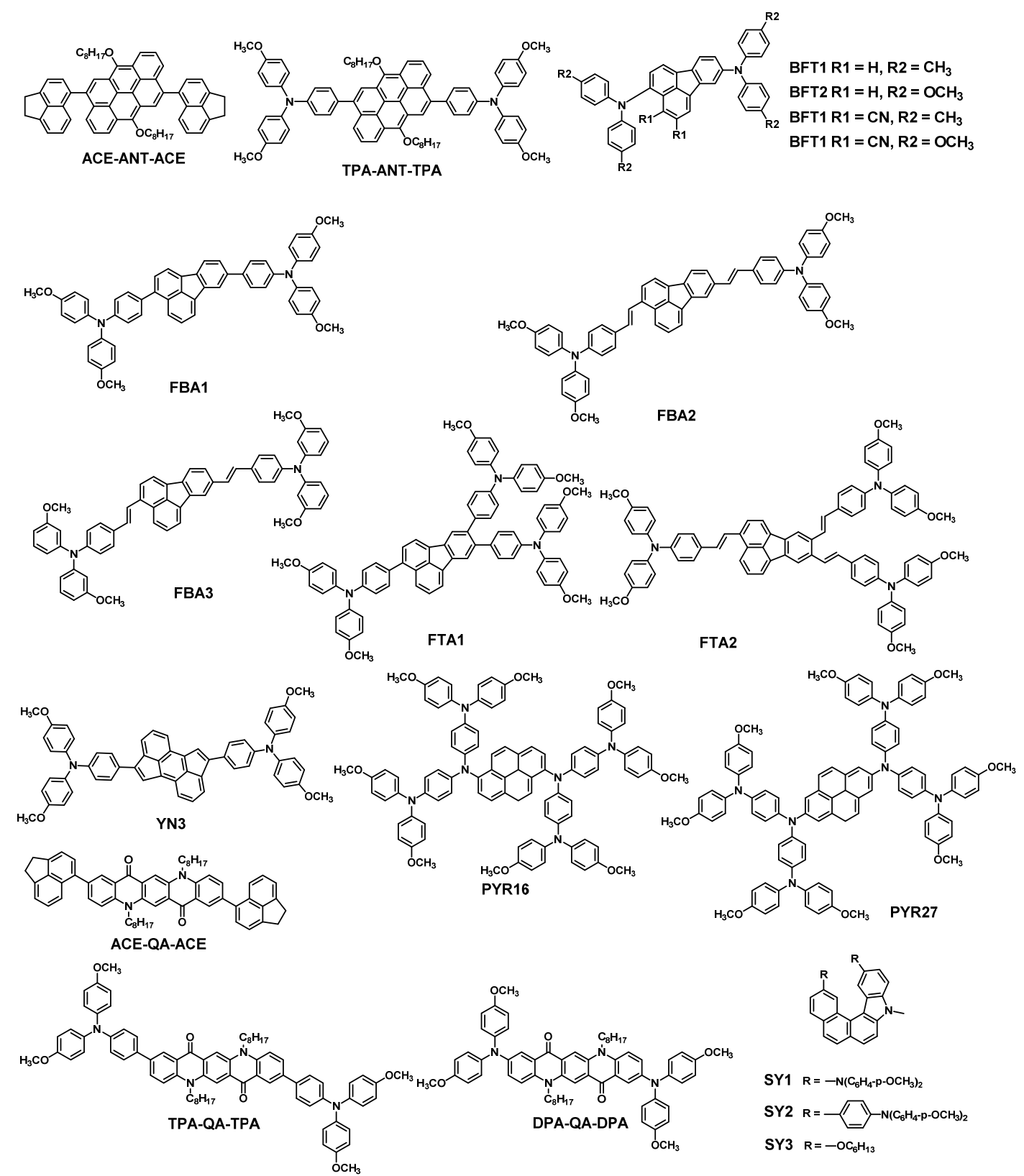

Scheme 1. Structures of organic dopant-free 1D linear HTMs.

The DOR3T-TBDT HTM [50] contains a benzodithiophene (BDT) central core and terthiophene and rodanine residues at both sides. This linear A-D-A HTM showed a 14.9\% efficiency, due to a relatively high conductivity $\left(4 \times 10^{-4} \mathrm{~S} \mathrm{~cm}^{-1}\right)$ and exceptional hole mobility $\left(0.26 \mathrm{~cm}^{2} \mathrm{~V}^{-1} \mathrm{~s}^{-1}\right.$ vs. $10^{-4} \mathrm{~cm}^{2} \mathrm{~V}^{-1} \mathrm{~s}^{-1}$ for spiro-OMeTAD for comparison). This was the first HTM approaching an efficiency of $15.0 \%$, thus overcoming the DSSC limit (14.3\%) [51] and confirming that PSCs would be an excellent opportunity in the photovoltaic field. These excellent results were obtained 6 years after the first use of a perovskite as a light harvester in DSSCs and in 3 years after the Perovskite Solar Cells revolution began.

Three similar structures, M6, M7-Br and M7-TFSI, were prepared, by changing the capping moiety and introducing a charge in the molecule, which performs an internal doping [52]. The general structure was originated from the BDT-C1 [53] HTM, which contains a central BDT (substituted with 2-ethylhexyloxy chains) which bears two benzothiadiazole (BTZ) moieties respectively surrounded by two 3-hexylthiophenes and at the edge of each arm the molecule is capped by 2-hexylthiophene. This molecule reached 
a top PCE of $13.9 \%$. In the M6 a 4-pyridine was used as a capping moiety, instead of the 2-hexylthiophene of BDT-C1. In the M7-Br and M7-TFSI, the pyridine ring was quaternized with a 2-ethylhexyl chain and they simply differ each other for the counterion $(\mathrm{Br}$ or bis(trifluoromethane)sulfonamide (TFSI) anions). In all of these structures, based on BDT, the BTZ is used as an electron trap, helping the charge carrier transfer. When the pyridine is quaternized (M7-Br and M7-TFSI), its higher electron withdrawing effect helps to tune the HOMO at a lower energy level and its positive charge is compensated by the presence of the counterions, such as $\mathrm{Br}$ and TFSI. This helps to obtain higher conductivity for M7-Br and M7-TFSI with respect to M6. The introduction of a charged moiety into the HTM increased the efficiency (13.0\% for M6, 15.1\% for M7-Br and 17.4\% for M7-TFSI) [52].

A further BDT containing structure, DERDTS-TBDT, showed a 16.2\% PCE [54]. The energy levels were correctly aligned and then hole mobility reasonably high $\left(1.0 \times 10^{-4} \mathrm{~cm}^{2} \mathrm{~V}^{-1} \mathrm{~s}^{-1}\right)$. The structure was built onto a central bis(alkylthienyl)BDT core with two dialkyldithienosilole (DTS) groups and capped with a rhodanine. A similar molecule having the same structure but where the BDT core was substituted by a difluorinated BTZ core, DORDTS-DFBT, showed a lower PCE (6.2\%) as a result of incorrectly aligned energy levels (the HOMO is deeper that the perovskite valence band) and very low hole mobility $\left(2.4 \times 10^{-6} \mathrm{~cm}^{2} \mathrm{~V}^{-1} \mathrm{~s}^{-1}\right)$.

Two linear D- $\pi-$ D HTMs, BDT-PTZ and BDT-POZ were prepared by connecting a central bis(hexylthio)-decorated BDT core to N-(6-bromohexyl)phenothiazine or $\mathrm{N}$-(6-bromohexyl)phenoxazine side arms [55]. These two materials showed quite low HOMO energy levels ( -5.42 and $-5.35 \mathrm{eV}$ for BDT-PTZ and BDT-POZ, respectively), and when used in inverted p-i-n $\mathrm{MAPbI}_{3}(-5.46 \mathrm{eV})$ based PSCs (ITO/HTM/MAPbI $/$ [6,6]-phenyl-C(61)-butyric acid methyl ester/bathocuproine/Ag), they showed remarkable efficiencies (18.26\% for BDT-PTZ and 19.16\% for BDT-POZ). Their performances were mainly connected with a very high fill factor. The efficiency order follows the holemobility order and charge-extraction ability, as measured by fluorescence quenching of perovskite by HTMs. The single-crystal XRD measurements gave important information about the molecular packing. While the dislocation of BDT-PTZ molecules in the crystal is not high, this is more pronounced in the case of BDT-POZ. As a result, the minimum distance between the nitrogen atoms of two adjacent molecules appeared to be shorter for BDT-POZ vs. BDT-PTZ (3.850 vs. $8.138 \AA$ ) , thus showing that the two electroactive centers of BDT-POZ are closer and can induce hole hopping among nearby molecules. It is worth mentioning that the same molecules bearing simple hexyl chains instead of 6-bromohexyl did not gave single crystals, and this was attributed to the more polar C-Br bond that seems to induce further interactions that promote an easier crystallization.

The phenothiazine-based HTMs, AZO-I and AZO-II were synthesized easily by bonding N-(4-methoxyphenyl)phenothiazine with TPA through the formation of an imine bond [56]. They showed thermal stability up to about $400{ }^{\circ} \mathrm{C}$, and a Glass Transition Temperature $\left(\mathrm{T}_{\mathrm{g}}\right)$ that, for AZO-II, was found at $120^{\circ} \mathrm{C}$. Their hole mobility was lower than that of spiro-OMeTAD, with AZO-II performing better than AZO-I. The PSCs were assembled with a triple cation perovskite $\left(\mathrm{Cs}_{0.05} \mathrm{MA}_{1-\mathrm{y}} \mathrm{FA}_{\mathrm{y}} \mathrm{PbI}_{3-\mathrm{x}} \mathrm{Cl}_{\mathrm{x}}\right)$, whose valence band is located approximately at $-5.9 \mathrm{eV}$. From this point of view, the high HOMO of the two HTMs (-4.97 eV for AZO-I and $-4.94 \mathrm{eV}$ AZO-II respectively) reduces considerably the $\mathrm{V}_{\mathrm{oc}}$ and the final performances. However, AZO-II gave a PCE of 15.6\%. The stability was checked for non-encapsulated devices at $25^{\circ} \mathrm{C}$, in ambient air, and AZO-II retained up to 91\% of its pristine PCE after 2 months.

Another series of compounds belonging to the triarylamine class was prepared. The compounds TPACOM, TPAC2M and TPAC3M were prepared by assembling a $\mathrm{N}$-phenylcarbazole and a bis(4-methoxyphenyl)phenylamine [57]. They were employed in p-i-n inverse PSC cells. Their HOMO energy levels are quite shallow with respect to the perovskite, and TPAC3M gave the higher $\mathrm{V}_{\mathrm{oc}}$ (about $1 \mathrm{~V}$ ). Those molecules showed a similar, not so great hole mobility. The higher number of alkoxy groups, 0,2 and 3 in TPAC0M, TPAC2M and TPAC3M, respectively, is expected to passivate defects in 
perovskite due to the $\mathrm{Pb}-\mathrm{O}$ interactions, improving the efficiency. This was exactly what was found, with a PCE of 13.92\%, 15.77\% and 17.54\% (PCE average: $12.92 \%, 15.20 \%$ and $16.58 \%$ ) for TPACOM, TPAC2M and TPAC3M, respectively, always higher than the PEDOT:PSS used as a reference (12.60\%, average: $11.44 \%)$ [57]. The same order was found for the smoothness of the HTM film deposited onto the perovskite.

Most of the previous and following HTMs belonging to the 1D linear HTMs are symmetric. Some linear HTMs, however, were built on a D- $\pi-A$ scheme, in an asymmetric way. CF-BTz-ThR is based on BTZ moiety and surrounded by a 3,5-bis(trifluoromethylbenzene) and an alkyl dithiophene substituents and was used in PSC cells where aligned $\mathrm{TiO}_{2}$ nanobundles were used as an Electron Transporting Layer. The nano-bundles seemed to reduce the number grain boundaries and thus the resistance of the film. CF-BTz-ThR showed good energy level alignment with perovskite and gave a PCE of $15.4 \%$ with nano-bundle $\mathrm{TiO}_{2}$ and $13.6 \%$ with mesoscopic $\mathrm{TiO}_{2}$ [58]. However, the CF-BTz-ThR outperformed the spiro-OMeTAD used on titania nanoparticles (10.4\%), showing the importance of this HTM. Another asymmetric HTM is the TPA-PB-OXD [59] that was studied for inverted PSCs in both rigid and flexible configurations. Among its properties, its HOMO lies at $-5.10 \mathrm{eV}$, the thermal stability is very good $\left(411^{\circ} \mathrm{C}\right)$ while the hole mobility is good. The two configurations and architectures, rigid (ITO/HTM/perovskite/PC61BM/ZnONP/Ag) and flexible (PET/ITO/HTM/perovskite/PC61BM/ZnO NP/Ag), were prepared. Using the $\mathrm{MAPbI}_{3}$ perovskite, the TPA-PB-OXD obtained a $15.46 \%$ in the rigid and $10.35 \%$ in the flexible configuration. The stability was determined on non-encapsulated devices at $25{ }^{\circ} \mathrm{C}, 35 \%$ relative humidity and $720 \mathrm{~h}$, retaining the $80 \%$ of the PCE for the rigid PSC, while for the flexible one the PCE reached $0 \%$ after 22 days.

The small-molecule DFBT(DTS-FBTTh $\left.{ }_{2}\right)_{2}$, is conceptually a D-A HTM, containing fluorinated benzothiadiazoles (FBT) and the 4,4-bis(2-ethylhexyl)-4H-silolo[3,2-b:4,5- $\mathrm{b}^{\prime}$ ] dithiophene (DTS) moieties. A high molecular density was obtained in the HTM layers since the presence of those moieties with a high conjugation and proneness to $\pi-\pi$ stacking. In particular, the coupling of these moieties showed to stabilize the quinoidal $\pi$-character of the HTM. The hole mobility was $1.78 \times 10^{-4} \mathrm{~cm}^{2} \mathrm{~V}^{-1} \mathrm{~s}^{-1}$, comparable with doped spiro-OMeTAD and, since the HOMO is deeper than spiro-OMeTAD, the better alignment with perovskite is warranted. In a planar architecture, the pristine DFBT(DTS-FBTTh $\mathbf{2}_{\mathbf{2}}$ showed a very good PCE (17.3\%), the same as the doped spiro-OMeTAD [60]. From the stability point of view, the DFBT(DTS-FBTTh $\left.{ }_{2}\right)_{2}$ showed a more hydrophobic behavior which ensured better protection of the perovskite. The use of a long, alternated, D'-A-D-A-D-A-D' structure of DFBT(DTS-FBTTh $\left.)_{2}\right)_{2}$, demonstrates that an extension of the molecular skeleton alternating Donors and Acceptors, like that obtained into a polymer, can be fruitful for the Perovskite Solar Cells application.

The p-DTS(FBTTh $\mathbf{2}_{\mathbf{2}}$ HTM is a simpler analog of the just above cited DFBT(DTSFBTTh $\left._{2}\right)_{2}$. This HTM showed just a $14.7 \%$ PCE as a dopant-free HTM. It was used in blend with the polymer PCDTBT (PCE 16.5\%) [61] and 1,8-diiodooctane (DIO) as the processing additive, without any doping [62]. The blend was optimized to have $93 \%$ of the HTM, 6\% of the polymer and $1 \%$ of the additive, to obtain a five-fold increase of the hole mobility. The hole mobility increase caused by DIO was ascribed to an enhancement in crystallinity, while when also the polymer is present, it seems that DIO causes a better compatibility of the materials and a better networking among molecules, thus improving the contact and the hole transport. Into planar- $\mathrm{MAPbI}_{3}$-based PSCs $\left(\mathrm{FTO} / \mathrm{TiO}_{2} / \mathrm{MAPbI}_{3} / \mathrm{HTM} / \mathrm{Au}\right)$, it showed up to $15.90 \%$ average efficiency and $18.0 \%$ for the champion device, thus improving the results for the small molecule alone. The stability was evaluated at $85{ }^{\circ} \mathrm{C}, 85 \%$ relative humidity for non-encapsulated devices. The blend maintained $78 \%$ of PCE after $100 \mathrm{~min}$. This opened the way to a further method for improving the PCE of PSCs.

A triarylamine material named CMO, was used as an HTM in planar PSCs. Its structure is based on a 2-ethylhexyl-9H-carbazole core, flanked by two bis(4-methoxyphenyl)amine substituents. The CMO has the HOMO lying at $-4.78 \mathrm{eV}$, showed thermal stability until $325^{\circ} \mathrm{C}$, a lower hole mobility than spiro-OMeTAD and a PCE of $13.63 \%$ for the best device 
(average PCE: >11\%), which, after optimization reached 15.92\% [63]. The state of the HTM film was affected by the concentration of the HTM in the solvent chlorobenzene, used for the deposition. The CMO film showed to be more hydrophobic than spiro-OMeTAD, and thus can be predicted to better protect the perovskite.

The carbazole core was used to prepare further HTMs, both connected with TPA moieties or thiophene-based arms. The first examples are the PhCz-4MeOTPA and the BDT4MeOTPA HTMs. They were prepared through a straightforward procedure [64]. These materials are based on an N-phenylcarbazole and a BDT core, respectively. An interesting procedure was drawn to prepare the $\mathrm{N}^{1}$-(4-(bis(4-methoxyphenyl)amino)phenyl)- $\mathrm{N}^{4}$, $\mathrm{N}^{4}$-bis(4-methoxyphenyl)benzene-1,4-diamine. The HTM properties were studied, finding an optimal thermal stability (over $400{ }^{\circ} \mathrm{C}$ ), a $\mathrm{T}_{\mathrm{g}}$ at about $140{ }^{\circ} \mathrm{C}$ for both materials and the HOMO level at -5.06 and $-5.13 \mathrm{eV}$ for PhCz-4MeOTPA and BDT-4MeOTPA respectively. DFT calculations suggested that the PhCz-4MeOTPA appeared to be less planar than BDT-4MeOTPA. This characteristic inhibited the molecular stacking and accounted for the formation of better films. The hole mobilities were found to be $1.13 \times 10^{-4}$ and $7.37 \times 10^{-5} \mathrm{~cm}^{2} \mathrm{~V}^{-1} \mathrm{~s}^{-1}$, and this was in agreement with the more homogeneous film formed by PhCz-4MeOTPA. The efficiency in triple-cation perovskite PSCSs was determined and appeared to be $16.09 \%$ for PhCz-4MeOTPA and only $8.78 \%$ for BDT-4MeOTPA, thus demonstrating the importance of the tridimensional structure, which was affected in this case by the difference in the scaffold. A more planar scaffold induced the molecular stacking, and this was detrimental for the final efficiency. While in most cases, such as for star-shaped HTMs, the stacking promoted the efficiency through a face-on columnar aggregation; this is not always opportune for other kind of molecules having different shape and structure. This suggested that the optimum state to promote efficiency is regulated by a delicate equilibrium among different conditions. The stability was measured on non-encapsulated devices at $80{ }^{\circ} \mathrm{C}$, in the dark in ambient air for $1200 \mathrm{~h}$, showing, in general, an excellent stability (92\% for PhCz-4-MeOTPA).

Some other HTMs were built onto cores which contains the carbazole or carbazolelike moieties in the central core and are here reported. As reported above for the crucial aspect of the architecture and kind of materials employed into a PSC, the use of $\mathrm{NiO}_{4}$ as a layer over PEDOT:PSS on inverted planar cells considerably increased the efficiency of four new HTMs, Cz-SY1, Cz-SY2, Cz-SY3 and Cz-SY4 (original names in the paper SY1 to SY4, that was here modified because of identical names for HTMs found in other papers) [65]. Cz-SY1 and Cz-SY3 are terminated with ester groups while Cz-SY2 and Cz-SY4 with amide groups, that are considered more prone to help in the passivation of uncoordinated $\mathrm{Pb}^{2+}$ surface traps. These materials showed a very good thermal stability and a $\mathrm{T}_{\mathrm{g}}$ over $150{ }^{\circ} \mathrm{C}$. Their HOMOs were in between -5.21 and $-5.29 \mathrm{eV}$, correctly aligned with the perovskite $(-5.4 \mathrm{eV})$ and the FTO/NiOx energy level $(-4.8 /-5.2)$. This was good enough to promote hole extraction. The large bad-gap of the Cz-SY1, Cz-SY2, Cz-SY3 and Cz-SY4 HTMs prevented recombination at the HMT-perovskite interface. When the Cz-SY1, Cz-Sy2, Cz-Sy3 and Cz-SY4 where used into an inverted configuration PSC (ITO/HTM/perovskite/PC 61 BM/BCP/Ag) their PCE was low (less than 12\%), while the modified ITO/NiOx/HTM/perovskite/ $\mathrm{PC}_{61} \mathrm{BM} / \mathrm{BCP} / \mathrm{Ag}$ configuration raised the averaged efficiencies up to 14.39-17.67\% (the best devices were in the range 15.86-18.96\%, with three HTMs showing a PCE over $18 \%$ ). The neat $\mathrm{NiO}_{4}$ layer without $\mathrm{HTM}$ produced a PCE of $16.92 \%$. The stability of NiOx based cells was evaluated in the dark at $25^{\circ} \mathrm{C}$ under Ar for $1000 \mathrm{~h}$, all the HTM retained more than $90 \%$ of the pristine PCE. Working at $25^{\circ} \mathrm{C}$ and $40 \%$ relative humidity, the retained efficiencies were in the range of $84-88 \%$.

The HTM C202 was prepared as a first example of an indolo[3,2-b]carbazole (technically, a 5,11-dihydroindolo[3,2-b]carbazole) based HTM showing an interesting 17.7\% PCE when used as a dopant-free HTM in mesoporous devices [66]. The partner compound C201, which was lacking of the bis(4-methoxytriphenyl)amine extensions on the central benzene ring, showed only 8.7\%. The larger C202 can give more homogenous films with absence of pinholes and this would better protect the perovskite layer from humidity. 
Interestingly, the HOMOs were evaluated by cyclic voltammetry to be -5.27 and $-5.23 \mathrm{eV}$ for C201 and C202 respectively, while in the deposited film the Ultraviolet Photoelectron Spectroscopy gave -5.38 and $-5.12 \mathrm{eV}$. This diverging behavior in the film state indicates that one have to take care of the proper final conditions in which the HTM is used and that a careful analysis of the material behavior should be performed to fully comprehend the reasons for the obtained performances. In this case, the low valence band of the mixed-ion $\left(\mathrm{FAPbI}_{3}\right)_{0.85}\left(\mathrm{MAPbBr}_{3}\right)_{0.15}$ perovskite ensure that the energy levels are properly aligned. The hole mobility of $\mathbf{C 2 0 2}$ was $1.5 \times 10^{-4} \mathrm{~cm}^{2} \mathrm{~V}^{-1} \mathrm{~s}^{-1}$, well higher than spiro-OMeTAD $\left(6.7 \times 10^{-5} \mathrm{~cm}^{2} \mathrm{~V}^{-1} \mathrm{~s}^{-1}\right)$. Finally, C202 also showed a remarkable stability under $40 \%$ humidity, retaining 72\% of the initial PCE over $288 \mathrm{~h}$, while spiro-OMeTAD retained only $23 \%$. This was confirmed by the higher contact angle with water of C202 with respect to spiro-OMeTAD.

The second example comes from a very similar and structurally related scaffold, the benzo[1,2-b:4,5- $\mathrm{b}^{\prime}$ ]dipyrrole core (BDP). This is the nucleus on which the dibenzo derivative 5,11-dihydroindolo[3,2-b]carbazole (used for the C202 HTM) was built. It can be also considered the nitrogen analog of the sulfur-based heterocycle BDT. The 2,3,6,7-tetraphenylbenzodipyrrole core (BDP) was alkylated with different sultones, giving several compounds related to the BDPSO family (2,3,6,7-tetraarylbenzo[1,2b:4,5- $\mathrm{b}^{\prime}$ ]dipyrrol1,5-yl alkanediylsulfonate). The position of fluorine atoms on the aryls was changed, and thus several compounds were obtained (3C, 4C, br-4C, 2F-br-4C, 3F-br-4C, 4F-br-4C) [67]. These compounds were interesting for several reasons. They can give substantially transparent films, their HOMO are well aligned with the perovskite $(-5.21 /-5-37 \mathrm{eV})$, the hole mobility is reasonable close to, or slightly higher than spiro-OMeTAD. All of them are able to work as HTMs. The PCE was very good, ranging from 12.1 to $16.9 \%$. The best compound, 3F-br-4C, showed a PCE of $16.9 \%$, with a best cell showing a $17.2 \%$ efficiency. The stability test (not encapsulated devices, 40-50\% humidity, room temperature, $40 \mathrm{~d}$ ) on a 3F-br-4C based PSC, showed a retention $>80 \%$ of the initial PCE while, if stored in a glove box under nitrogen, the retention was $>90 \%$.

The third example is related to the DBC-1, DBC-2 and DBC-3 HTMs, which were proposed by Liu et al [68]. The core is the new more complex heterocycle dibenzo[a,c]carbazole. Technically speaking, DBC-1 is a 1D linear molecule, while DBC-2 and DBC-3 can be considered as 2D star-shaped molecules (see section below) but are here reported to describe how the transition from 1D to 2D star-shaped molecules can influence the final photovoltaic behavior. All of them gave very good efficiencies which, however, were modulated on the base of the number of the N-fluorenyl-N-4-methoxyphenylamine substituents. Their HOMOs are lying at $-5.26,-5.22$ and $-5.14 \mathrm{eV}$, respectively. It is worth to note that the substitution on $\mathrm{C}_{11}$ in DBC-3 increases the HOMO energy considerably. All the materials gave quite good films. However, DBC-1 and particularly DBC-2, gave smoother films than DBC-3. This is in agreement with a better packing for DBC-2. Grazing-Incidence WideAngle X-Ray Scattering (GIWAXS) measurements showed for all the DBC HTMs a face-on arrangement on the surface which was more pronounced for DBC-2. The hole mobility was higher than spiro-OMeTAD for DBC-1 and DBC-2, while it was lower for DBC-3. However, in the planar architecture $\left(\mathrm{FTO} / \mathrm{c}-\mathrm{TiO}_{2} /\right.$ perovskite $\left.\left(\mathrm{CH}_{3} \mathrm{NH}_{3} \mathrm{PbI}_{3-\mathrm{x}} \mathrm{Cl}_{\mathrm{x}}\right) / \mathrm{HTM} / \mathrm{Ag}\right)$, the PSCs made with these HTMs were $18.81 \%, 20.02 \%$ and $16.77 \%$, respectively, with spiro-OMeTAD (18.18\%) underperforming with respect to DBC-1 and DBC-2.

A series of triarylamines based on the DBTP (di(1-benzothieno)[3,2-b:2', $\left.3^{\prime}-\mathrm{d}\right]$ pyrrole) central nucleus were prepared: mDPA-DBTP, pDPA-DBTP and pTPA-DBTP [69]. The differences among them consist on the presence/absence of a phenyl ring extending the conjugation on both sides of the linker and on a different substitution pathway of the terminal phenyl groups ( $\mathrm{m}$ - or $\mathrm{p}$-methoxy substitution on the di- or triphenylamino moieties). The UV-Vis absorption onsets for the three compounds (in the $423-454 \mathrm{~nm}$ range) showed that these materials are nearly transparent in the visible region. The HOMOs were $-5.31,-5.05$ and $-5.20 \mathrm{eV}$ for mDPA-DBTP, pDPA-DBTP and pTPA-DBTP, respectively, showing that they are aligned with the perovskite energy level. Notably, grazing incidence 
in-plane X-ray diffraction (GIXD) measurements showed a 010 peak which means that all those materials adopt a $\pi-\pi$ stacking arrangement, with face-on orientation on the perovskite surface which generally generates a positive effect on the charge transport. All of these "convergent" positive effects gave an excellent PCE trend: $18.09 \%, 14.10 \%$ and $15.63 \%$ for the mDPA-DBTP, pDPA-DBTP and pTPA-DBTP respectively [69]. The best HTM, mDPA-DBTP, which outperformed spiro-OMeTAD, not only showed the best PCE but also negligible hysteresis, an indication that its arrangement and behavior in the device is optimal to help to remove the charges properly, avoiding the charge accumulation that normally increases the recombination probability. This was further demonstrated by fluorescence quenching measurements, which showed that this HTM was the best efficient one, in collecting holes from the perovskite. The devices prepared with these interesting HTMs were tested for stability (not encapsulated devices, ambient air atmosphere, room temperature, 33 days). The spiro-OMeTAD retained about $1 \%$ of its original PCE, while mDPA-DBTP devices retained $81 \%$.

Analogously to the DBTP (di(1-benzothieno)[3,2-b:2 $\left.2^{\prime} 3^{\prime}-\mathrm{d}\right]$ pyrrole), the DTP core (dithieno[3,2-b:2', $3^{\prime}$-d]pyrrole) was used to build a D- $\pi-$ A HTM by linking it to a thienyl (ICTH1) or thiazolyl (ICTH2) moiety and finally to the strong dicyanovinyl Acceptor group [70]. These relatively simple structures showed deep HOMOs ( $-5.3 \mathrm{eV}$ for ICTH1 and $-5.41 \mathrm{eV}$ for ICTH2), still aligned with the perovskite $(-5.43 \mathrm{eV})$ and a sufficiently high LUMO $(-3.93 \mathrm{eV})$ to help those HTMs to work as an electron blocking layer, thus reducing the recombination probability. The ICTH1 and ICTH2 were thermally stable, enough to be easily processed, and their hole mobility was about ten times than the spiro-OMeTAD. The PSCs (FTO/MesoTiO $/ \mathrm{MAPbI}_{3} / \mathrm{HTM} / \mathrm{Ag}$ ) based on them produced very good PCE (17.91\% for ICTH1 and 18.75\% for ICTH2) which were still retained reasonably high (13.32\% and $16.09 \%$ ) after 40 days (devices maintained in the dark, ambient air and at room temperature), always outperforming the spiro-OMeTAD.

The simple DTP core, dithieno[3,2-b:2', $\left.3^{\prime}-\mathrm{d}\right]$ pyrrole, gave further impulse to the HTM research. Its application in the preparation of small molecules and polymers was important to achieve results of the outmost interest.

Two HTMs based on the scaffold dithieno[3,2-b:2', $\left.3^{\prime}-\mathrm{d}\right]$ pyrrole were prepared by Zhou et al [71]. In this case the dithieno[3,2-b:2', $\left.3^{\prime}-\mathrm{d}\right]$ pyrrole was flanked by two thiophenes to which the TPA substituents were attached. The DTPC8-ThTPA and DTPC13-ThTPA differ only for the chain length, a modification that in the last times is becoming more and more crucial, suggesting that every aspect of the HTMs should be tuned and optimized. In this case, the HOMOs were both at $-4.82 \mathrm{eV}$, but in the solid-state films, the IP (Ionization Potential) was $-5.04 \mathrm{eV}$ for DTPC13-ThTPA and -4.94 eV for DTPC8-ThTPA, showing that, in the solid state, DTPC13-ThTPA had a better alignment with perovskite, giving it, in perspective, a higher $\mathrm{V}_{\mathrm{oc}}$. A high thermal stability of the HTM was found for both HTMs. The inverted devices were prepared by using a $\mathrm{MA}_{0.7} \mathrm{FA}_{0.3} \mathrm{PbI}_{2.85} \mathrm{Br}_{0.15}$ perovskites with a FTO/ $\mathrm{SnO}_{2} / \mathrm{C} 60-\mathrm{SAM} / \mathrm{MA}_{0.7} \mathrm{FA}_{0.3} \mathrm{PbI}_{2.85} \mathrm{Br}_{0.15} / \mathrm{PMMA} / \mathrm{HTM} / \mathrm{Au}$ architecture. Both HTMs performed in an excellent way. DTPC8-ThTPA reached an efficiency of $17.74 \%$ (best device: $18.37 \%$ ) and DTPC13-ThTPA of 19.30\% (best device: $20.38 \%$ ). This was mainly due to the higher $\mathrm{V}_{\mathrm{Oc}}$ and FF for the last HTM. Unfortunately, the long-term stability was not assessed for those HTMs.

A finer tuning on the same scaffold (DTP) was performed by the same authors, who prepared a molecule having the same conjugated skeleton of DTPC13-ThTPA, DTP-C6Th, by using a 5-hexylthiophene substituent on the pyrrole nitrogen, instead of alkyl chains [34]. The structure, due to the two thiophenes surrounding the central core, was quite planar and this was able to promote stacking and a high hole mobility, which was found to be one order of magnitude larger than for spiro-OMeTAD. The HOMO was at $-4.87 \mathrm{eV}$ and the band gap was $2.22 \mathrm{eV}$. In the normal planar PSC architecture, a 18.56\% PCE was obtained for DTP-C6Th, but the $\mathrm{V}_{\mathrm{oc}}$ and fill factor was lower than expected from the characterization parameters. To address this problem, an ultrathin layer of PMMA was spin-coated onto the perovskite to efficiently passivate the traps, obtaining a PCE of $20.42 \%$, while to improve 
further the efficiency a small excess of bromine was added in the perovskite. This operation is known to be beneficial to increase the $\mathrm{V}_{\mathrm{oc}}$ but it depresses the current. Through a judicious optimization of this step, the final perovskite $\mathrm{MA}_{0.7} \mathrm{FA}_{0.3} \mathrm{~Pb}\left(\mathrm{I}_{0.925} \mathrm{Br}_{0.075}\right)_{3}$ was obtained and DTP-C6Th gave a PSC cell efficiency of $21.04 \%$, reaching one of the best results ever obtained up to 2019. Besides, an excellent stability was found. In 60 days, the PSC kept at $25{ }^{\circ} \mathrm{C}$ in $35 \%$ relative humidity conditions showed a retention of PCE of $85 \%$. The same core bearing four TPA substituents, was classified as a star-shaped molecule, and gave a very high PCE (see below in the 2D star-shaped section). The DTP core can thus be considered one of the best performing scaffolds for HTMs.

A paper from Wang et al. about the MPA-BTI and MPA-BTTI compounds gave a further increase to the PCE up to $21 \%$ [35]. BTI, (4H-dithieno[3,2-c:2', $3^{\prime}$-e]azepine-4,6(5H)-dione), and BBTI, (4H-thieno[ $\left[2^{\prime}, 3^{\prime}: 4,5\right]$ thieno[3,2-c]thieno[ $\left.2^{\prime}, 3^{\prime}: 4,5\right]$ thieno[2,3-e]azepine-4,6(5H)-dione) were used as strictly related scaffolds. Due to the central imide structure, the core is behaving as an Acceptor. The structure of the core is highly planar for both molecules, but due to the presence of the BTI core, the MPA-BTI is V-shaped, while MPA-BTTI, which contains BTTI, is more or less linear. It was found that, in solid-state films, MPA-BTI forms J-aggregates while MPA-BTTI forms $\mathrm{H}$-aggregates. All the properties of this last molecule cooperated to obtain an excellent efficiency (Figure 4). In the conditions used in this case, in planar PSC with CsFAMA perovskite the MPA-BTTI based devices showed an excellent and unprecedented efficiency of $20.7 \%$ ( $21.17 \%$ for the best device), while MPA-BTI gave however an important $17.20 \%$ for its best device (average data not reported). Interestingly, the devices obtained from the best performing HTM, MPA-BTTI, did not show any hysteresis. The stability was assessed only for MPA-BTTI, for non-encapsulated devices at $25^{\circ} \mathrm{C}, 30-40 \%$ of relative humidity and under constant illumination, for $500 \mathrm{~h}$. In those conditions, the MPA-BTTI retained 90\% of its pristine PCE (Figure 5). Another important point can be derived for the exam of these last two papers.

The same authors wrote a further paper about the selection of the proper chain length onto a triarylamine series of compounds in which the central scaffold was the BTTI (4H-thieno[2',3':4,5]thieno[3,2-c] thieno[ $\left.2^{\prime}, 3^{\prime}: 4,5\right]$ thieno[2,3-e]azepine-4,6(5H)-dione) [72]. The authors centered the study on the role of the chain length by preparing three compound having hexyl, octyl and dodecyl chains (BTTI-C6, BTTI-C8 and BTTI-C12). It should be remarked that BTTI-C12 is just the same compound that the same authors published under the name MPA-BTTI (see just above) and that achieved over 21\% efficiency. While not being an "active" element of the structure from the point of view of hole extraction, the chain gives the solubility needed for the preparation of the film and can hinder or not the molecular packing which is relevant in the solid-state film. As a confirmation, the hole mobility and conductivity of the films increased slightly when the chain length was reduced. This is probably due to a better molecular packing, where the molecular distances are reduced. An excellent thermal stability was detected and the $T_{g}$ was around $224{ }^{\circ} \mathrm{C}$ for all the compounds. Those HTMs formed very good pinhole-free films. Following those data, the PSCs gave an efficiency of $19.05 \%$ (19.69\% for the best device) for BTTI-C6, $18.04 \%$ (18.89\% for the best device) for BTTI-C8 and 16.83\% (17.49\% for the best device) for BBTI-C12. Those results brought to the attention this new scaffold, in which both sulfur and oxygen atoms are working to passivate the surface traps. The long-term stability was encouraging. When the non-encapsulated devices were kept at $25^{\circ} \mathrm{C}$ and $24 \%$ relative humidity, the BTTI-C6 maintained 85\% of the starting PCE after 100 days. This is extremely encouraging in view of potential application. As a further, more general comment, the same molecule (reported with different names in two separated papers: BTTI-C12 or MPA-BTTI) gave two different behaviors, depending on the configuration of the cell and on its preparation. 
a

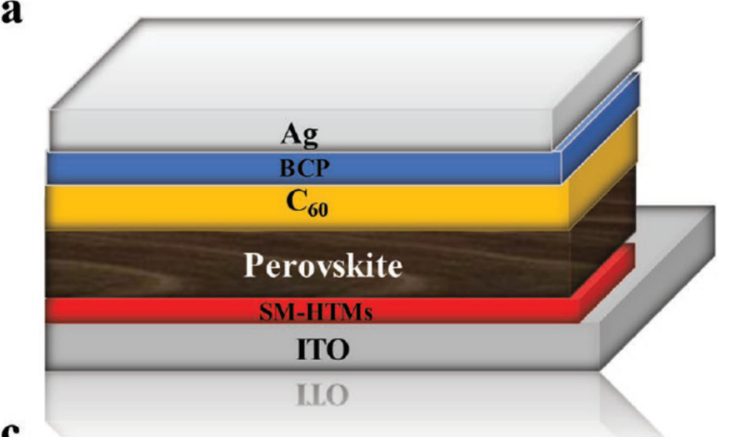

c

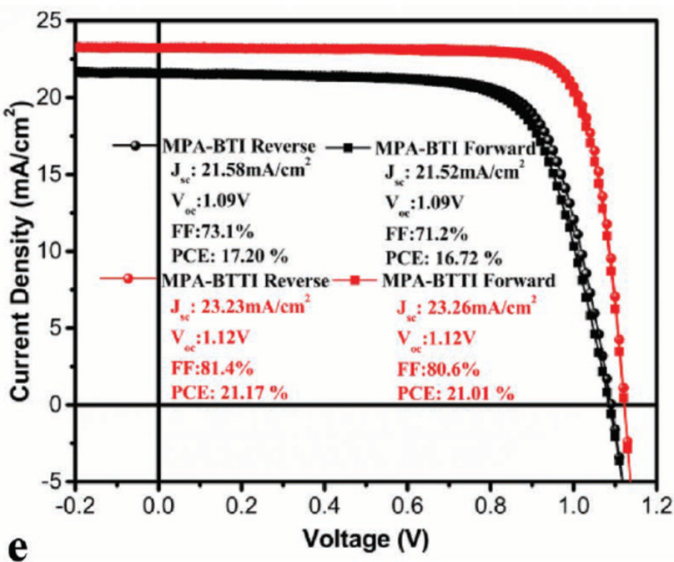

e

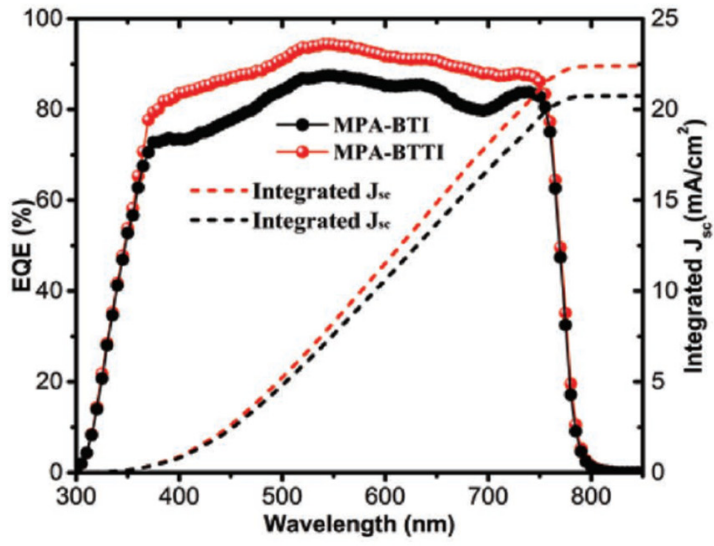

b

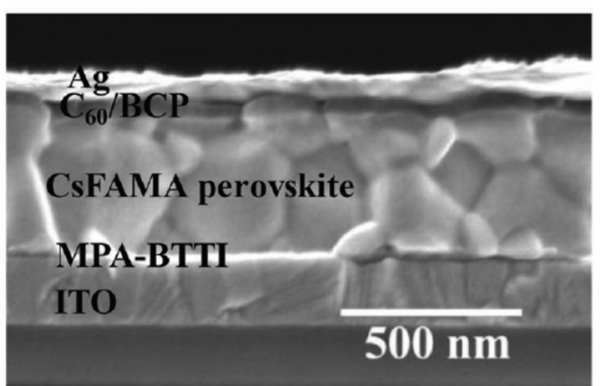

d

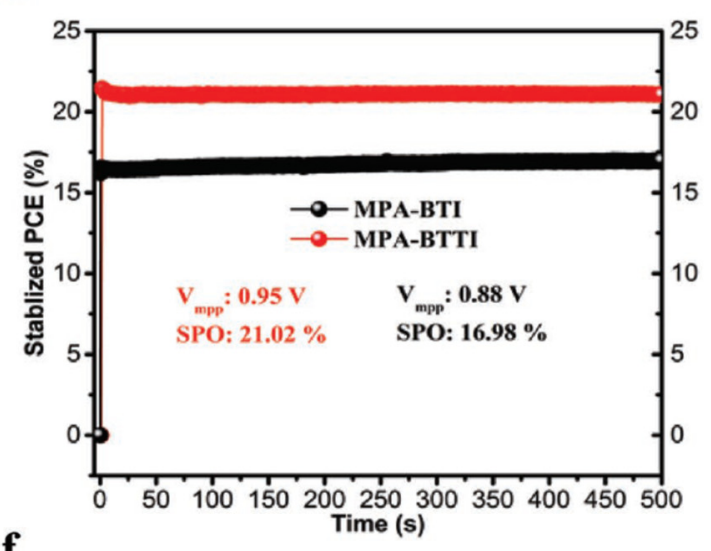

f

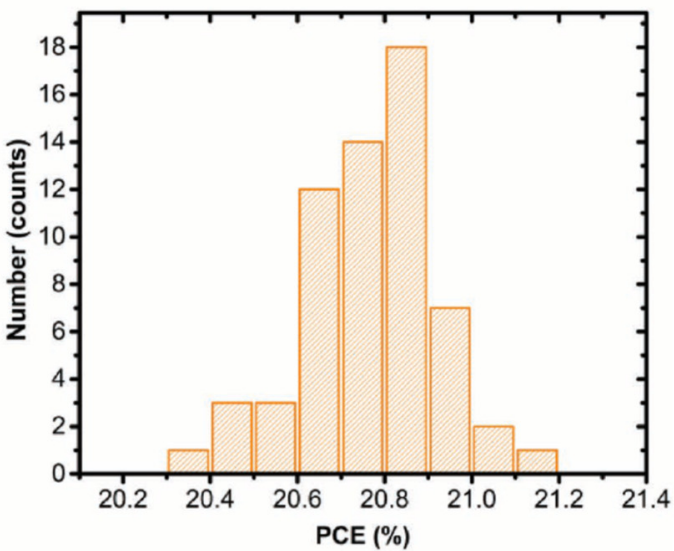

Figure 4. Device structure, cross-section SEM, and device performance. (a) Schematic diagram of the device structure with $\mathrm{p}-\mathrm{i}-\mathrm{n}$ (inverted) configuration. (b) Cross-section SEM images of the MPA-BTTI-based PVSCs. (c) The J-V curves of the best performing MPA-BTI- and MPA-BTTI-based solar cells. (d) Stabilized PCE measurement of the best device for MPA-BTI and MPA-BTTI. (e) External quantum efficiency (EQE, solid circles) with the integrated short-circuit current density (dashed lines) for the MPA-BTI- and MPA-BTTI-based cells. (f) PCE histograms of 60 devices from different batches utilizing MPA-BTTI as the HTM. Reprinted with permission from Reference [35]. Copyright 2019 John Wiley and Sons. 

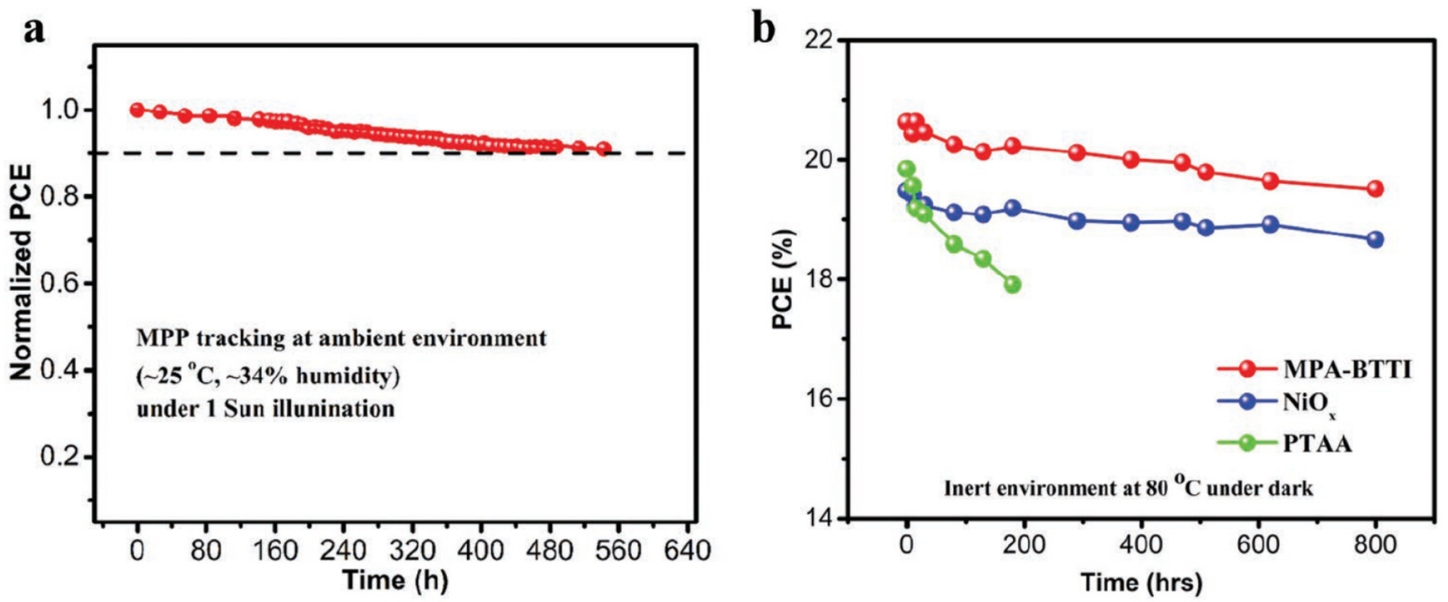

Figure 5. Device stability. (a) The evolution of normalized power conversion efficiency obtained from MPA-BTTI-based device with encapsulation at ambient environment $\left(\approx 25^{\circ} \mathrm{C}, 34 \%\right.$ humidity) under maximum power point (MPP) tracking and continuous light irradiation (AM 1.5G, $100 \mathrm{~mW} \mathrm{~cm}^{-2}$, white LED). (b) Long-term thermal stability of MPA-BTTI-based device stressed at $80^{\circ} \mathrm{C}$ in inert environment in the dark. Reprinted with permission from Reference [35]. Copyright 2019, John Wiley and Sons.

It is obvious that every component of the cell contributes significantly to the final efficiency, but here we can appreciate how, by changing from a planar to an inverted planar architecture, one can bring an HTM from a very good to an excellent PCE. In fact, BTTI-C12 was used in a PSC having a ITO/ $\mathrm{SnO}_{2} / \mathrm{CsFAMA} / \mathrm{HTMs} / \mathrm{Au}$ architecture while MPA-BTTI was applied in a more complex, architecture, ITO/HTM/perovskite/C60/bathocuproine (BCP)/Ag. This was enough, for an already excellent HTM, to obtain a "leader" PCE.

The HTM PCA-1 and PCA-2 were built by assembling naphthalene building block fused with thiophene (PCA-1) and naphthalene (PCA-2) [73]. These are a particular case of fully conjugated and fully planar HTM, since all the rings are fused together, giving the diacenaphtho[1,2-b:1', $\left.2^{\prime}-\mathrm{d}\right]$ thiophene system. To ensure solubility, four t-butyl groups are attached to each HTM. Both PCA-1 and PCA-2 show higher hole mobility than spiro-OMeTAD, but after annealing, the hole mobility reaches very high values $\left(8.3 \times 10^{-2} \mathrm{~cm}^{2} \mathrm{~V}^{-1} \mathrm{~s}^{-1}\right.$ for PCA-1, and $3.2 \times 10^{-1} \mathrm{~cm}^{2} \mathrm{~V}^{-1} \mathrm{~s}^{-1}$ for PCA-2). Their HOMO lye at $-5.34 \mathrm{eV}$ and $-5.51 \mathrm{eV}$, respectively. The too low HOMO level for PCA-2 showed that the hole injection from perovskite is not favored. In a n-i-p planar PSC cells, this yielded a 4.25\% PCE, while PCA-1 worked better, with a PCE of 15.59\% [73]. In mesoscopic PSC cells PCA-1 gave further improvements, up to $17.23 \%$ (best cell: $18.17 \%$ ). In every case, they showed a somewhat lower performance than doped spiro-OMeTAD, but the relatively easy synthesis and excellent performances as dopant-free HTM are very promising.

The anthanthrone core was assembled with acenaphthene (ACE-ANT-ACE) and TPA (TPA-ANT-TPA) [74]. TPA-ANT-TPA showed a proneness to charge transfer from the anthanthrone nucleus to the terminal TPA groups during the HOMO-LUMO transition. The HOMO levels for ACE-ANT-ACE and TPA-ANT-TPA were at -5.32 and $-5.41 \mathrm{eV}$ respectively. The hole mobility of TPA-ANT-TPA was higher than spiro-OMeTAD while for ACE-ANT-ACE was well lower. The TPA-ANT-TPA HTM gave homogeneous films on perovskite, while ACE-ANT-ACE provided films with pinholes. The better film forming ability of TPA-ANT-TPA explains in part its higher photovoltaic performances. In glass/FTO/compact-TiO 2 /mesoporous- $\mathrm{TiO}_{2} / \mathrm{CH}_{3} \mathrm{NH}_{3} \mathrm{PbI}_{3} / \mathrm{HTL} / \mathrm{Ag}$ devices, the ACEANT-ACE and TPA-ANT-TPA showed a PCE of $11.4 \%$ (best cell: $13.1 \%$ ) and $16.0 \%$ (best cell: $17.5 \%$ ) respectively, while spiro-OMeTAD reached $16.8 \%$. The stability (under continuous illumination, 58\% humidity, room temperature, 200h) of spiro-OMeTAD PSCs was shown to be worse, going down to $2 \%$ after $10 \mathrm{~h}$, while the TPA-ANT-TPA PCE was very encouraging, being reduced to $80 \%$ after $200 \mathrm{~h}$. 
The fluoranthene core was used to prepare four HTMs, BTF1, BTF2, BTF3 and BTF4 [75]. The packing of those molecules was studied, and BTF4 showed a dense packing, with short contact distances. Interestingly, their packing shows four different aggregation modes, based on both $\mathrm{H}$-aggregate and J-aggregate forms, occurring by dipoles or $\pi-\pi$ interaction. The presence of two cyano groups in BTF3 and BTF4 caused a red shift of the UV spectrum with respect to BTF1 and BTF2. The HOMOs were found at -4.90 , $-4.80,-5.19,-5.02 \mathrm{eV}$ for BTF1, BTF2, BTF3 and BTF4. respectively and thus they can work as HTMs in the PSCs. The best hole mobilities were found for BTF3 and BTF4 $\left(6.35 \times 10^{-5}\right.$ and $1.17 \times 10^{-4} \mathrm{~cm}^{2} \mathrm{~V}^{-1} \mathrm{~s}^{-1}$ respectively $)$ and were well higher than that of spiro-OMeTAD. Using a mixed perovskite $\left(\left(\mathrm{FAPbI}_{3}\right)_{0.85}\left(\mathrm{MAPbBr}_{3}\right)_{0.15}\right)$ in a standard n-i-p cell, BTF1 and BTF2 reached a reasonable PCE: 9.97\% and 10.45\% respectively, nearly similar to the undoped spiro-OMeTAD. The better-aligned HOMO and high hole mobility made BTF3 and BTF4 to show increased performances: BTF3 gave a PCE of $16.34 \%$ and BTF4 of $18.03 \%$ [75]. Those HTMs were used also in inverted, p-i-n, giving slightly lower results for BTF3 and BTF4 (BTF4 had a PCE of 17.01\%) and slightly higher for BTF1 and BTF2 (BTF2 had a PCE of 11.96\%). It is worth noting that rarely an HTM works reasonably well in both n-i-p and p-i-n cells. BTF4 retained $>50 \%$ of the original PCE when stored in air, at 50\% humidity and at room temperature, for 30 days.

A further study on fluoranthene core was done, searching for structure-activity relationships [76]. Like the BTF series shown just above [75], the core bears TPA substituents, two for the FBA series (FBA1, FBA2 and FBA3) and three for FTA series (FTA1 and FTA2). Through every series, further modifications were made by insertion of a double bond spacer (FBA2, FBA3 and FTA2) and the shift of methoxy group from the $\mathrm{p}$ - to the $\mathrm{m}$ - position on the TPA (FBA3). Some of the new compounds were made through an easier multistep synthesis that simplify the reaction requirements and cut down the costs. The introduction of TPA instead of DPA as in the BTF series, helped to lower the HOMO, thus helping in establishing $\pi-\pi$ interactions and increasing the hole mobility. Besides, the introduction of an ethylene as the spacer between the core and the TPA, made the molecule more coplanar, but in the whole series the HOMO is around $-5.00 \mathrm{eV}, 0.20 \mathrm{eV}$ lower than the BTF series. The thermal stability was as high as $371^{\circ} \mathrm{C}$ or above. The introduction of TPA and of the ethylene spacer increased the hole mobility from $2.89 \times 10^{-5} \mathrm{~cm}^{2} \mathrm{~V}^{-1} \mathrm{~s}^{-1}$ for BTF up to $2.12 \times 10^{-4} \mathrm{~cm}^{2} \mathrm{~V}^{-1} \mathrm{~s}^{-1}$ for FBA3. Notably remarkable results were obtained, since in the planar PSC, with a $\mathrm{MAPbI}_{\mathrm{x}} \mathrm{Cl}_{3-\mathrm{x}}$ perovskite, all compounds overcame at least $15 \%$ of PCE. The best performing results were obtained by the FBA2 (18.70\%) and FBA3 (19.27\%) and FTA2 (17.73\%), with spiro-OMeTAD reaching 17.57\%. The stability was evaluated on non-encapsulated devices, at $25{ }^{\circ} \mathrm{C}$ and $30 \%$ relative humidity for $180 \mathrm{~h}$, in which the HTMs retained at least $80 \%$ of their pristine PCE.

Another scaffold was brought to the HTM attention, the cyclopenta[hi]aceantrylene. This was similar to the fluoranthene core, used into the BTF, FBA and FTA series. It was used by et al. to build the YN3 triarylamino-based HTM [77]. The HOMO was at $-5.31 \mathrm{eV}$. From DFT calculations, it appeared that the HOMO is well delocalized over the whole molecule, while the LUMO is delocalized on the central core. This overlap of the two frontier orbitals suggests that a good hole mobility could be obtained. Besides, the new scaffold enhanced the coplanarity thus increasing the stacking and the hole mobility. As matter of fact, the hole mobility was higher than spiro-OMeTAD. The PCE in mesoporous cells $\left(\mathrm{FTO} / \mathrm{c}-\mathrm{TiO}_{2} / \mathrm{m}-\mathrm{TiO}_{2} /\left(\mathrm{FAPbI}_{3}\right)_{0.85}\left(\mathrm{MAPbBr}_{3}\right)_{0.15} / \mathrm{HTM} / \mathrm{Au}\right)$ as $18.84 \%$ and in fully inorganic $\mathrm{CsPbI}_{2} \mathrm{Br}$ attained $12.05 \%$. The long-term stability at $25{ }^{\circ} \mathrm{C}$ and $40-45 \%$ relative humidity was very good: After 300 h, 92\% of the PCE was retained with the organoinorganic perovskite and $97 \%$ with the fully inorganic one.

The pyrene core was another large core with several fused rings. The PYR16 and PYR 27 were built on the pyrene scaffold and studied for the use in PSC [78].

Thermal stability was excellent, i.e., over $450{ }^{\circ} \mathrm{C}$. From DFT calculations, it was seen that PYR16 is less planar than PYR27, losing the stacking ability but giving more chances for the formations of a good amorphous and smoother film. The more symmetric 
structure gave higher dipole moment for PYR16 which can transfer charges more efficiently than PYR27. Those materials were tested in PSC based on the triple cation perovskite $\left(\left[\mathrm{Cs}_{0.05}\left(\mathrm{FA}_{0.83} \mathrm{MA}_{0.17}\right)_{0.95}\right] \mathrm{Pb}\left(\mathrm{I}_{0.83} \mathrm{Br}_{0.17}\right)_{3}\right)$. As a final result PYR16 achieved an efficiency of $17.00 \%$ while PYR27 reached $14.67 \%$. On a large area $\left(1 \mathrm{~cm}^{2}\right)$ the PYR16 gave a PCE of $12.45 \%$. After light soaking at $45-50{ }^{\circ} \mathrm{C}$ for $672 \mathrm{~h}$, PYR16 and PYR 27 retained 85\% and $79 \%$ of their pristine PCE, respectively. By maintaining those HTMs based cell for $1080 \mathrm{~h}$, at $80^{\circ} \mathrm{C}$, under dark, the PYR16 and PYR27 saved 98\% and 91\% of their initial PCE, respectively.

Finally the quinacridone scaffold was used to prepare some D-A-D structure were prepared, ACE-QA-ACE, TPA-QA-TPA and DPA-QA-DPA [79]. The HOMO levels, obtained in films by Photoelectron Spectroscopy in Air (PESA) measurements, are spread on a quite large range $(-5.28$ to $-5.59 \mathrm{eV})$, due to substituents effects. The TPA and DPTA show different contribution in raising the HOMO, with DPA being larger. The thermal stability is excellent, and the TPA and DPA derivatives showed a $\mathrm{T}_{\mathrm{g}}\left(105\right.$ and $74{ }^{\circ} \mathrm{C}$, respectively). Mesoporous PSCs made with $\mathrm{MAPbI}_{3}$ and those HTMs gave interesting efficiencies: 18.2\% for ACE-QA-ACE, $16.6 \%$ for TPA-QA-TPA and 15.5\% for DPA-QA-DPA. While the HOMO of ACE-QA-ACE was estimated to be well lower than $\mathrm{MAPbI}_{3}$ perovskite, the higher hole mobility of this HTM can explain the better PSC performance. The stability of those cells was established to be around 78-80\% of retained PCE for 30 days, at $25{ }^{\circ} \mathrm{C}$ and $75 \%$ relative humidity, for non-encapsulated devices.

Finally, a specific class of compounds which relay on a complex 3D structure, the helicenes, brought attention for its application in PSCs. Three azahelicene-based HTMs were prepared by attaching bis(4-methoxyphenyl)-amino or bis(p-alkoxyphenyl)aminophenyl groups to a helicene (2,12-dibromo-9-methyl-9Hnaphtho[2,1-c]carbazole) core [80]. Their HOMOs were at $-4.82,-4.95$ and $-4.94 \mathrm{eV}$ for SY1, SY2 and SY3, respectively, while the high LUMO levels should efficiently prevent the charge recombination. The rigid conformation can enable different packing ability than that driven by $\pi-\pi$ stacking interactions. The morphology of the films formed by all of those HTMs is very homogeneous and good.

In particular, SY1 showed a long-range structure order in the film since by XRD it appeared as largely crystalline. The SY1 and SY2 showed good hole mobilities than spiro-OMeTAD, also related the mentioned high crystallinity of the film, while SY3 was well lower. The presence of long alkyl chains in SY3 seemed to block a fast hole transfer among HTM molecules. The helical structure introduces rigidity in the system, increases the $\mathrm{T}_{\mathrm{g}}$ and thus, the thermal stability. In the mesoporous PSCs (FTO/c- $\mathrm{TiO}_{2} / \mathrm{mp}$ $\mathrm{TiO}_{2} / \mathrm{CH}_{3} \mathrm{NH}_{3} \mathrm{PbI}_{3} / \mathrm{HTM} / \mathrm{Ag}$ ), SY1 gave a PCE of $17.34 \%$ for the best cell (average $16.20 \%$ ), not far from spiro-OMeTAD (18.14\%). For SY2 and SY3, the PCE was $16.10 \%$ (average $14.46 \%$ ) and $3.03 \%$ (average $2.50 \%$ ), the last one in agreement with its lower hole mobility. The stability of cell built with SY1 was tested (not encapsulated devices, $80 \%$ humidity, $35{ }^{\circ} \mathrm{C}, 72 \mathrm{~h}$ ), showing a retention of $80 \%$ of the initial PCE, while spiro-OMeTAD retained only $42 \%$.

\subsection{Two-Dimensional Star-Shaped Structures}

Two-dimensional star-shaped structures (Table 2 and Scheme 2) can rely on some central scaffold which has three or more "arms" attached to it and, in principle resembling a dendrimer. This particular shape along with the high number of aromatic rings involved in the structure, helps these kinds of molecules to show stacking of the aromatic rings. This helps to obtain ordered structure also in the solid state. When a film is deposited onto a surface, and in particular onto the perovskite surface, it can easily stack and obtain two main possible arrangements: (1) edge-on, in which the molecular plane has a perpendicular arrangement to the surface; and (2) face-on, in which the molecular plane is lying flat onto the surface. This last arrangement is particularly effective in helping the hole extraction and mobility into the PSC device, since the holes move easily and fast through the stacked molecular planes, in the vertical direction to the perovskite surface, which is also the preferred direction to obtain an efficient device. 
Table 1. Selected 1D linear structure dopant-free HTMs, based on performances exceeding 15\% (see legend for details)

\begin{tabular}{|c|c|c|c|c|c|c|c|c|c|c|c|c|c|}
\hline HTM & PSK & $\begin{array}{l}\text { Cell } \\
\text { a }\end{array}$ & PCE (\%) & $\begin{array}{c}\text { Standard PCE } \\
(\%)\end{array}$ & $\begin{array}{l}\mathrm{V}_{\mathrm{oc}} \\
(\mathrm{mV})\end{array}$ & $\begin{array}{c}\mathrm{J}_{\mathrm{sc}}(\mathrm{mA} \\
\left.\mathrm{cm}^{-2}\right)\end{array}$ & $\begin{array}{l}\mathrm{FF} \\
(\%)\end{array}$ & $\begin{array}{c}\text { HOMO } \\
(\mathrm{eV})\end{array}$ & $\begin{array}{l}B_{g} \\
(e V)\end{array}$ & $\begin{array}{l}\mathrm{HM}^{\mathrm{f}}\left(\mathrm{cm}^{2}\right. \\
\left.\mathrm{V}^{-1} \mathrm{~s}^{-1}\right)\end{array}$ & $\begin{array}{l}\text { Conductivity } \\
\left(\mathrm{S} \mathrm{cm}^{-1}\right)\end{array}$ & Stability $^{\mathrm{g}}(\mathrm{h})$ & Reference \\
\hline TTF-1 & $\mathrm{MAPbI}_{3}$ & $\mathrm{M}$ & 11.03 & $6.18^{b} / \mathbf{1 1 . 4}$ & 860 & 19.9 & 64.4 & -5.05 & 3.07 & 0.1 & - & $550 \mathrm{~h}(40 \% \mathrm{RH})$ & [49] \\
\hline $\begin{array}{l}\text { DOR3T- } \\
\text { TBDT }\end{array}$ & $\mathrm{MAPbI}_{x} \mathrm{Cl}_{-1 x}$ & M & 14.9 & $3.5^{b} / \mathbf{1 4 . 0}$ & 0.97 & 20.7 & 74 & -5.5 & 1.77 & 0.26 & $4.0 \times 10^{-4}$ & - & [50] \\
\hline M7-Br & $\left(\mathrm{FAPbI}_{3}\right)_{0.85}\left(\mathrm{MABr}_{3}\right)_{0.15}$ & M & 15.5 & $17.9^{\mathrm{b}}$ & 1045 & 21.94 & 67.6 & -5.28 & 1.7 & $3.04 \times 10^{-4}$ & $1.58 \times 10^{-4}$ & $\begin{array}{c}76 \%, 30 \mathrm{~d}(30 \% \\
\mathrm{RH}, \mathrm{rt})\end{array}$ & [52] \\
\hline M7-TFSI & $\left(\mathrm{FAPbI}_{3}\right)_{0.85}\left(\mathrm{MABr}_{3}\right)_{0.15}$ & M & 17.7 & $17.9^{b}$ & 1093 & 22.84 & 70.6 & -5.28 & 1.7 & $3.24 \times 10^{-4}$ & $2.01 \times 10^{-4}$ & $\begin{array}{c}64 \%, 30 \mathrm{~d}(30 \% \\
\mathrm{RH}, \mathrm{rt})\end{array}$ & [52] \\
\hline $\begin{array}{l}\text { DERDTS- } \\
\text { TBDT }\end{array}$ & $\mathrm{MAPbI}_{x} \mathrm{Cl}_{-1 \mathrm{x}}$ & $\mathrm{P}$ & 16.2 & $5.4^{\mathrm{b}}$ & 1050 & 21.2 & 72.8 & -5.09 & 1.83 & $1.0 \times 10^{-4}$ & - & - & [54] \\
\hline BDT-PTZ & $\mathrm{MAPbI}_{3}$ & I & $\begin{array}{l}18.26 \text { (best) } 16.91 \\
\text { (average) }\end{array}$ & $\begin{array}{c}17.85^{\mathrm{d}} \text { (best) } \\
16.82 \text { (average) }\end{array}$ & 1.02 & 22.43 & 79.8 & -5.42 & 2.62 & $9.8 \times 10^{-5}$ & - & $\begin{array}{c}80 \%, 400 \mathrm{~h}, \mathrm{NE} \\
(60 \% \mathrm{RH}, \mathrm{rt})\end{array}$ & [55] \\
\hline BDT-POZ & $\mathrm{MAPbI}_{3}$ & I & $\begin{array}{c}19.16 \text { (best) } 18.10 \\
\text { (average) }\end{array}$ & $\begin{array}{c}17.85^{\mathrm{d}} \text { (best) } \\
16.82 \text { (average) }\end{array}$ & 1.04 & 22.56 & 81.6 & -5.35 & 2.57 & $2.1 \times 10^{-4}$ & - & $\begin{array}{c}80 \%, 400 \mathrm{~h}, \mathrm{NE} \\
(60 \% \mathrm{RH}, \mathrm{rt})\end{array}$ & [55] \\
\hline AZO-II & $\mathrm{Cs}_{0.05} \mathrm{MA}_{1-\mathrm{y}} \mathrm{FA}_{\mathrm{y}} \mathrm{PbI}_{3-\mathrm{x}} \mathrm{Cl}_{\mathrm{x}}$ & $\mathrm{P}$ & $\begin{array}{l}15.6 \text { (best) } 14.0 \\
\text { (average) }\end{array}$ & $19.3^{b}$ & 0.95 & 21.6 & 71 & -4.94 & 2.2 & $2.0 \times 10^{-5}$ & - & $\begin{array}{c}91 \%, 60 \mathrm{~d}, \mathrm{NE} \\
\text { (ambient air, rt) }\end{array}$ & [56] \\
\hline TPAC2M & $\mathrm{MAPbI}_{3}$ p-in & $\mathrm{P}$ & $\begin{array}{l}15.77 \text { (best) } 15.20 \\
\text { (average) }\end{array}$ & $\begin{array}{c}12.60^{\mathrm{c}} \text { (best) } \\
11.44 \text { (average) }\end{array}$ & 990 & 22.58 & 71 & -4.98 & 3.25 & $1.0 \times 10^{-5}$ & - & - & [57] \\
\hline ТРАСЗМ & $\mathrm{MAPbI}_{3}$ p-in & $\mathrm{P}$ & $\begin{array}{l}17.54 \text { (best) } 16.58 \\
\text { (average) }\end{array}$ & $12.60^{c}$ & 1000 & 22.79 & 78 & -4.96 & 3.25 & $1.1 \times 10^{-5}$ & - & - & [57] \\
\hline $\begin{array}{l}\text { CF-BTz- } \\
\text { ThR }\end{array}$ & $\mathrm{MAPbI}_{3}$ & $\mathrm{M}$ & 15.4 & $10.4^{\mathrm{b}}$ & 1020 & 22.42 & 67 & -5.42 & 2.03 & - & $8.4 \times 10^{-4}$ & - & [58] \\
\hline $\begin{array}{l}\text { TPA-PB- } \\
\text { OXD }\end{array}$ & $\mathrm{MAPBI}_{3}$ & I & $\begin{array}{l}15.46 \text { (rig) } 15.29 \\
\text { (flex) }\end{array}$ & $\begin{array}{l}14.04^{c} \text { (rig) } \\
10.35 \text { (flex) }\end{array}$ & 1.03 & 21.23 & 70.56 & -5.1 & 2.67 & $3.12 \times 10^{-5}$ & - & $\begin{array}{c}80 \%, 720 \mathrm{~h}, \mathrm{NE} \\
(35 \% \mathrm{RH}, \mathrm{rt})\end{array}$ & [59] \\
\hline $\begin{array}{l}\text { DFBT(DTS- } \\
\left.\text { FBTTh }_{2}\right)_{2}\end{array}$ & $\mathrm{MAPbI}_{3}$ & $\mathrm{P}$ & 17.3 & $17.4^{b}$ & 1100 & 20.7 & 76 & -5.27 & 1.41 & $1.78 \times 10^{-4}$ & - & $\begin{array}{c}80 \%, 500 \text { h, NE } \\
(60 \% \text { RH, light, rt })\end{array}$ & [60] \\
\hline $\begin{array}{c}\text { p- } \\
\text { DTS(FBTTh })_{2} \\
\text { /PCDTBT }\end{array}$ & $\mathrm{MAPbI}_{3}$ & $\mathrm{P}$ & $\begin{array}{l}18.0 \text { (best) } 15.90 \\
\quad \text { (average) }\end{array}$ & - & 1.1 & 20.6 & 79.4 & -5.15 & n.a & $1.07 \times 10^{-4}$ & - & $\begin{array}{c}78 \%, 100 \mathrm{~min}, \mathrm{NE} \\
\left(85 \% \mathrm{RH}, 85^{\circ} \mathrm{C}\right)\end{array}$ & [62] \\
\hline CMO & $\mathrm{MAPbI}_{3}$ & $\mathrm{P}$ & 15.92 & $16.70^{b}$ & 930 & 25.19 & 67.9 & -4.78 & 2.96 & $1.4 \times 10^{-5}$ & - & 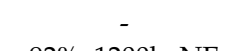 & [63] \\
\hline $\begin{array}{c}\text { PhCz- } \\
\text { 4OMeTPA }\end{array}$ & $\mathrm{Cs}_{0.05}\left(\mathrm{MA}_{0.17} \mathrm{FA}_{0.83}\right)_{0.95} \mathrm{~Pb}\left(\mathrm{I}_{0.83} \mathrm{Br}_{0.17}\right)_{3}$ & M & 16.04 & $19.20^{\mathrm{b}}$ & 1.08 & 21.52 & 69 & -5.06 & 3.12 & $1.13 \times 10^{-4}$ & - & $\begin{array}{c}92 \%, 1200 \mathrm{~h}, \mathrm{NE} \\
\text { (ambient air, dark, } \\
80^{\circ} \mathrm{C} \text { ) }\end{array}$ & [64] \\
\hline Cz-SY1 & $\mathrm{MAPbI}_{3}$ & I & $\begin{array}{c}18.18 \text { (best) } 16.73 \\
\text { (average) }\end{array}$ & $12.33^{\mathrm{c}} 16.92^{\mathrm{e}}$ & 1.099 & 21.57 & 76.7 & -5.29 & 2.22 & $8.19 \times 10^{-6}$ & - & $\begin{array}{c}\text { 85\%, 216h, NE } \\
(40 \% \text { RH, light, rt) }\end{array}$ & [65] \\
\hline Cz-SY2 & $\mathrm{MAPbI}_{3}$ & I & $\begin{array}{c}18.96 \text { (best) } 17.67 \\
\text { (average) }\end{array}$ & $12.33^{c} 16.92^{e}$ & 1.102 & 21.76 & 79.1 & -5.26 & 2.27 & $9.41 \times 10^{-5}$ & - & $\begin{array}{c}85 \%, 216 \mathrm{~h}, \mathrm{NE} \\
(40 \% \mathrm{RH}, \text { light, rt })\end{array}$ & [65] \\
\hline Cz-SY3 & $\mathrm{MAPbI}_{3}$ & I & $\begin{array}{c}15.86 \text { (best) } 14.39 \\
\text { (average) }\end{array}$ & $12.33^{\mathrm{c}} 16.92^{\mathrm{e}}$ & 1.06 & 20.44 & 73.2 & -5.28 & 2.39 & $6.79 \times 10^{-6}$ & - & $\begin{array}{c}88 \%, 216 \mathrm{~h}, \mathrm{NE} \\
(49 \% \text { RH, light, rt) }\end{array}$ & [65] \\
\hline Cz-SY4 & $\mathrm{MAPbI}_{3}$ & I & $\begin{array}{l}18.44 \text { (best) } 17.42 \\
\quad \text { (average) }\end{array}$ & $12.33^{\mathrm{c}} 16.92^{\mathrm{e}}$ & 1.102 & 21.71 & 77.1 & -5.21 & 2.45 & $1.81 \times 10^{-5}$ & - & $\begin{array}{c}84 \%, 216 \text { h, NE } \\
\text { (40\% RH, light, rt) }\end{array}$ & [65] \\
\hline
\end{tabular}


Table 1. Cont

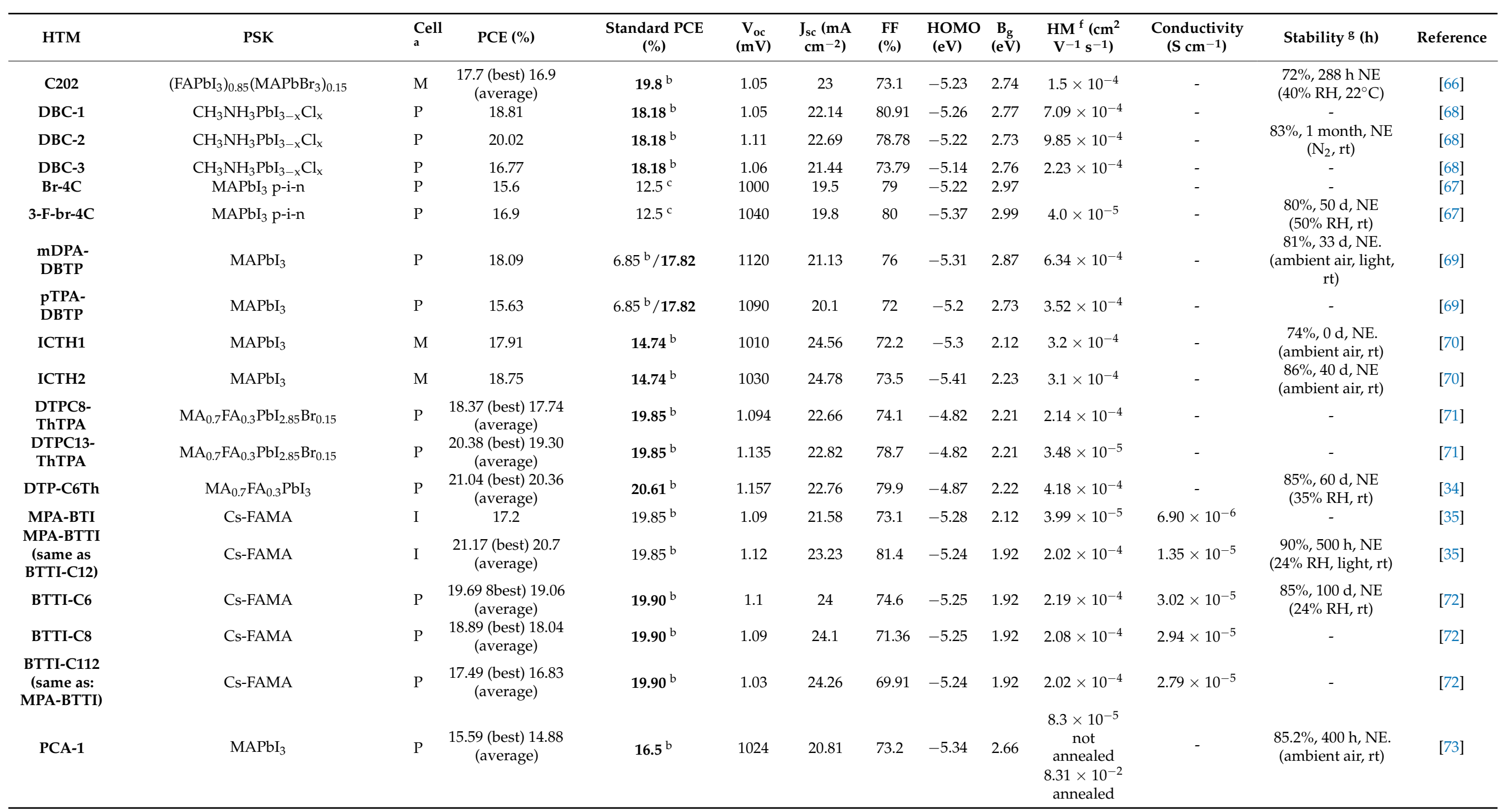


Table 1. Cont.

\begin{tabular}{|c|c|c|c|c|c|c|c|c|c|c|c|c|c|}
\hline HTM & PSK & $\begin{array}{l}\text { Cell } \\
\text { a }\end{array}$ & PCE (\%) & $\begin{array}{c}\text { Standard PCE } \\
(\%)\end{array}$ & $\begin{array}{c}\mathrm{V}_{\mathrm{oc}} \\
(\mathrm{mV})\end{array}$ & $\begin{array}{c}\mathrm{J}_{\mathrm{sc}}(\mathrm{mA} \\
\left.\mathrm{cm}^{-2}\right)\end{array}$ & $\begin{array}{l}\mathrm{FF} \\
(\%)\end{array}$ & $\begin{array}{l}\text { HOMO } \\
(\mathrm{eV})\end{array}$ & $\begin{array}{l}B_{g} \\
(e V)\end{array}$ & $\begin{array}{l}\mathrm{HM}^{\mathrm{f}}\left(\mathrm{cm}^{2}\right. \\
\left.\mathrm{V}^{-1} \mathrm{~s}^{-1}\right)\end{array}$ & $\begin{array}{l}\text { Conductivity } \\
\left(\mathrm{S} \mathrm{cm}^{-1}\right)\end{array}$ & Stability ${ }^{g}(h)$ & Reference \\
\hline PCA-1 & $\mathrm{MAPbI}_{3}$ & M & $\begin{array}{l}18.17 \text { (best) } 17.23 \\
\quad \text { (average) }\end{array}$ & $18.30^{\mathrm{b}}$ & 1062 & 22.3 & 76.7 & -5.34 & 2.66 & $\begin{array}{c}8.3 \times 10^{-5} \\
\text { not } \\
\text { annealed } \\
8.31 \times 10^{-2} \\
\text { annealed }\end{array}$ & - & $\begin{array}{l}85 \%, 400 \mathrm{~h}, \mathrm{NE} \\
\text { (ambient air, rt) }\end{array}$ & [73] \\
\hline $\begin{array}{l}\text { TPA-ANT- } \\
\text { TPA }\end{array}$ & $\mathrm{MAPbI}_{3}$ & $\mathrm{M}$ & $\begin{array}{l}17.5 \text { (best) } 16.0 \\
\quad \text { (average) }\end{array}$ & $\begin{array}{c}16.8^{\mathrm{b}} \text { (best) } 13.8 \\
\text { (average) }\end{array}$ & 1030 & 21.07 & 79.6 & -5.41 & 2.48 & $2.6 \times 10^{-4}$ & - & $\begin{array}{c}84 \%, 50 \mathrm{~h}, \mathrm{NE} \\
\left(58 \% \mathrm{RH}, 22^{\circ} \mathrm{C}\right)\end{array}$ & [74] \\
\hline BTF3 & $\left(\mathrm{FAPbI}_{3}\right)_{0.85}\left(\mathrm{MAPbBr}_{3}\right)_{0.15}$ & $\mathrm{P}$ & 16.34 & $\begin{array}{c}9.33^{b} / \mathbf{1 8 . 8} \\
16.42^{c}\end{array}$ & 1080 & 20.4 & 74.3 & -5.19 & 1.7 & $6.36 \times 10^{-5}$ & - & - & [75] \\
\hline BTF4 & $\left(\mathrm{FAPbI}_{3}\right)_{0.85}\left(\mathrm{MAPbBr}_{3}\right)_{0.15}$ & $\mathrm{P}$ & 18.03 & $\begin{array}{c}9.33^{b} / \mathbf{1 8 . 8} \\
16.42^{c}\end{array}$ & 1060 & 22.5 & 75.6 & -5.02 & 1.59 & $1.17 \times 10^{-4}$ & - & - & [75] \\
\hline FBA1 & $\mathrm{MAPbI}_{x} \mathrm{Cl}_{3-\mathrm{x}}$ & $\mathrm{P}$ & $\begin{array}{l}16.80 \text { (best) } 16.24 \\
\text { (average) }\end{array}$ & $17.57^{\mathrm{b}}$ & 1.05 & 21.57 & 74.2 & -5 & 2.48 & $8.91 \times 10^{-4}$ & - & $\begin{array}{c}80 \% 180 \mathrm{~h}, \mathrm{NE} \\
(30 \% \mathrm{RH}, \mathrm{rt})\end{array}$ & [76] \\
\hline FBA2 & $\mathrm{MAPbI}_{x} \mathrm{Cl}_{3-\mathrm{x}}$ & $\mathrm{P}$ & $\begin{array}{l}18.70 \text { (best) } 17.97 \\
\text { (average) }\end{array}$ & $17.57^{b}$ & 1.06 & 22.32 & 79 & -4.98 & 2.24 & $1.36 \times 10^{-4}$ & - & $\begin{array}{c}80 \% 180 \mathrm{~h}, \mathrm{NE} \\
(30 \% \mathrm{RH}, \mathrm{rt})\end{array}$ & [76] \\
\hline FBA3 & $\mathrm{MAPbI}_{x} \mathrm{Cl}_{3-\mathrm{x}}$ & $\mathrm{P}$ & $\begin{array}{l}19.27 \text { (best) } 18.46 \\
\text { (average) }\end{array}$ & $17.57^{b}$ & 1.09 & 22.12 & 79.9 & -5.07 & 2.29 & $2.12 \times 10^{-4}$ & - & $\begin{array}{c}80 \% 180 \mathrm{~h}, \mathrm{NE} \\
(30 \% \mathrm{RH}, \mathrm{rt})\end{array}$ & [76] \\
\hline FTA1 & $\mathrm{MAPbI}_{x} \mathrm{Cl}_{3-\mathrm{x}}$ & $\mathrm{P}$ & $\begin{array}{l}15.15 \text { (best) } 14.52 \\
\text { (average) }\end{array}$ & $17.57^{b}$ & 1.01 & 20.76 & 72.3 & -5 & 2.49 & $4.83 \times 10^{-5}$ & - & $\begin{array}{c}80 \% 180 \mathrm{~h}, \mathrm{NE} \\
(30 \% \mathrm{RH}, \mathrm{rt})\end{array}$ & [76] \\
\hline FTA2 & $\mathrm{MAPbI}_{x} \mathrm{Cl}_{3-\mathrm{x}}$ & $\mathrm{P}$ & $\begin{array}{l}17.73 \text { (best) } 17.12 \\
\quad \text { (average) }\end{array}$ & $17.57^{b}$ & 1.03 & 22.04 & 78.1 & -4.99 & 2.21 & $1.07 \times 10^{-4}$ & - & $\begin{array}{c}80 \% 180 \mathrm{~h}, \mathrm{NE} \\
(30 \% \mathrm{RH}, \mathrm{rt})\end{array}$ & [76] \\
\hline YN3 & $\left(\mathrm{FAPbI}_{3}\right)_{0.85}\left(\mathrm{MAPbBr}_{3}\right)_{0.15}$ & M & 18.84 & $18.41^{b}$ & 1.12 & 22.43 & 75 & -5.31 & 1.54 & $2.25 \times 10^{-4}$ & $1.98 \times 10^{-4}$ & $\begin{array}{c}92 \%, 300 \mathrm{~h}, \mathrm{NE} \\
(45 \% \mathrm{RH}, \mathrm{rt})\end{array}$ & [77] \\
\hline PYR16 & {$\left[\mathrm{Cs}_{0.05}\left(\mathrm{FA}_{0.83} \mathrm{MA}_{0.17}\right)_{0.95}\right] \mathrm{Pb}\left(\mathrm{I}_{0.83} \mathrm{Br}_{0.17}\right)_{3}$} & $\mathrm{M}$ & 17 & $19.74^{\mathrm{b}}$ & 1.11 & 21.56 & 71 & -5.14 & 2.36 & $1.19 \times 10^{-4}$ & - & $\begin{array}{c}98 \%, 1080 \mathrm{~h}, \mathrm{NE} \\
\text { (ambient air, dark, } \\
80^{\circ} \mathrm{C} \text { ) }\end{array}$ & [78] \\
\hline $\begin{array}{l}\text { ACE-QA- } \\
\text { ACE }\end{array}$ & $\mathrm{MAPbI}_{3}$ & M & 18.2 & $15.2^{b}$ & 1.06 & 22.41 & 77 & -5.59 & 2.12 & $2.3 \times 10^{-4}$ & - & $\begin{array}{c}81 \%, 30 \mathrm{~d}, \mathrm{NE} \\
(75 \% \text { RH, dark, rt })\end{array}$ & [79] \\
\hline $\begin{array}{l}\text { TPA-QA- } \\
\text { TPA }\end{array}$ & $\mathrm{MAPbI}_{3}$ & M & 16.6 & $15.2^{\mathrm{b}}$ & 0.99 & 22.4 & 75.1 & -5.41 & 1.98 & $1.6 \times 10^{-4}$ & - & $\begin{array}{c}78 \%, 30 \mathrm{~d}, \mathrm{NE} \\
(75 \% \mathrm{RH}, \text { dark, rt })\end{array}$ & [79] \\
\hline $\begin{array}{l}\text { DPA-QA- } \\
\text { DPA }\end{array}$ & $\mathrm{MAPbI}_{3}$ & M & 15.5 & $15.2^{\mathrm{b}}$ & 0.95 & 22.38 & 73.2 & -5.28 & 1.87 & $1.2 \times 10^{-4}$ & - & $\begin{array}{c}78 \%, 30 \mathrm{~d}, \mathrm{NE} \\
(75 \% \mathrm{RH}, \text { dark, rt })\end{array}$ & [79] \\
\hline SY1 & $\mathrm{MAPbI}_{3}$ & $\mathrm{M}$ & $\begin{array}{l}17.34 \text { (best) } 16.20 \\
\text { (average) }\end{array}$ & $\begin{array}{c}\mathbf{1 8 . 1 4}{ }^{\mathrm{b}} \text { (best) } \\
16.57 \text { (average) }\end{array}$ & 1010 & 23.68 & 72.1 & \multicolumn{2}{|c|}{0.94140628 .74} & $2.55 \times 10^{-5}$ & - & $\begin{array}{c}504 \mathrm{~h}, \mathrm{NE}(30 \% \\
\left.\mathrm{RH}, 35^{\circ} \mathrm{C}\right)\end{array}$ & [80] \\
\hline SY2 & $\mathrm{MAPbI}_{3}$ & M & $\begin{array}{l}16.10 \text { (best) } 14.46 \\
\text { (average) }\end{array}$ & $\begin{array}{c}\mathbf{1 8 . 1 4}{ }^{\mathrm{b}} \text { (best) } \\
16.57 \text { (average) }\end{array}$ & 1000 & 21.87 & 73.2 & \multicolumn{2}{|c|}{0.94285713301} & $3.46 \times 10^{-5}$ & - & $\begin{array}{c}504 \mathrm{~h} \text {, not enc. } \\
\left(30 \% \mathrm{RH}, 35^{\circ} \mathrm{C}\right)\end{array}$ & [80] \\
\hline
\end{tabular}

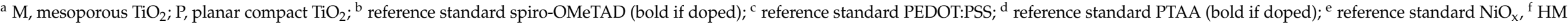

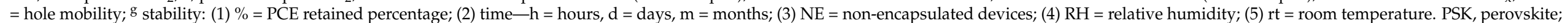

$\mathrm{FF}$, fill factor; $\mathrm{V}_{\mathrm{oc}}$, open circuit voltage; $\mathrm{J}_{\mathrm{sc}}$, short-circuit current density. 

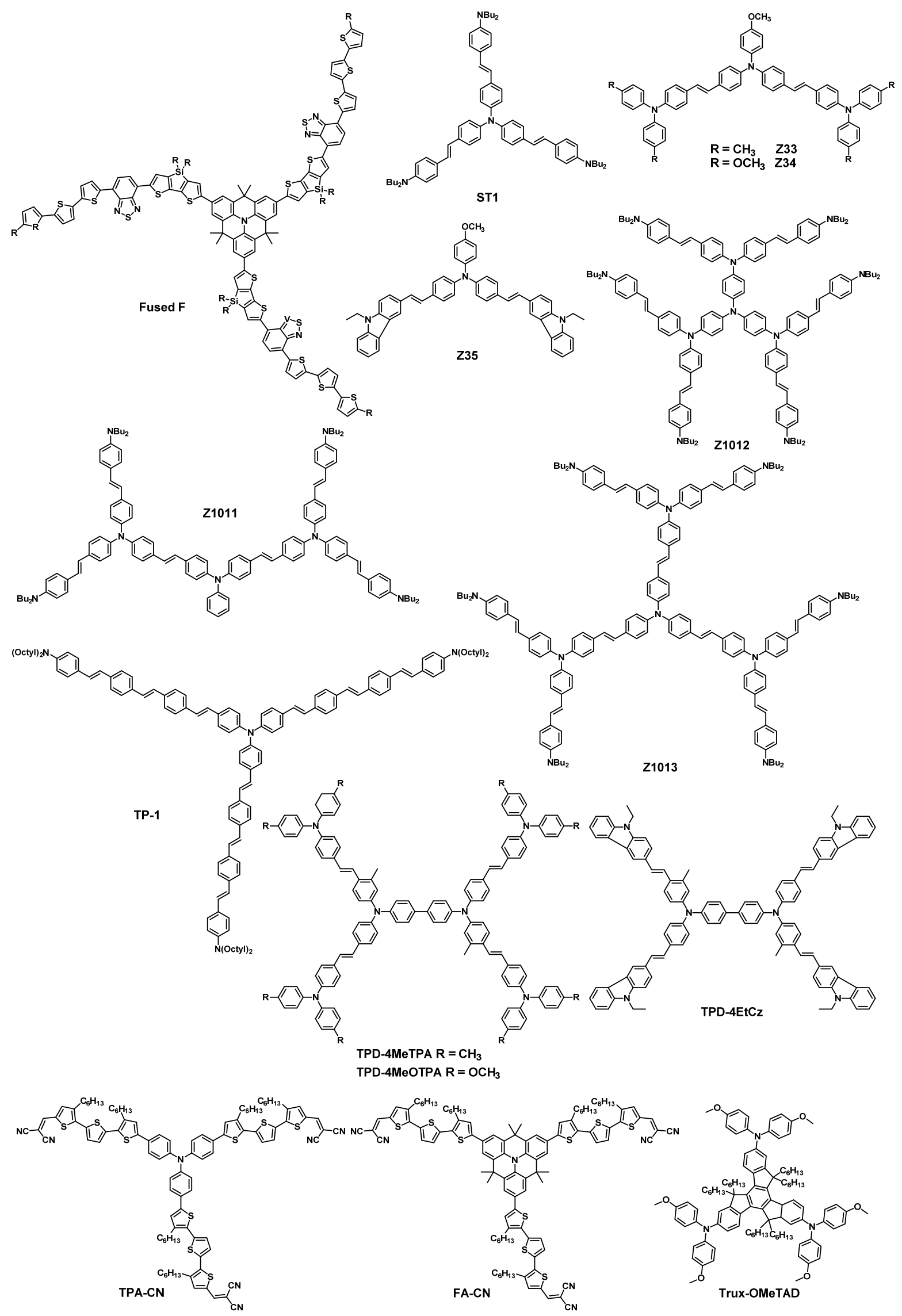

Scheme 2. Cont. 
Energies 2021, 14, 2279

25 of 49

$$
\begin{aligned}
& 30 \text { ong } \\
& \text { n= ristom } \\
& \text { oro.... }
\end{aligned}
$$
r. 0 .

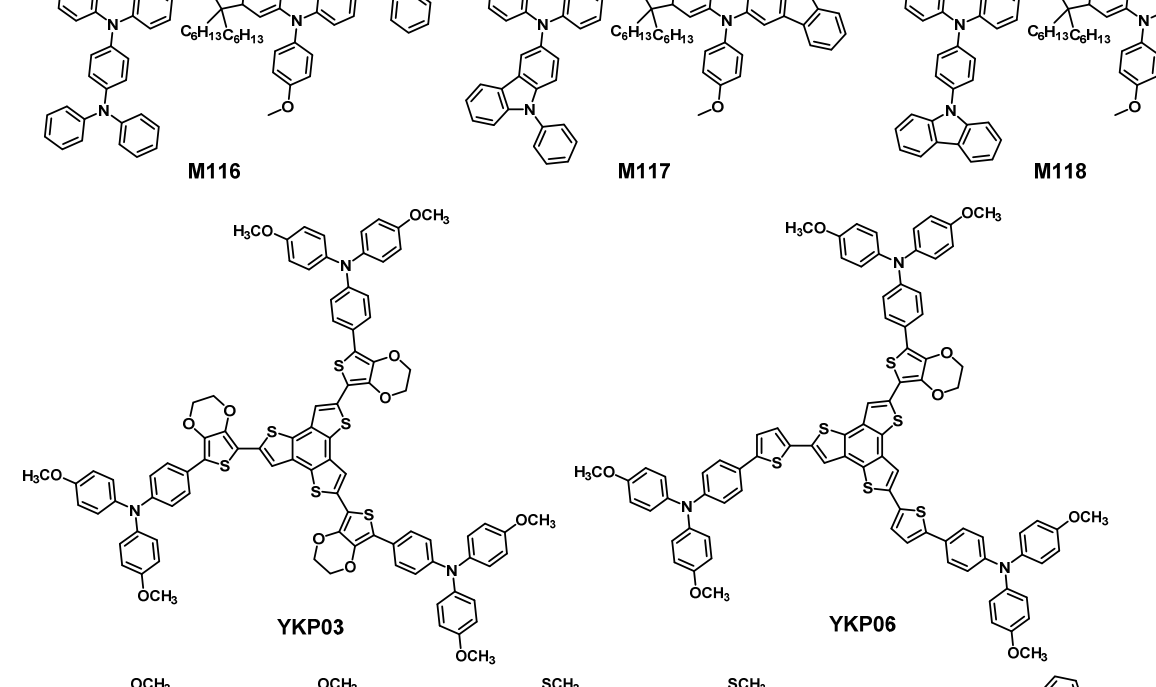

$$
\begin{aligned}
& \text { con }
\end{aligned}
$$

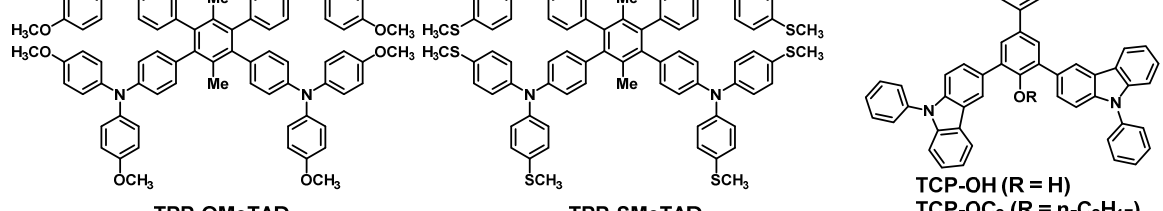

$$
\begin{aligned}
& \text { TPP-OMETAD }
\end{aligned}
$$

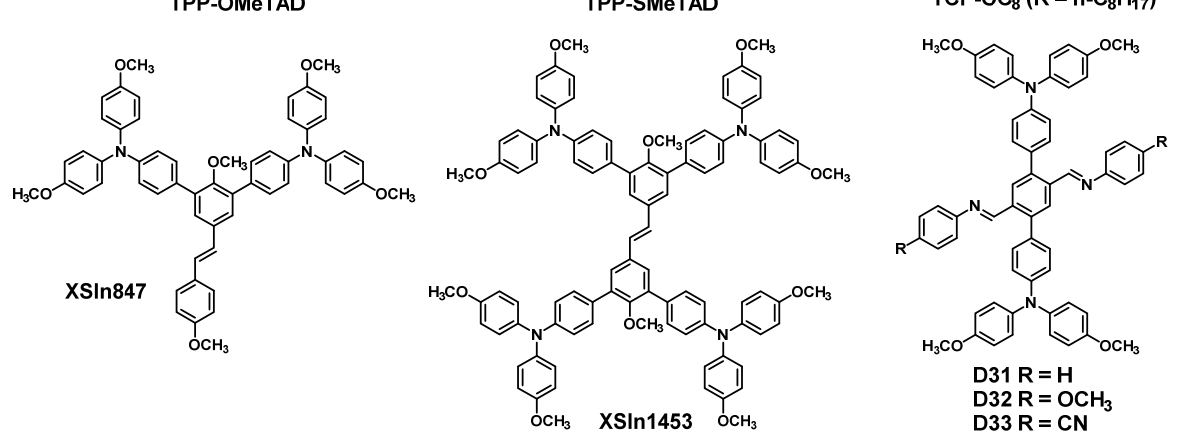

Scheme 2. Cont. 

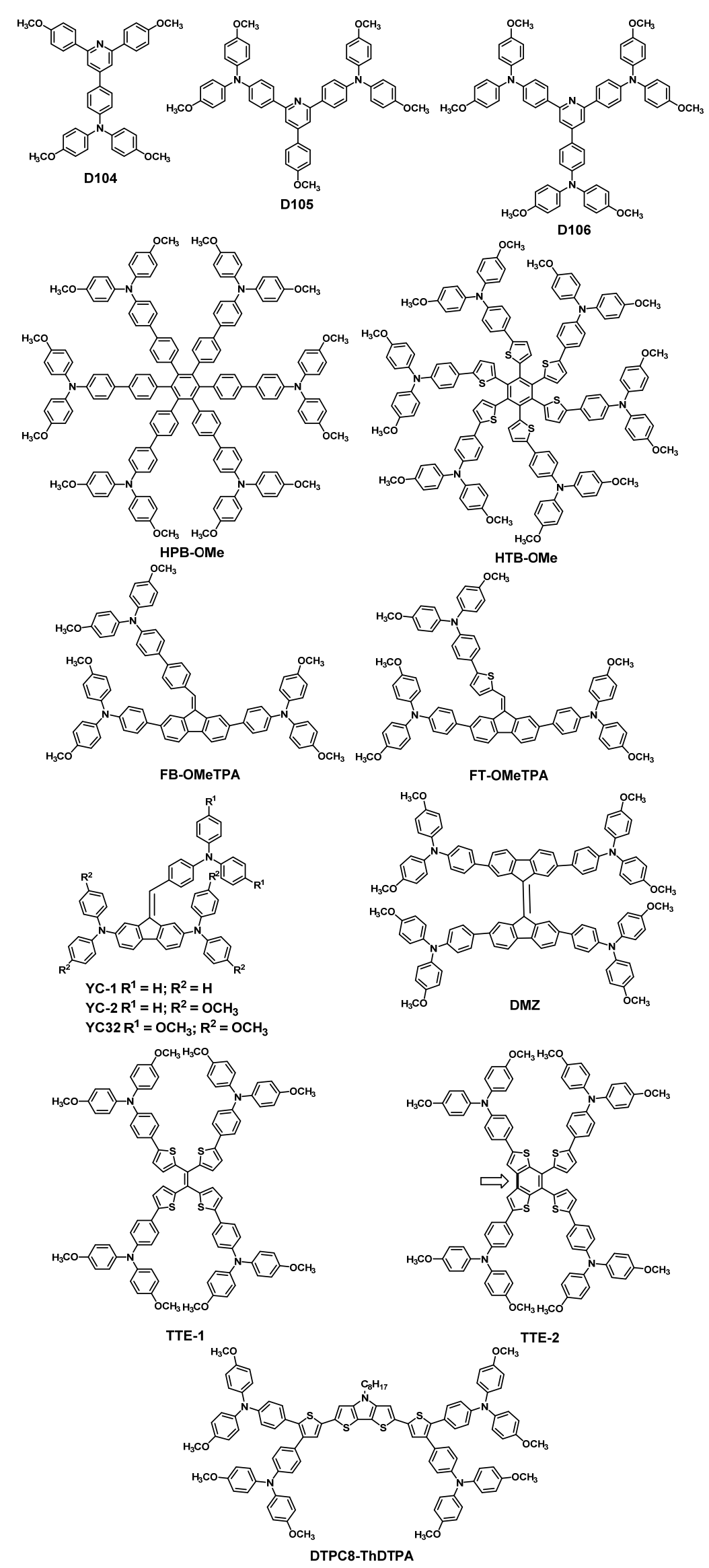

Scheme 2. Structures of 2D star-shaped HTM. 
The Fused-F HTM [81] was the first example of a star-shaped molecule used for PSCs, showing a tripodal branching. It was based on the quinolizino-acridine nucleus forming a D- $\pi-$ A system. Every branching arm is composed by one dithienosililole moiety, one benzothiadiazole and three thiophenes capped with an alkyl chain. The star-shaped molecules often stack in a face-on assembly. However, nothing was said for this molecule for which the organization in the film was not studied.

It showed good hole mobility $\left(6 \times 10^{-5} \mathrm{~cm}^{2} \mathrm{~V}^{-1} \mathrm{~s}^{-1}\right)$, similar to spiro-OMeTAD, very good thermal stability and film forming ability. The final efficiency of this "historical" in $\mathrm{PSC}$ with $\mathrm{MAPbI}_{3}$ perovskite was $12.8 \%$. An easy way to make star-shaped molecules is to exploit the triphenylamine scaffold which has a $C_{3}$ h symmetry. This kind on central core was largely exploited, giving very interesting results. In the series of the triarylamine small molecules, the stilbene linker was used to prepare several triarylamine derivatives. In a first case, a trisubstituted tris(4-bromophenyl)amine central core was reacted with the 4-(N,N-dibutylamino)styrene by Heck reaction, to give ST1. This is a D- $\pi-\mathrm{D}$ structure with the molecule showing trigonal $\mathrm{C}_{3}$ h symmetry. ST1 showed good thermal stability, up to $400{ }^{\circ} \mathrm{C}$ [82]. The material was cost-effective since it needs only one synthetic step and the synthesis is scalable. Its HOMO energy level is better at matching the perovskite level, while its LUMO energy level, which is higher than the corresponding spiro-OMeTAD level, is better able to block the recombination, by avoiding electron transport from perovskite to the metal counter electrode. The ST1 hole mobility is about twice that of spiro-OMeTAD, producing less hysteresis between forward and backward scans in the current vs. voltage J-V measurements. A remarkable 15.4\% PCE was obtained in the undoped state for ST1. A stability test (not encapsulated devices, 30\% humidity for 2-4 weeks) was run, and the ST1 showed a decrease from $15.4 \%$ to $13.2 \%$ (86\% PCE retention), while spiro-OMeTAD decreased from $16.3 \%$ to $10.3 \%$, showing a better performance over a long time [82].

Stilbene-based triarylamine dimeric structures, Z33 and Z34, and an analogous compound containing a carbazole moiety, Z35, were prepared [83]. In principle, their structures are strictly related to the ST1, as shown above. They were easily assembled by the Wittig reaction between a triarylamine bearing two formyl groups and a diarylaminobenzylphosphonium salt. The yield was good and the products were reasonably cheap. Their hole mobilities were higher than spiro-OMeTAD and, in mesoscopic PSCs, gave 15.3\% and $15.9 \%$ PCE for Z33 and Z34 in their undoped state, reasonably close to the doped spiro-OMeTAD (16.6\%), while Z35 achieved a well lower PCE. Stability tests (not encapsulated devices, 30\% humidity, for over $1000 \mathrm{~h}$ ) showed a slight increase in PCE for Z33 and Z34 (16.1\%), while spiro-OMeTAD decreased substantially. Another triarylamine related HTM, Z1011, already based on stilbene linker, was synthesized by the same researchers. This molecule can be considered about a "dimeric" version of ST1 obtained by connection with a triarylamino core through stilbene linkers. This HTM showed a PCE of $16.3 \%$ in its undoped state [84]. This was the result of a hole mobility more than four times higher than spiro-OMeTAD. During stability tests (not encapsulated devices, dry air, up to $1008 \mathrm{~h}$ ) the PCE increased slightly for Z1011 while decreased for spiro-OMeTAD.

Strongly related to Z1011, the structures Z1012 and Z1013, contain a TPA or tris (4-styryl)phenyl)amine central core, which was reacted by Buchwald-Hartwig coupling with the bis(4-(2-(4-N,N-dibutylaminophenyl)ethenyl)phenyl)amine [85]. The hole mobilities were similar (Z1012) or higher (Z1013) than spiro-OMeTAD, while the HOMO energies matched the perovskite valence band level. The Z1013 HTM reached a PCE of $15.4 \%$, while Z1012 reached only $12.4 \%$. Stability tests (not encapsulated devices, $30 \%$ humidity, $80{ }^{\circ} \mathrm{C}$, in the dark) established that while Z1012 and spiro-OMeTAD decreased their PCE of 21.5\% and 39.9\%, the devices prepared from Z1013 increased slightly their performances.

Another TPA structure was proposed by using a dimeric stilbene linker further extending the conjugation with respect to ST-1. While not reaching the PCE cutoff limit, the TP-1 HTM is reported for comparison reasons. The TP-1 showed a slightly lower hole mobility than spiro-OMeTAD, but however reached a PCE of $12.63 \%$ in its pristine state, quite close to the $14.93 \%$ shown by doped spiro-OMeTAD [86]. The use of dopants did not improve 
the performances of TP-1. The stability tests (under 30\% humidity, 5 weeks) showed a PCE decrease of $30 \%$ for TP-1 and about $48 \%$ for spiro-OMeTAD. This case was reported to show that sometimes the continuous elongation of the conjugation in those molecules does not provide the expected effects in photovoltaic efficiency. As a final possible hint on this series of strictly related molecules, it seems that the best result was obtained by trying to "dimerize" the ST1 structure by using a TPA core and connecting to other TPA by and ethylene space in a "stilbene-like" way. This could be extended to an oligomeric or polymeric structure to search for PCE improvement.

Further triarylamino-based HTMs, TPD-4Me, TPD-4MeOTPA and TPD-4EtCz, were prepared with a central biphenyl linker and stilbene "arms". Different groups were used of the terminal TPA groups: methyl, methoxy and carbazole. Working on a PSC having an architecture based on $\mathrm{FTO} / \mathrm{c}-\mathrm{TiO}_{2} / \mathrm{m}-\mathrm{TiO}_{2} /$ perovskite/HTM/Au with the perovskite $\left[(\mathrm{FAI})_{0.85}\left(\mathrm{PbI}_{2}\right)_{0.85}(\mathrm{MABr})_{0.15}-\left(\mathrm{PbBr}_{2}\right)_{0.15}\right]$, the three HTMs performed well, with PCE $11.73 \%$ for TPD-4EtCz, 14.33\% for TPD-4Me and 15.28\% for TPD-4MeOTPA, which followed exactly the order for hole mobility [87]. The stability was evaluated at room temperature in ambient air for over $600 \mathrm{~h}$, demonstrated a PCE retention of about $92 \%$ for all three HTMs, while spiro-OMeTAD retained about $70 \%$.

Tripodal star-shaped Donor- $\pi-$ Acceptor $(\mathrm{D}-\pi-\mathrm{A})$ structures were prepared, based on a flexible triphenylamine (TPA-CN) or the rigid quinolizino-acridine Donor cores (FA-CN), to which, the peripheral groups were assembled by the Suzuki reaction [88]. The peripheral pods are based on a terthiophene, capped with a dicyanovinyl moiety which was inserted at the and by the Vilsmeier-Haack reaction. For both molecules, the hole mobility was found about five times that of spiro-OMeTAD. One should note that the FA-CN is an evolution of the Fused F, cited above [81]. It is important to note that arms of FA-CN are shorter than those of Fused F, and also easier to prepare.

The FA-CN showed an impressive PCE of $18.9 \%$ (average PCE: $18.06 \%$ ), while TPA-CN exhibited a PCE of $17.5 \%$ (average PCE: $17.2 \%$ ). This showed the superior performances for star-shaped molecules having a central planar and rigid core, similar to the truxenes (see below). The stability of devices was tested (unsealed devices under argon, constant illumination: $100 \mathrm{~mW} \mathrm{~cm}{ }^{-2}$ ) by keeping the maximum power point tracking. The performances decreased for all the compounds, at the beginning, while for spiro-OMeTAD, they decreased dramatically during the first $100 \mathrm{~h}$. Probable migration of Au metal from the electrode into the perovskite layer was the reason of this degradation of the performances. The FA-CN was stable for $500 \mathrm{~h}$, while both TPA-CN and spiro-OMeTAD decreased continuously for $1000 \mathrm{~h}$. At $1300 \mathrm{~h}, \mathrm{FA}-\mathrm{CN}$ retained $65 \%$ of the initial PCE, while TPA-CN retained $35 \%$ and spiro-OMeTAD only $15 \%$.

Some truxene-based compounds appeared on the scene as a new family of HTMs. Truxenes are well-known to be a discotic mesogen, showing a columnar packing face-on arrangement in solids [89].

The specific $\mathrm{C}_{3} \mathrm{~h}$ symmetry of truxene molecules helps them to pack in a discotic way in the so-called face-on arrangement, so that the molecules pack in pillars, with the truxene aromatic rings parallel to the deposition surface. This greatly helps the vertical conductivity needed to give high efficiency in PSC cells, because this shortens substantially the hole diffusion pathway towards the metal electrode. The first truxene used in PSCs, Trux-OMeTAD, was prepared as a mimic of spiro-OMeTAD built on a truxene scaffold [36]. The molecule was synthesized in four steps and easily purified. The central core needed three steps from indanone to obtain a reactive tribromotruxene, which was reacted by the Buchwald-Hartwig reaction with the bis(4-methoxyphenyl)amine. The Lewis basic heteroatoms (oxygen) can act as passivators for perovskite surface, by coordinating lead ion [32,90-92]. The six alkyl chains of this material are directed from the surface towards the air giving a high hydrophobicity to this material. This feature helped to protect the perovskite (water contact angle of $90.4^{\circ}$ ). Trux-OMeTAD also showed a very high hole mobility $\left(2.3 \times 10^{-3} \mathrm{~cm}^{2} \mathrm{~V}^{-1} \mathrm{~s}^{-1}\right.$, which increased to $3.6 \times 10^{-3} \mathrm{~cm}^{2} \mathrm{~V}^{-1} \mathrm{~s}^{-1}$ 
after annealing at $150{ }^{\circ} \mathrm{C}$ ). The final PCE boosted to the impressive value of $18.6 \%$, showing Trux-OMeTAD as a reliable material to substitute the spiro-OMeTAD.

A further evolution, TBDI, was prepared as an aza-truxene structure [93]. The azatruxene core was a simple and easily accessible truxene, built as a result of a one-step reaction starting from a cheap material, such as 2-indolinone, which was dehydrated with $\mathrm{POCl}_{3}$. The hole mobility of TBDI was two orders of magnitude higher than that of spiro-OMeTAD and in fact its hole extraction ability was higher than the standard material, as demonstrated by fluorescence quenching. When used in its pristine form, without any additives/dopants, TBDI showed a PCE of 7.3\%, which raised up to $14.85 \%$ when a $\mathrm{MO}_{3}$ was deposited on the ITO. The $\mathrm{MO}_{3}$ thin layer did not act as a barrier as it could expect from the energy alignment, but it worked as a thin dielectric layer and helped to better tune the energy levels; moreover, the hole extraction ability was improved.

A further series of D- $\pi-A$ star-shaped molecules, K321, K353 and K355 were prepared. The core is of the aza-truxene type [8]. The aza-truxene core was prepared as shown above for TBDI. The connection with its pendant arms was performed by the Suzuki reaction.

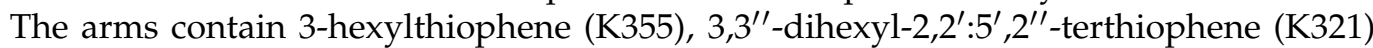
and 4,4-dihexyl-4H-cyclopenta[2,1-b:3,4- $\mathrm{b}^{\prime}$ ]dithiophene (K353), capped with dicyanovinyl groups. The arms used in K321 are the same used in the FA-CN and TPA-CN molecules shown just above [88]. The vertical hole mobility was shown to be very high for K321, about one order of magnitude higher than for K353 and three orders of magnitude than K355. By using Grazing-Incidence Wide-Angle X-Ray Scattering (GIWAXS) (Figure 6), it was demonstrated the discotic columnar stacking (due to $\pi-\pi$ interactions) of the K321 molecules in a face-on orientation on the perovskite surface, which explain the high vertical hole mobility. The molecular structure heavily affects the aggregation and orientation of molecules on the surface. As a final result, the K321 gained an excellent PCE of 19.03\%, while for K353 and K355, the PCE was $14.87 \%$ and 8.88\%, respectively [8].

a)

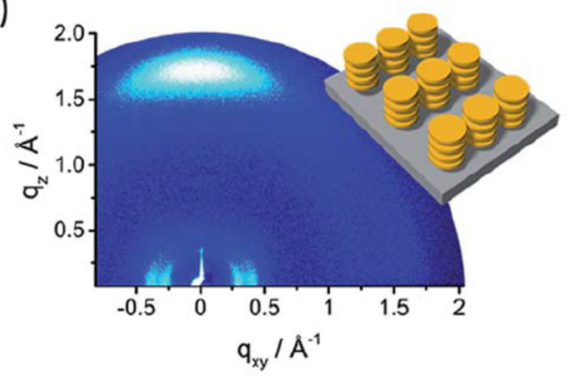

b)

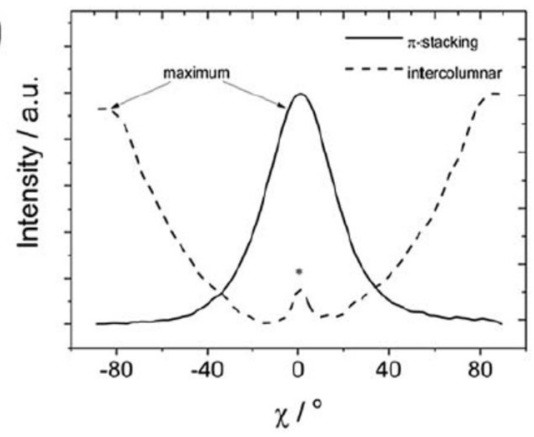

Figure 6. (a) GIWAXS pattern of the KR321 film coated from tetrachloroethane on a silica wafer (schematic illustration of the molecular surface arrangement), and (b) azimuthal integration of the p-stacking and intercolumnar reflections (the star indicates scattering at the beam stop). Reproduced from Reference [8], with permission from The Royal Society of Chemistry.

Several other truxene HTMs were prepared by modulating alkyl chains or the substituents, M115, M116, M117 and M118 [94]. The difference between M115 and M116 was simply due to the change from propyl to the hexyl chains. Differently to the typical bis(4-methoxyphenyl)amine substituent, in these HTMs the substituents are $\mathrm{N}$-(4-methoxyphenyl) substituted amines, based on the triphenylamine (MDPA, M115 and M116), the 9-phenyl-9H-carbazol-3-amine (MPCA, M117) and the 4-(9H-carbazol-9-yl)aniline (CPMA, M118). The HOMO levels were all similar, around $-5.05--5.08 \mathrm{eV}$, apart from M118 which showed a deeper $\mathrm{HOMO}(-5.27 \mathrm{eV})$, due to the specific characteristics of the CPMA substituent. The M118 energy level closer matches the valence band for the $\mathrm{MAPbI}_{3}$ perovskite. Besides, this substitution makes M118 to be more transparent and to be less competitive with perovskite for light absorption. All those materials showed a high hole mobility, around 50-fold than spiro-OMeTAD. The HOMO levels are delocalized over the triphenylamine and truxene core, while the LUMO levels are delocalized on the truxene 
core, apart from M117, in which it is delocalized on the truxene core end the carbazole nucleus. This should be beneficial for the hole mobility, since this HOMO-LUMO overlap reduces the reorganization energy and increases the intramolecular electrical coupling strength. The efficiency was found to be 13.2\% for M115, 15.5\% for M116, 15.7\% for M117 and 17.1\% for M118. Most of them were superior to the 14.4\% PCE shown by the standard PEDOT:PSS. The PCE was following the hole-mobility order, apart for the switch between M117 and M118. In this series one should expect the highest PCE performance for M117, but M118 was better. The reasons were found into a smoother and better film for M118.

Based on the already prepared BTT-3 compound [95] which reached the excellent efficiency (18.2\%) in its doped state, the two new HTMs, YKP03 and YKP06 were prepared, looking for a C-H activation protocol [96]. The scaffold is the benzodithiophene (BTT) and the differences were simply based on the absence of a spacer (BTT-3), the thiophene (YKP06) or the EDOT (YKP03) spacer between the core and the TPA moiety. This clever approach made it possible to achieve reasonable yields while saving time, synthetic steps and money. The authors made an effort to make the $\mathrm{C}-\mathrm{H}$ activation useful for practical applications and their work was rewarded by finding that YKP03 was working better in the dopant-free state, giving a $16.15 \%$ PCE in a mesoporous $\mathrm{MAPbI}_{3}$ based PSC, when spiro-OMeTAD reached $17.59 \%$. The other compound showed a lower PCE, around $13 \%$ in its doped state. These efficiency results were mainly due to the higher Donor ability of the EDOT group which act as a spacer in the molecule and gave a two-fold increase of the hole mobility with respect to the BTT-3 which does not have any spacer.

Another core that was used to build star-shaped molecules was the simple benzene, whose substitution pattern can give several opportunities. As a first example, two mimicking spiro-OMeTAD, i.e., TPP-OMeTAD and TPP-SMeTAD, were synthesized, still containing triarylamine moieties as substituents [97]. The central core, 1,4-dimethyl-2,3,5,6tetraphenylbenzene was prepared in one step by a Diels-Alder reaction. The only difference between the two HTMs is the substitution of phenyl rings of the triphenylamines with methoxy or methylthio groups. The TPP-OMeTAD and TPP-SMeTAD showed higher thermal stability than spiro-OMeTAD and the TPP-SMeTAD HOMO was deeper than TPP-OMeTAD, resulting better aligned with the perovskite level. The two materials showed very good efficiencies (14.6\% for TPP-OMeTAD and 16.6\% for TPP-SMeTAD). The highest PCE of TPP-SMeTAD seems to be related to the passivation of trap states at the grain boundaries of perovskite nanocrystals by $\mathrm{Pb}$-sulfur interaction [97]. Since the HTM was deposited on ITO and the perovskite was prepared on this HTM layer, it seems that a small quantity of HTM can be solubilized, interacting with the formation of the perovskite, which, for TPP-SMeTAD, formed larger crystals and a lower number of grain boundaries and defects.

Other two HTMs having $\mathrm{C}_{3}$ h symmetry (TCP-OH and TCP-OC 8 ) were prepared by attaching three $\mathrm{N}$-phenylcarbazole residues to a phenol central core in its 2, 4, and 6 positions [98]. Despite their apparently very low hole mobility, in the range of $10^{-6} \mathrm{~cm}^{2} \mathrm{~V}^{-1} \mathrm{~s}^{-1}$, they showed respectable PCE (16.97\% and 15.28\%). These HTMs showed excellent thermal stability a high hydrophobic character, and they can produce good films that protect the perovskite layer. The very deep HOMO $(-5.47 \mathrm{eV}$ for TCP-OH and $-5.56 \mathrm{eV}$ for $\mathbf{T C P}-\mathrm{OC}_{8}$ ) prevented their use for the common $\mathrm{MAPbI}_{3}$ perovskite, for which the valence band is located at $-5.40 \mathrm{eV}$. The authors chose a different perovskite, (DMPV: double-mixed perovskite, $\left.(\mathrm{FAI})_{0.81}\left(\mathrm{PbI}_{2}\right)_{0.85}\left(\mathrm{MAPbBr}_{3}\right)_{0.15}\right)$ ), whose valence band is located at $-5.65 \mathrm{eV}$. Coupled with this perovskite, the LUMOs of these HTMs are so high that these materials can also work well as electron-blocking materials. The apparent mismatch between HTMs hole mobility and PCE was deeply discussed into this paper [98], giving further information about the complex role that several parameters play into defining the final Power Conversion Efficiency. This system was also studied by theoretical calculations, confirming the good properties shown by the experimental values [99].

The XSIn847 and XSIn1453 are two HTMs based on the benzene scaffold with triarylamine substituent. The core of those HTMs is a diphenylethene molecule bearing two 
methoxy groups. This was assembled by a Wittig reaction. Alternatively, XSIn847 could be considered as an evolution of TPP-OMeTAD, where the benzene substitution pattern was modified from a TPA to a 4-methoxy phenylethene. The XSIn847 HTM is an asymmetric molecule while XSIn1453 is its symmetric partner. They were used on $\mathrm{MAPbI}_{3}$ perovskite, showing their HOMOs at $-5.26 \mathrm{eV}$ and $5.24 \mathrm{eV}$, respectively. Their UV-Vis absorption, showing an onset well below $450 \mathrm{~nm}$, made them transparent. The XSIn847 showed a higher mobility than XSIn1453 $\left(7.75 \times 10^{-5}\right.$, and $\left.3.09 \times 10^{-5} \mathrm{~cm}^{2} \mathrm{~V}^{-1} \mathrm{~s}^{-1}\right)$. Their use in inverse PSC (glass/ITO/HTL/ $\mathrm{MAPbI}_{3} / \mathrm{PCBM} / \mathrm{Ag}$ ) gave PCE 15.02\% and 12.65\% for XSin847 and XSin1453 in their pristine state, respectively. In the doped state, the PCE of XSin847 was $17.16 \%$ [100].

Similar to the previous star-shaped molecules, the X-shaped series D31, D32 and D33 was easily prepared from cheap materials [101]. The phenyl central core bears two TPA and two N-phenylimino groups. The molecules differ for the substituents on the phenylimino residue. The HOMO levels are close to each other, while the thermal stability and film forming ability were good $\left(386-404^{\circ} \mathrm{C}\right)$, with D31 being the worse since it is less soluble. The CN electron withdrawing substituent showed to reduce consistently the charge on the TPA residue, being the only site on which the negative charge is concentrated, while for D31 and D32 the negative charge is found on the nitrogen of TPA groups. As a matter of fact, D33 gave the best efficiency results with a PCE of $17.85 \%$, also overcoming the methoxy group substituent of D32 (15.83\%), with D31 performing only $13.47 \%$.

Always looking at a central benzene-like ring as a core, a variant example was given by three small-molecules HTMs, D104, D105 and D106 [102]. They were conceived by attaching TPA and/or methoxyphenyl groups on a central pyridine core. They differ for the number of TPA residues inserted into the central pyridine core, one for D104, two for D105 and three for D106, while the residual positions are occupied by methoxyphenyl groups. The synthesis was straightforward and affordable. The increase in TPA groups raised the HOMO, from $-5.36 \mathrm{eV}$ for D104 to -5.30 and $-5.29 \mathrm{eV}$ for D105 and D106, respectively, while the hole mobility reached the best value for D104. The thermal stability was around $400{ }^{\circ} \mathrm{C}$ or above. The pyridine ring, as for the commonly used additive $\mathrm{t}-\mathrm{BP}$, acted as a passivating agent for interfacial traps, while also the oxygens of methoxy groups worked in similar way. As far as the arrangement in single crystals is concerned, D104 and D105 adopted a columnar arrangement referred as "slipped" stacking in which molecules ad arranged in a face-on way in the single column and a tight adjacent columnar edge-on packing. D106 adopted a brick layer stacking, in which the molecular distances are increased. It is known that this arrangement can boost the charge transport in two dimensions and increase the efficiency [103]. The final PSCs gave efficiencies as high as $16.28 \%$ for D104, $17.40 \%$ for D105 and 18.24\% for D106, showing an improvement when the TPA residues were increased. Stability tests were performed at $20{ }^{\circ} \mathrm{C}$, at $30 \%$ of relative humidity, in the dark. The D106 maintained 75\% of the initial PCE after $275 \mathrm{~h}$, while the degradation for the other materials was higher.

A final possibility to exploit the benzene scaffold was to attach to substitute it completely, giving a propeller-like compound. A hexaphenylbenzene and a hexathienylbenzene cores were capped by Suzuki reaction, with the pinacol ester of the bis(4-methoxyphenyl)aniline, giving the compounds HPB-OMe, and HTB-OMe, respectively [104]. The synthesis is relatively short and proceeds with high yield. The HTB-OMe showed higher thermal stability and a better-aligned HOMO, lower than that of HPB-OMe. Moreover, the hole mobility of HTB-OMe was more than five times that of HPB-OMe, which accounted for a better photovoltaic efficiency: $15.92 \%$ vs. $10.95 \%$ (best cells: $17.29 \%$ vs. $12.94 \%$ ).

The smallest scaffold to make a 2D star-shaped molecule while maintaining the planarity is ethylene. A few examples can be found, which gave even a huge increase of PCE, up to $20 \%$.

The FT-OMeTPA and FB-OMeTPA were prepared in a two-step synthetic pathway which afforded a reasonably cheap procedure [105]. In principle, it is a star-shaped (Y-shaped) molecule. While the solubility in organic solvents was higher for FB-OMe- 
TPA, the HOMO and LUMO levels of those two HTMs were nearly similar, making them well aligned with perovskite and prone to avoid charge recombination from the conduction band of perovskite. Both HTMs showed excellent stability, over $400{ }^{\circ} \mathrm{C}$ and a $T_{g}$ of $133^{\circ} \mathrm{C}$ and $120^{\circ} \mathrm{C}$ for FT-OMeTPA and FB-OMeTPA, respectively. The lower steric hindrance of thiophene caused the FT-OMeTPA to be a bit more planar and to show better delocalization than FB-OMeTPA. Moreover, also connected with these observations, the hole mobility was 4 to 5 times higher for FT-OMeTPA over FB-OMeTPA, and when those HTMs were used in inverted PSC, the FT-OMeTPA gave an efficiency of 16.65\%, while FB-OMeTPA reached only $13.66 \%$. No information on the long-term stability was reported.

The dibenzofulvene-based HTMs YC-1, YC-2 and YC3, were synthesized [106]. They are quite similar to the above cited FT-OMeTPA and FB-OMeTPA and differ from them due to the presence of DPA instead TPA as substituents on the benzene ring of the central core. The thermal stability was excellent for YC-1 and YC-2 but around $200{ }^{\circ} \mathrm{C}$ for YC-3. Interestingly, the $\mathrm{YC}-1$ which does not have methoxy groups on the triphenylamine units shows the highest HOMO, whilst the YC-2 and YC-3 show lowest and close HOMOs. This is quite unexpected, and the authors attributed this behavior to the extended conjugation through the alkyliden-9H-fluorene core. In the inverted PSC based on $\mathrm{MAPbI}_{3}$, YC-1 reached a PCE of $16.53 \%$ and when a $\mathrm{NiO}_{\mathrm{x}}$ layer was prepared just below the HTM layer, the PCE raised to an excellent $19.57 \%$ PCE, while YC-2 and YC-3 performed bad, since their too low HOMOs were not correctly aligned with the perovskite. While $\mathrm{NiO}_{\mathrm{x}}$ helped YC-1 to perfume better, YC-1 helped the $\mathrm{NiO}_{x}$ to overcome its interfacial defects, which often a detrimental on its performances. Both kind of PSC, with or without NiOx, retained more than $92 \%$ of their PCE after $100 \mathrm{~h}$ at $25^{\circ} \mathrm{C}$ and $30 \%$ relative humidity.

Lai et al. obtained the new DMZ HTM by coupling the dimethoxytriphenylamine onto the bifluorenylidene scaffold (tetrabenzo[5,5]fulvalene), which was obtained from the dimerization of dibromofluorenone [107]. This is a particular case in which the ethylene is the central scaffold or at least at center of a more complex scaffold. The authors were inspired by the concept of FCTC (Flexible Core with Tunable Conformation). When the core is flexible, the HTMs can modify its configuration based on the interactions between side arms and perovskite or interactions between side arms themselves. By obtaining a material with sufficiently planar structure to get an easy $\pi-\pi$ stacking (to show high hole mobility) and modulated rigidity (to extract holes efficiently) one can achieve a reasonable balance of mobility and charge recombination. The DMZ helped to grow perovskite with larger grains than PEDOT:PSS. The optimization of the HTM concentration in the deposition solution $(2 \mathrm{mg} / \mathrm{mL}$ ) and of the deposited film thickness (around $13 \mathrm{~nm}$ ), brought to an efficiency of $17.62 \%$ (18.61\% for the best device). The stability, measured on non-encapsulated devices at $25{ }^{\circ} \mathrm{C}$ and $45-50 \%$ relative humidity, showed a retention of $90 \%$ of the pristine PCE over $556 \mathrm{~h}$, while PEDOT:PSS was fully degraded in only $77 \mathrm{~h}$.

How much is important a single bond? How is it critical to determine success or failure for an HTM? This has been demonstrated in a paper from Chen et al., on tetrathienylethylene (TTE) (Figure 7) [108]. Two HTMs were prepared, TTE1 and TTE-2. While TTE-1 has a simple TTE core, in TTE-2 two thienyl groups were further connected by a single bond. As a result, the conformations of the two molecules are largely different from each other. TTE-1, which contains the simple TTE core shows an orthogonal conformation in which the two orthogonal planes are defined by the alkene and two thienyl group in trans (or E) relationship to each other. This is roughly mimicking the orthogonal conformation of spiro-bifluorene. TTE-2, on the contrary possess a semi-locked conformation, in which two cis $(Z)$ thienyl groups and the double bond are lying in the same plane (since they constitute an aromatic triannular heterocycle). 

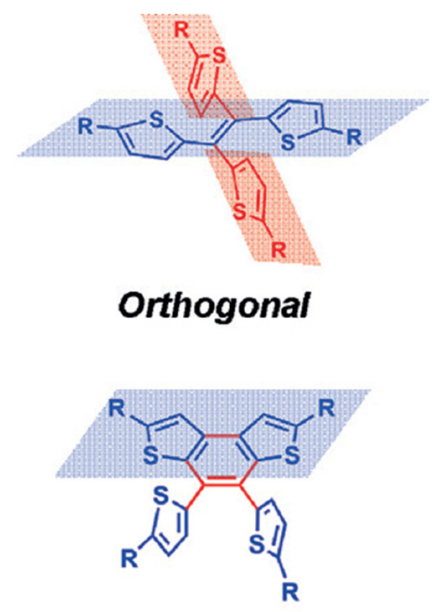

\section{Planar-Orthogonal Hybridization}

Figure 7. Orthogonal and planar-orthogonal arrangements for TTE-2. Reprinted with permission from Reference [108]. Copyright 2019, John Wiley and Sons.

The other two thienyl groups are rotated in an orthogonal way with respect to the large heterocycle, to attain a conformation that was defined as "planar-orthogonal". It was also found that the fully locked planar conformation gives high degree of stacking and low solubility for its derived HTMs and was no more exploited. The semi-locked conformation gave a good balance among the mobility and morphology modulations, also lowering the $\mathrm{HOMO}$ with respect to the unlocked conformation $(-5.01 \mathrm{eV}$ for TTE- 1 and $-5.30 \mathrm{eV}$ for TTE-2). Due to this, it also reduced the UV absorption limit from $600 \mathrm{~nm}$ to less than 500 $\mathrm{nm}$, since it breaks the conjugation with the other thiophenes. The higher planarity gave to TTE-2 a hole mobility higher about one order of magnitude than that of TTE-1. Both TTE- 1 and TTE-2 showed higher $\mathrm{T}_{\mathrm{g}}$ than spiro-OMeTAD $\left(139^{\circ} \mathrm{C}\right.$ and $158^{\circ} \mathrm{C}$ vs. $126^{\circ} \mathrm{C}$, respectively). This should help to obtain homogeneous films which can be resistant when in operative conditions at high temperature. The photovoltaic efficiencies of the two HTMs were assessed in planar PSC, based on the $\left(\mathrm{FAPbI}_{3}\right)_{0.95}\left(\mathrm{MAPbBr}_{3}\right)_{0.05}$ perovskite $(\mathrm{VB}$ at $-5.5 \mathrm{eV}$ ). A simple bond changed the photovoltaic efficiency from $13.68 \%$ for TTE- 1 , to $20.04 \%$ for TTE-2!

A star-shaped molecule, DTPC8-ThDTPA was built around a dithieno-[3,2-b:2', $3^{\prime}$-d] pyrrole core (DTP), by assembling two thieno-DTPA arms onto it [109]. This core was already used for 1D linear HTMs and also for polymeric ones, demonstrating to be very powerful. The HTM showed a HOMO at $-4.85 \mathrm{eV}$ and a higher hole mobility than spiro-OMeTAD. It was observed that the HOMO is delocalized partly also on the TPA in position 3- of the thiophene spacer. This accounts for a participation of all the TPA moieties to the hole transport. A high thermal stability $\left(444{ }^{\circ} \mathrm{C}\right)$ was observed, which is good for potential applications in PSCs. The HTM was used into a planar cell with $\mathrm{SnO}_{2} \mathrm{ETL}, \mathrm{MA}_{0.7} \mathrm{FA}_{0.3} \mathrm{PbI}_{2.85} \mathrm{Br}_{0.15}$ perovskites into PSC, having a $\mathrm{FTO} / \mathrm{SnO}_{2}-\mathrm{C}_{60}-\mathrm{SAM} /$ perovskite/PMMA/HTM/Au structure. The PMMA was used as a passivating layer for the perovskite. The DTPC8-ThDTPA gave a PCE of $19.42 \%$, comparable to the doped spiro-OMeTAD (19.59\%) and well higher than the undoped spiro-OMeTAD $(12.83 \%)$. The doping of this HTM did not improve the PCE.

\subsection{Three-Dimensional Spiro-Orthogonal Structures}

Three-dimensional spiro-orthogonal structures (Table 3 and Scheme 3) contain a central "spiro" motif, or some tilting motif that mimics the spiro arrangement. Starting from the reference state-of-the-art spiro-OMeTAD, researchers prepared molecules by inserting the fluorene moiety, which has a sp ${ }^{3}$ carbon inducing a spiro/spiro-like arrangement. In some cases, also the crowding caused by the substituents at the lateral positions induced 
tilting in molecules not having a specific spiro group. Most molecules in this context still need dopants, but some of them rose to the domain of dopant-free HTMs, showing excellent results. In this case, a relatively small number of produced materials reached a good level of photovoltaic efficiency.

A triarylamine-related compound, BTPA-TCNE, was prepared as a D-A structure with a bis(triphenylamine) Donor and tricyanoethylene Acceptor counterparts [110]. While this material at a first look should be based onto a planar core, one triphenylamino group is tilted and the whole system achieve a "spiro-like" arrangement, while still conjugated with the second triphenylamino group. For this reason, it was included in this section. The strong D-A structure was confirmed by NMR and, principally, X-ray diffraction. This compound adopts a some quinoidal form for the arylene system, which indicated a nearly fully conjugated skeleton, which stabilized a zwitterionic form. The strong dipolar character of the molecule induces resonance forms in the ground state, which outcome is an inherent internal doping effect, that enhances the conductivity and the performances as a dopant-free HTM. This material showed higher hole mobility than its precursor BTPA and the spiro-OMeTAD, reaching the remarkable PCE of $17.0 \%$ in its undoped state.

The indacenodithiophene (IDT) and indacenodithienothiophene (IDTT) were used as the core of triarylamino-based molecules, IDT-TPA and IDTT-TPA, having excellent thermal stability [111]. The cores were transformed into their stannyl derivatives and coupled with the bromo derivative of the $4,4^{\prime}$-dimethoxytriphenylamine by the Stille reaction. The IDTT-TPA showed higher hole mobility and proneness to $\pi-\pi$ stacking, as determined on single crystal X-ray structure determination. The hexylphenyl groups lye quite perpendicular to the indacenothiophene and/or indacenothienothiophene cores, giving a 3D spiro-like arrangement, but they oppose to the stacking for IDT-TPA more than for IDTT-TPA. This explains the better $\pi-\pi$ stacking contact between IDTT-TPA molecules, explaining its better performances. While both structures showed reasonable efficiencies, IDTT-TPA gave the best average PCE (15.1\%, best cell 15.7\%). In the same PSC architecture, the spiro-OMeTAD performed better only in its doped state (17.0\%).

Three triarylamine HTMs (AS37, X41 and X44), having a dihexylfluorene central linker were developed [112]. The goal of the study was to introduce charges directly into the HTM structure, along with counterions., in order to make the compound a better hole transporter. The $\mathbf{X 4 4}$, in fact, contains two cationic ammonium groups with TFSI counterions.

The presence of the TFSI counterions, intimately connected with the HTM structure, improved the performances. The AS37 and X41 were taken as standards, for reference. The HOMOs of these HTMs were very similar to the HOMO of spiro-OMeTAD. The X44 showed a hole mobility higher of an order of magnitude than that of spiro-OMeTAD. While X41 showed very low photovoltaic properties, AS37 gave a PCE of 7.8\% and X44 gave an interesting PCE of $15.2 \%$. Stability tests $\left(\mathrm{N}_{2}\right.$ atmosphere, $20 \%$ humidity, $25^{\circ} \mathrm{C}$, 15 days) showed an increase of PCE from $15.2 \%$ to $16.2 \%$ for X44, indicating that this HTM has a great potential for future applications [112].

The FMT HTM had an even simple structure than X44, since it was developed as a simple HTM, not being internally doped as X44. Notwithstanding, FMT was prepared by a dihexylfluorene as the scaffold and two N,N-di(4-methylthiophenyl)amine groups as substituents and showed an impressive PCE [113]. Its $\mathrm{HOMO}$ was found at $-4.89 \mathrm{eV}$, in agreement to be aligned with $\mathrm{MAPbI}_{3}$ perovskite $(-5.4 \mathrm{eV})$ and the thermal stability was excellent $\left(387^{\circ} \mathrm{C}\right)$. The hole mobility was quite low $\left(2.28 \times 10^{-6} \mathrm{~cm}^{2} \mathrm{~V}^{-1} \mathrm{~s}^{-1}\right)$ with respect to most of the HTMs shown in the literature. However, the very thin layer of HTM used in the inverted PSC could make the hole mobility not so relevant for final performances. The FMT was used into p-i-n inverted PSCs, obtaining an efficiency of $19.06 \%$, which is of absolute interest if one considers the simple structure and limited cost of the material, along with the minimal quantity required for the cell (a $12.5 \mathrm{~nm}$ thick layer). Interestingly, the devices needed at least $24 \mathrm{~h}$ to stabilize their efficiency output, since they were increasing in PCE with time, due to a slow reorganization and stabilization of the perovskite onto the HTM, which brought to a better passivation of traps. The stability at $25^{\circ} \mathrm{C}$ under nitrogen, 
the FTM PSCs showed a retention of $86 \%$ of PCE after $270 \mathrm{~h}$. In the same conditions, but working at $60{ }^{\circ} \mathrm{C}$, the FMT retained 59\% of the pristine PCE after $132 \mathrm{~h}$.

Two HTMs based on spiro-[dibenzo[c,h]xanthene-7, $9^{\prime}$-fluorene], X61 and X62 were prepared as analogs of the spiro-OMeTAD [114]. The two HTMs differ for the presence of two (X61) or four (X62) bis(4-methoxypnehyl)main substituent groups. The HOMOs of these HTMs are lying at $-5.11 \mathrm{eV}(\mathrm{X} 61)$ and $-5.14 \mathrm{eV}(\mathrm{X} 62)$. The hole mobility and conductivity were higher for $\mathbf{X} 62$ than spiro-OMeTAD. This was ascribed to a better $\pi-\pi$ stacking interaction in the solid-state film, supported by the fact that $\mathbf{X} 62$ showed a better film forming ability than $\mathrm{X} 61$. On PSCs having a structure $\left(\mathrm{FTO} / \mathrm{c}-\mathrm{TiO}_{2} / \mathrm{m}-\mathrm{TiO}_{2} /\right.$ mixedperovskite/HTM/Au) the PCE of X62 was 15.9\% overcoming the spiro-OMeTAD (10.8\%), while X61 gave only $8.0 \%$ [114]. Under 50\% humidity, the not encapsulated devices showed a PCE retention of $81 \%, 49 \%$ and $80 \%$ for spiro-OMeTAD, X61 and X62, respectively, after 10 days. Crystal structures were studied to relate the short contact distances between molecules to the performances in PSC. The X62 showed a higher number of very short contact distances with respect to X61, demonstrating that there is a high probability to promote a high and fast charge transfer within the HTM.

The 2mF-X59 HTM is based on the modified version of the SFX core, which is a spiro compound, spiro(fluorene-9, $9^{\prime}$-xanthene), a mimic of the spiro-OMeTAD core. This core was already used for a few HTMs which worked well in their doped state, like X59, which gave PCE as high as $19.8 \%$ in its doped state but only of $3.95 \%$ in the undoped state [115]. In this case, the core of $\mathbf{2 m F - X 5 9}$ contained two fluorine atoms in meta position with respect the xanthene oxygen. The goal was to induce similar structures to work as effective dopant-free HTM, at least avoiding the sensitive dopants (LiTFSI, t-BP, etc.). The 2mF-X59 HTM had a HOMO at $-5.14 \mathrm{eV}$ which was deepened a bit by the addition of the F4TCNQ additive. The thermal properties were very good with a stability up to $410^{\circ} \mathrm{C}$ and a $\mathrm{T}_{\mathrm{g}}$ of $113{ }^{\circ} \mathrm{C}$. It was used into a planar PSC having a $\mathrm{FTO} / \mathrm{TiO}_{2} / \mathrm{CH}_{3} \mathrm{NH}_{3} \mathrm{PbI}_{3} / \mathrm{HTM} / \mathrm{Au}$ architecture. As a dopant-free HTM, it gave a PCE of $15.45 \%$, and the fluorination showed to be effective to increase the PCE of 3.9 times with respect to X59. The performances were further raised up to $18.13 \%$ by the addition of the F4TCNQ additive, which is not a sensitive dopant. This efficiency is comparable with the doped spiro-OMeTAD in the same conditions. The material was transparent and useful for inverted PSC, and its cost in \$/g was quite low, making it reasonably interesting for potential commercial use. Finally, the stability of PSC was evaluated for not encapsulated devices, at $30 \%$ relative humidity and $25{ }^{\circ} \mathrm{C}$. The $2 \mathrm{mF}-\mathrm{X} 59$ retained up to $90 \%$ of the pristine PCE after $500 \mathrm{~h}$, and the $\mathbf{2 m F - X 5 9}$ with the F4TCNQ additive was even better, retaining up to $95 \%$.

The IDF core (6,6,12,12-tetrahexyl-6,12-dihydroindeno[1,2-b]fluorene) was functionalized with a few amino substituents: two or four (bis(4-methoxyphenyl)amine groups (IDF-DiDPA and IDF-TeDPA, respectively), or a 4-methoxylphenylamine bearing a further SFX substituent on the nitrogen (IDF-SFXPh) [116]. While the other material did not show an interesting PCE, IDF-SFXPh had a remarkable efficiency. The base concept for the choice of these molecules was to modulate the properties by building molecules having a planar core, which increases the hole mobility, and inserting twisted units, which inhibit excessive aggregation. The authors used the typical DPA substituent and modulate the steric hindrance by varying the number of units and tried to use also a more steric demanding DPA based substituent. In particular, the huge steric hindrance of SFX helped to obtain a reliable and interesting HTM. The HOMO of the best-performing material, IDF-SFX-Ph can be found to be $-5.22 \mathrm{eV}$ with a $2.79 \mathrm{eV}$ band gap, which makes this HTM transparent and also useful for inverted PSCs. As a result, in the (FTO) $/ \mathrm{C}_{60} /$ perovskite $\left(\mathrm{CH}_{3} \mathrm{NH}_{3} \mathrm{PbI}_{3-\mathrm{x}} \mathrm{Cl}_{\mathrm{x}}\right) / \mathrm{HTM} / \mathrm{MoO}_{3} / \mathrm{Ag}$ PSCs, only IDF-SFXPh reached a PCE $>15 \%$, (best cell PCE: $17.6 \%)$, as the spiro-OMeTAD. 
Table 2. Selected 2D star-shaped dopant-free HTMs, based on performances exceeding 15\% (see legend for details).

\begin{tabular}{|c|c|c|c|c|c|c|c|c|c|c|c|c|c|}
\hline HTM & PSK & Cell $^{a}$ & PCE (\%) & $\begin{array}{l}\text { Standard } \\
\text { PCE }(\%)^{b}\end{array}$ & $\mathrm{~V}_{\mathrm{oc}}(\mathrm{mV})$ & $\begin{array}{c}\mathrm{J}_{\mathrm{sc}}(\mathrm{mA} \\
\left.\mathrm{cm}^{-2}\right)\end{array}$ & FF (\%) & $\begin{array}{c}\text { HOMO } \\
(\mathrm{eV})\end{array}$ & $B_{g}(e V)$ & $\begin{array}{l}\mathrm{HM}\left(\mathrm{cm}^{2}\right. \\
\left.\mathrm{V}^{-1} \mathrm{~s}^{-1}\right)\end{array}$ & $\begin{array}{l}\text { Conductivity } \\
\left(\mathrm{S} \mathrm{cm}^{-1}\right)\end{array}$ & Stability (h) & Reference \\
\hline ST1 & $\mathrm{MAPbI}_{3}$ & M & 15.4 & $16.3^{\mathrm{b}}$ & 1059 & 21.07 & 66 & -5.24 & 2.61 & $4.57 \times 10^{-4}$ & - & $\begin{array}{c}80 \%, 30 \mathrm{~d}, \mathrm{NE}(30 \% \mathrm{RH}, \\
\mathrm{rt})\end{array}$ & [82] \\
\hline Z33 & $\mathrm{MAPbI}_{3}$ & M & $\begin{array}{l}15.4 \text { (best) } \\
15.3 \\
\text { (average) }\end{array}$ & $3.9^{b} / \mathbf{1 6 . 6}$ & 1087 & 20.46 & 66 & -5.34 & 2.72 & $4.67 \times 10^{-4}$ & - & $\begin{array}{l}>100 \% \text {, (incr.), } 1000 \mathrm{~h}, \\
\quad \mathrm{NE}(30 \% \mathrm{RH}, \mathrm{rt})\end{array}$ & [83] \\
\hline Z34 & $\mathrm{MAPbI}_{3}$ & M & $\begin{array}{l}16.1 \text { (best) } \\
15.9 \\
\text { (average) }\end{array}$ & $3.9^{b} / \mathbf{1 6 . 6}$ & 1053 & 21.27 & 69 & -5.14 & 2.71 & $7.46 \times 10^{-4}$ & - & $\begin{array}{l}>100 \% \text {, (incr.), } 1000 \mathrm{~h}, \\
\quad \mathrm{NE}(30 \% \mathrm{RH}, \mathrm{rt})\end{array}$ & [83] \\
\hline Z1011 & $\mathrm{MAPbI}_{3}$ & M & 16.3 & $9.6^{b} / 16.5$ & 1096 & 20.52 & 70 & -5.21 & 2.64 & $8.49 \times 10^{-4}$ & - & $\begin{array}{c}>100 \% \text { (incr.), } 1000 \text { h, NE } \\
\text { (dry air, rt) }\end{array}$ & [84] \\
\hline Z1013 & $\mathrm{MAPbI}_{3}$ & M & 15.4 & $16.7^{\mathrm{b}}$ & 1027 & 21.33 & 70.2 & -5.14 & 2.6 & $6.67 \times 10^{-4}$ & - & $\begin{array}{l}>100 \% \text {, (incr.), } 1000 \mathrm{~h}, \\
\mathrm{NE}\left(30 \% \mathrm{RH}, 80^{\circ} \mathrm{C}\right)\end{array}$ & {$[85]$} \\
\hline $\begin{array}{c}\text { TPD- } \\
\text { 4MeOTPA }\end{array}$ & $\left(\mathrm{FAPbI}_{3}\right)_{0.85}\left(\mathrm{MAPbBr}_{3}\right)_{0.15}$ & M & 15.28 & $17.26^{\mathrm{b}}$ & 1099 & 20.84 & 66.7 & -5.28 & 2.59 & $4.92 \times 10^{-4}$ & - & $\begin{array}{c}92 \%, 600 \text { h, NE (RH 30\%, } \\
\text { rt) }\end{array}$ & [87] \\
\hline TPA-CN & $\left(\mathrm{FAPbI}_{3}\right)_{0.85}\left(\mathrm{MAPbBr}_{3}\right)_{0.15}$ & M & $\begin{array}{c}17.5 \text { (best) } \\
16.4 \\
\text { (average) }\end{array}$ & $\begin{array}{l}19.2^{\mathrm{b}} \text { (best) } \\
18.06 \\
\text { (average) }\end{array}$ & 1090 & 20.85 & 77 & -5.38 & 2.03 & $1.1 \times 10^{-4}$ & & $\begin{array}{c}25 \%, 1300 \mathrm{~h}, \mathrm{NE}(\mathrm{Ar}, \\
\text { light, rt) }\end{array}$ & [88] \\
\hline FA-CN & $\left(\mathrm{FAPbI}_{3}\right)_{0.85}\left(\mathrm{MAPbBr}_{3}\right)_{0.15}$ & M & $\begin{array}{l}18.9 \text { (best) } \\
17.2 \\
\text { (average) }\end{array}$ & $\begin{array}{l}19.2^{\mathrm{b}} \text { (best) } \\
18.06 \\
\text { (average) }\end{array}$ & 1130 & 21.71 & 77 & -5.3 & 1.99 & $1.2 \times 10^{-4}$ & & $\begin{array}{c}65 \%, 1300 \mathrm{~h}, \mathrm{NE}(\mathrm{Ar}, \\
\text { light, rt) }\end{array}$ & [88] \\
\hline TBDI & $\mathrm{MAPbI}_{3}$ p-i-n & $\mathrm{P}$ & 14.85 & $15.30^{\mathrm{d}}$ & 1.09 & 18.73 & 72.8 & -5.25 & 3.27 & $5.95 \times 10^{-3}$ & - & - & [93] \\
\hline KR321 & $\left(\mathrm{FAPbI}_{3}\right)_{0.85}\left(\mathrm{MAPbBr}_{3}\right)_{0.15}$ & $\mathrm{M}$ & 19.03 & $19.01^{b}$ & 1130 & 21.7 & 78 & -5.24 & 2.05 & $2.6 \times 10^{-4}$ & - & - & [8] \\
\hline M116 & $\mathrm{MAPbI}_{3}$ & $\mathrm{P}$ & 15.5 & $14.4^{\mathrm{c}}$ & 1.03 & 21.1 & 72 & -5.05 & 2.95 & $1.42 \times 10^{-3}$ & - & - & [94] \\
\hline M117 & $\mathrm{MAPbI}_{3}$ & $\mathrm{P}$ & 15.7 & $14.4^{\mathrm{c}}$ & 1.03 & 21.7 & 70 & -5.08 & 2.88 & $2.41 \times 10^{-3}$ & - & - & [94] \\
\hline M118 & $\mathrm{MAPbI}_{3}$ & $\mathrm{P}$ & 17.1 & $14.4^{\mathrm{c}}$ & 1.06 & 22.4 & 72 & -5.27 & 3.1 & $1.75 \times 10^{-3}$ & - & - & [94] \\
\hline YKP03 & $\mathrm{MAPbI}_{3}$ & M & 16.15 & $17.59^{\mathrm{b}}$ & 1.03 & 23.07 & 68 & -5.16 & 2.6 & $5.80 \times 10^{-4}$ & - & $\begin{array}{l}80 \%, 800 \mathrm{~h}, \mathrm{NE} 5 \% \mathrm{RH}, \\
\text { glove-box, rt) }\end{array}$ & [96] \\
\hline $\begin{array}{c}\text { TPP- } \\
\text { OMeTAD }\end{array}$ & $\mathrm{MAPbI}_{3}$ p-i-n & $\mathrm{P}$ & 14.6 & - & 1000 & 18.56 & 79 & -5.08 & 3.2 & - & - & - & [97] \\
\hline $\begin{array}{c}\text { TPP- } \\
\text { SMeTAD }\end{array}$ & $\mathrm{MAPbI}_{3}$ p-i-n & $\mathrm{P}$ & 16.6 & - & 1007 & 20.15 & 77 & -5.18 & 3.25 & - & - & - & [97] \\
\hline TCP-OC 8 & $\begin{array}{l}(\mathrm{FAI})_{0.81}\left(\mathrm{PbI}_{2}\right)_{0.85} \\
\left.\left(\mathrm{MAPbBr}_{3}\right)_{0.15}\right)\end{array}$ & M & 15.28 & $13.26^{\mathrm{b}} / \mathbf{1 8 . 8 5}$ & 1090 & 22.38 & 61.4 & -5.56 & 3.45 & $2.56 \times 10^{-7}$ & - & $\begin{array}{c}87 \%, 720 \mathrm{~h}, \mathrm{E} \text { (ambient } \\
\text { air, } 45^{\circ} \mathrm{C} \text { ) }\end{array}$ & [98] \\
\hline ТСР-OH & $\begin{array}{l}(\mathrm{FAI})_{0.81}\left(\mathrm{PbI}_{2}\right)_{0.85} \\
\left.\left(\mathrm{MAPBr}_{3}\right)_{0.15}\right)\end{array}$ & $\mathrm{M}$ & 16.97 & $13.26^{\mathrm{b}} / \mathbf{1 8 . 8 5}$ & 1070 & 23.15 & 66.7 & -5.47 & 3.45 & $5.85 \times 10^{-6}$ & - & $\begin{array}{c}\text { approx. } 85 \%, 720 \mathrm{~h}, \mathrm{E} \\
\left.\text { (ambient air, } 45^{\circ} \mathrm{C}\right)\end{array}$ & [98] \\
\hline XSIn847 & $\mathrm{MAPbI}_{3} \mathrm{p}-\mathrm{i}-\mathrm{n}$ & $\mathrm{P}$ & 15.02 & $11.95^{c}$ & 1090 & 21.58 & 65.7 & -5.26 & 3.16 & $7.75 \times 10^{-5}$ & - & - & [100] \\
\hline D32 & $\mathrm{MAPbI}_{3}$ & I & $\begin{array}{l}15.83 \text { (best) } \\
14.32 \\
\text { (average) }\end{array}$ & $13.16^{\mathrm{c}} 16.19^{\mathrm{e}}$ & 1 & 20.86 & 75.9 & -5.36 & 2.62 & $1.39 \times 10^{-4}$ & - & $\begin{array}{c}48 \%, 400 \mathrm{~h}, \mathrm{NE}(35 \% \mathrm{RH}, \\
\mathrm{rt})\end{array}$ & [101] \\
\hline
\end{tabular}


Table 2. Cont

\begin{tabular}{|c|c|c|c|c|c|c|c|c|c|c|c|c|c|}
\hline HTM & PSK & Cell $^{\text {a }}$ & PCE (\%) & $\begin{array}{l}\text { Standard } \\
\text { PCE }(\%){ }^{b}\end{array}$ & $\mathrm{~V}_{\mathrm{oc}}(\mathrm{mV})$ & $\begin{array}{c}\mathrm{J}_{\mathrm{sc}}(\mathrm{mA} \\
\left.\mathrm{cm}^{-2}\right)\end{array}$ & FF (\%) & $\begin{array}{c}\text { HOMO } \\
(\mathrm{eV})\end{array}$ & $B_{g}(e V)$ & $\begin{array}{l}\mathrm{HM}\left(\mathrm{cm}^{2}\right. \\
\left.\mathrm{V}^{-1} \mathrm{~s}^{-1}\right)\end{array}$ & $\begin{array}{c}\text { Conductivity } \\
\left(\mathrm{S} \mathrm{cm}^{-1}\right)\end{array}$ & Stability (h) & Reference \\
\hline D33 & $\mathrm{MAPbI}_{3}$ & I & $\begin{array}{c}17.85 \text { (best) } \\
16.38 \\
\text { (average) }\end{array}$ & $13.16^{c} 16.19^{e}$ & 1.02 & 22.19 & 78.8 & -5.38 & 2.32 & $2.41 \times 10^{-4}$ & - & $\begin{array}{c}70 \%, 400 \mathrm{~h}, \mathrm{NE}(35 \% \mathrm{RH}, \\
\mathrm{rt})\end{array}$ & [101] \\
\hline D104 & $\mathrm{MAPbI}_{3}$ & I & 16.28 & $14.37^{c}$ & 1.05 & 22.22 & 73.4 & -5.36 & 2.88 & $7.1 \times 10^{-5}$ & - & $\begin{array}{c}33 \%, 275 \mathrm{~h}, \mathrm{NE}(30 \% \mathrm{RH}, \\
\left.20^{\circ} \mathrm{C}\right)\end{array}$ & [102] \\
\hline D105 & $\mathrm{MAPbI}_{3}$ & I & 17.4 & $14.37^{c}$ & 1.04 & 21.96 & 76.1 & -5.3 & 2.94 & $2.41 \times 10^{-4}$ & - & $\begin{array}{c}70 \%, 275 \mathrm{~h}, \mathrm{NE}(30 \% \mathrm{RH}, \\
\left.20^{\circ} \mathrm{C}\right)\end{array}$ & [102] \\
\hline D106 & $\mathrm{MAPbI}_{3}$ & I & 18.24 & $14.37^{c}$ & 1.05 & 22.32 & 77.8 & -5.29 & 2.9 & $1.65 \times 10^{-4}$ & - & $\begin{array}{c}75 \%, 275 \mathrm{~h}, \mathrm{NE}(30 \% \mathrm{RH}, \\
\left.20^{\circ} \mathrm{C}\right)\end{array}$ & [102] \\
\hline $\begin{array}{l}\text { HTB- } \\
\text { OMe }\end{array}$ & $\mathrm{MAPbI}_{3}$ & $P$ & 17.29 & - & 1030 & 22.79 & 73.7 & -5.33 & 2.78 & $5.48 \times 10^{-4}$ & - & - & [104] \\
\hline $\begin{array}{c}\text { FT- } \\
\text { OMeTPA }\end{array}$ & $\begin{array}{l}\left(\mathrm{CsPbI}_{3}\right)_{0.05}\left[\left(\mathrm{FAPbI}_{3}\right)_{0.83}\right. \\
\left.\quad\left(\mathrm{MAPbBr}_{3}\right)_{0.17}\right]_{0.95}\end{array}$ & I & $\begin{array}{c}17.57 \text { (best) } \\
16.65 \\
\text { (average) }\end{array}$ & $18.67^{\mathrm{e}}$ & 1.09 & 20.5 & 78.43 & -5.11 & 2.03 & $1.42 \times 10^{-5}$ & - & - & [105] \\
\hline YC-1 & $\mathrm{MAPbI}_{3}$ & I & $\begin{array}{c}16.53 \text { (best) } \\
15.78 \\
\text { (average) }\end{array}$ & $14.38^{c}$ & 1.022 & 20.98 & 72.9 & -5.28 & 2.57 & - & - & $\begin{array}{c}93 \%, 1000 \mathrm{~h}, \mathrm{NE}(30 \% \\
\mathrm{RH}, \mathrm{rt})\end{array}$ & [106] \\
\hline $\begin{array}{c}\text { YC- } \\
\text { 1/NiOx }\end{array}$ & $\mathrm{MAPbI}_{3}$ & I & $\begin{array}{c}19.37 \text { (best) } \\
18.18 \\
\text { (average) }\end{array}$ & & 1.069 & 22.14 & 79.5 & -5.28 & 2.57 & - & - & $\begin{array}{c}96 \%, 1000 \mathrm{~h}, \mathrm{NE}(30 \% \\
\text { RH, rt })\end{array}$ & [106] \\
\hline TTE-2 & $\left(\mathrm{FAPbI}_{3}\right)_{0.95}\left(\mathrm{MAPbBr}_{3}\right)_{0.05}$ & $\mathrm{P}$ & 20.04 & - & 1.11 & 23.26 & 77.53 & -5.3 & 2.62 & $6.18 \times 10^{-4}$ & & $\begin{array}{c}85 \%, 1000 \mathrm{~h}, \mathrm{NE}(35 \% \\
\mathrm{RH}, \mathrm{rt})\end{array}$ & [108] \\
\hline $\begin{array}{c}\text { DTPC8- } \\
\text { ThDTPA }\end{array}$ & $\mathrm{MA}_{0.7} \mathrm{FA}_{0.3} \mathrm{PbI}_{2.85} \mathrm{Br}_{0.15}$ & $\mathrm{P}$ & $\begin{array}{c}19.42 \text { (best) } \\
18.37 \\
\text { (average) }\end{array}$ & $12.83^{b} / \mathbf{1 9 . 5 9}$ & 1.14 & 23.02 & 74.1 & -4.85 & 2.26 & $6.50 \times 10^{-5}$ & - & 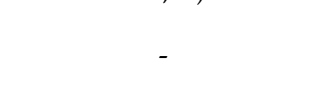 & [109] \\
\hline
\end{tabular}

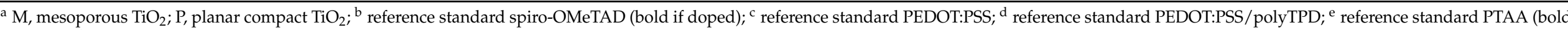

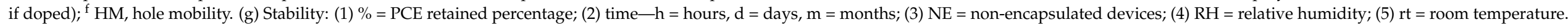



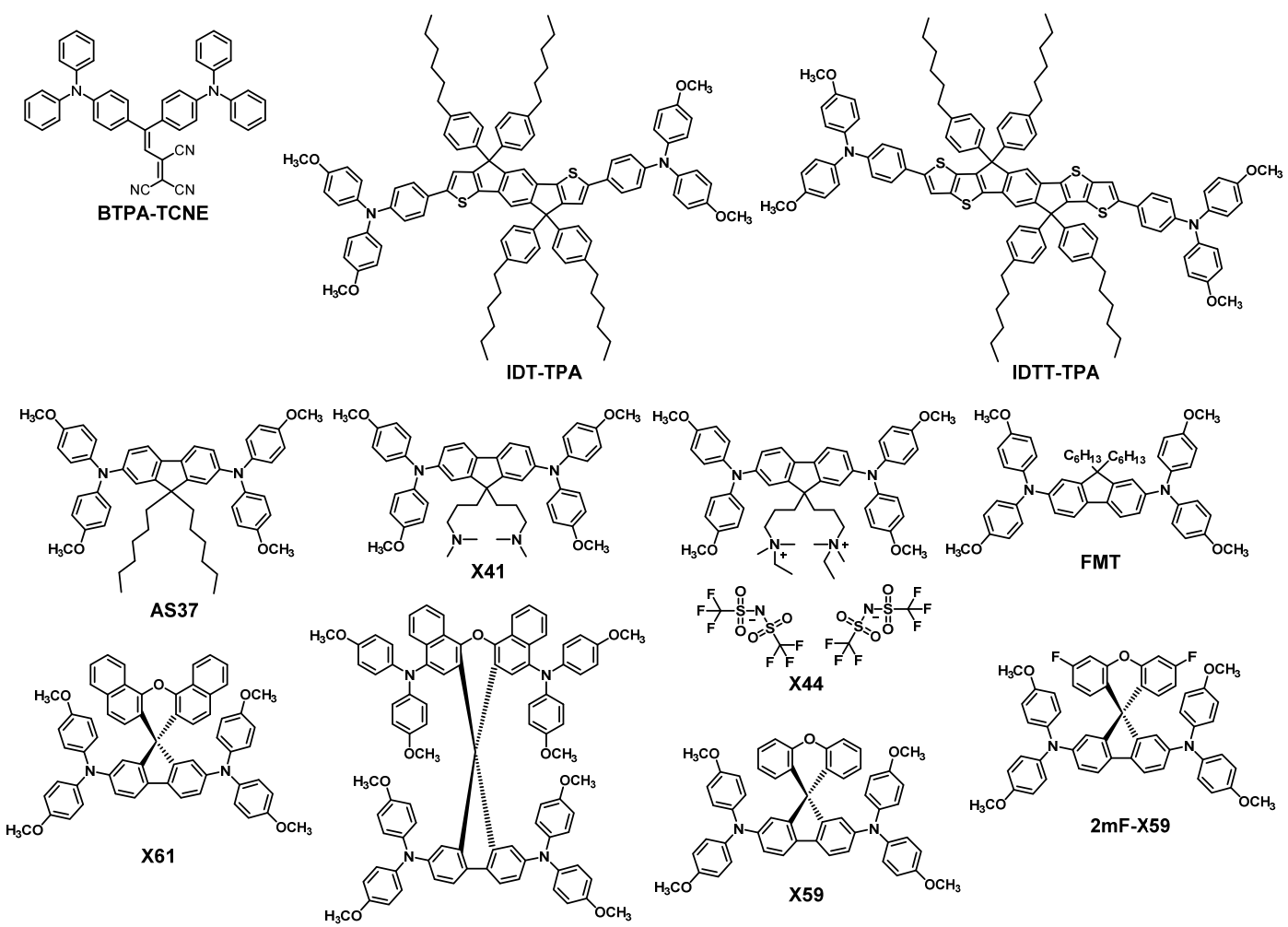

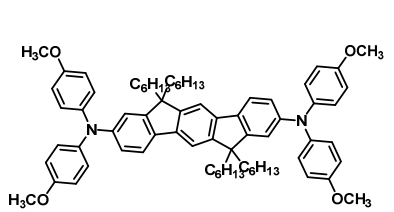

IDF-DiDPA

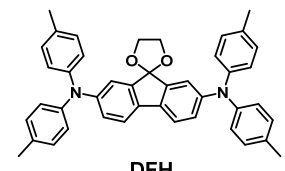

DFH
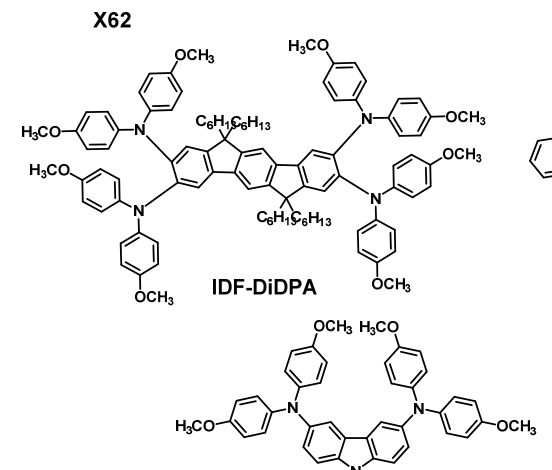

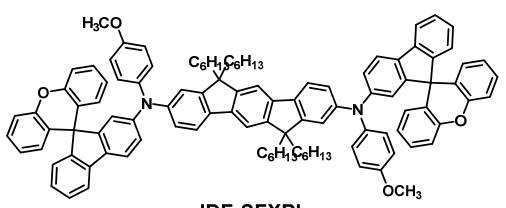

IDF-SFXPh

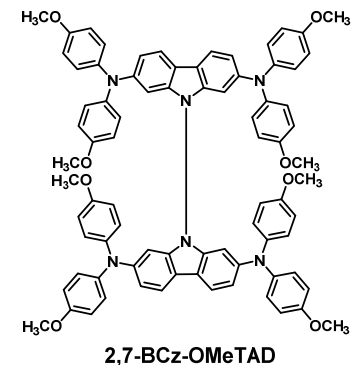

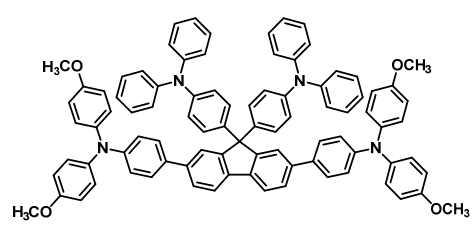

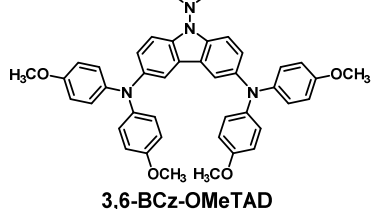

3,6-BCz-OMeTAD
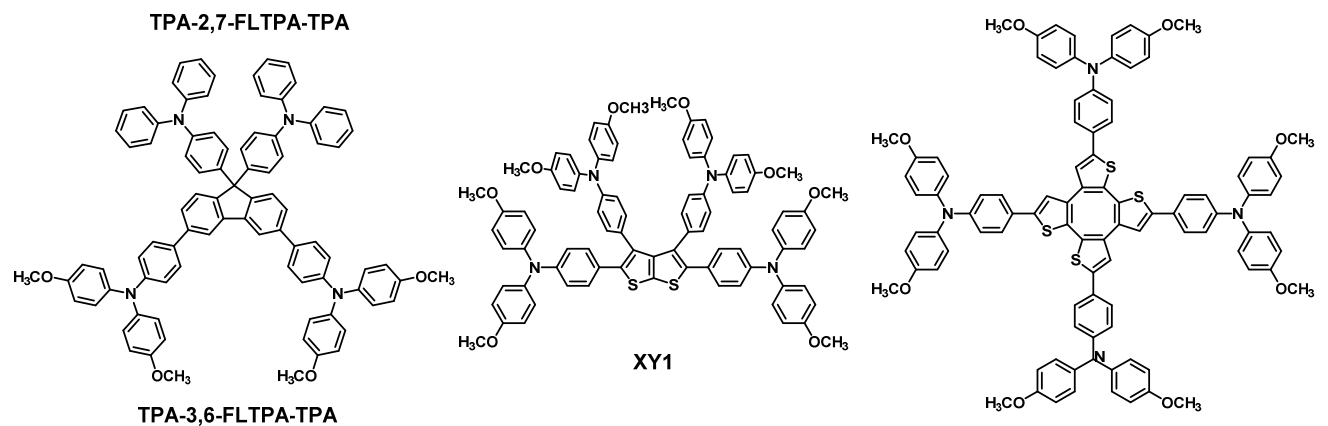

COTh-Ph-OMETAD

Scheme 3. Three-dimensional orthogonal (spiro or spiro-like) HTM structures. 
The DFH $\left(\mathrm{N}^{2}, \mathrm{~N}^{2}, \mathrm{~N}^{7}, \mathrm{~N}^{7}\right.$-tetra-p-tolylspiro[fluorene-9,20-[1,3]dioxolane]-2,7-diamine), a simpler spiro HTM, was prepared in an expensive way, so that its scaled-up cost should be around 3\$/g [117]. The core is an acetal of the fluorenone with ethylene glycol. The use of DFH in an inverted p-i-n PSC gave an impressive PCE (20.6\%). Despite its simple structure, DFH behaved properly, since it has a properly aligned HOMO level and it can induce an anisotropic molecular ordering which improves the hole mobility and electronic conductivity in the normal direction to the cell plane. The film annealing with temperature induced an organization of the molecules orthogonal to the substrate, without a long-range ordering in the film, so that the $\mathrm{C}-\mathrm{H}$ and oxygens of the 1,3-dioxolane group are in close contacts and also $\mathrm{C}-\mathrm{H}-\pi$ interactions take place. While the annealed film organizes in a crystalline way, this ordered structure does not promote the formation of pinholes. This annealing promoted crystallization occurs above the $T_{g}$ and was also studied and confirmed by ${ }^{13} \mathrm{C}$ solid-state NMR and XRD (Figure 8 ). From XRD it was shown that the electroactive TPA groups are kept exceptionally close to each other, without producing large crystals. This mediates for a preferential direction of the charge extraction and hole mobility which is normal to the substrate. The hole mobility was found to be around $1.0 \times 10^{-3} \mathrm{~cm}^{2} \mathrm{~V}^{-1} \mathrm{~s}^{-1}$, for both crystal and annealed film, similar to the single crystal of spiro-OMeTAD but well higher than the dopant-free state-of-the-art HTMs and of the doped spiro-OMeTAD. The annealing at $135^{\circ} \mathrm{C}$ gave the best results, with a pinhole-free and smooth film. Using a $\mathrm{MA}_{0.9} \mathrm{FA}_{0.1} \mathrm{PbI}_{3-\mathrm{x}} \mathrm{Cl}_{\mathrm{x}}$ perovskite, in an ITO I DFH I perovskite I C60 I BCP I Ag inverted cell (BCP = bathocuproine), the DFH showed to outperform (PCE: 20.6\%) both PTAA (annealed at $100{ }^{\circ} \mathrm{C}$, PCE: $19.2 \%$ ) and the already cited star-shaped molecule KR321 (PCE: 19.0\%). As a final result, this specific ordering shows another feature that can be exploited to improve the vertical charge mobility other than the columnar stacking [117].
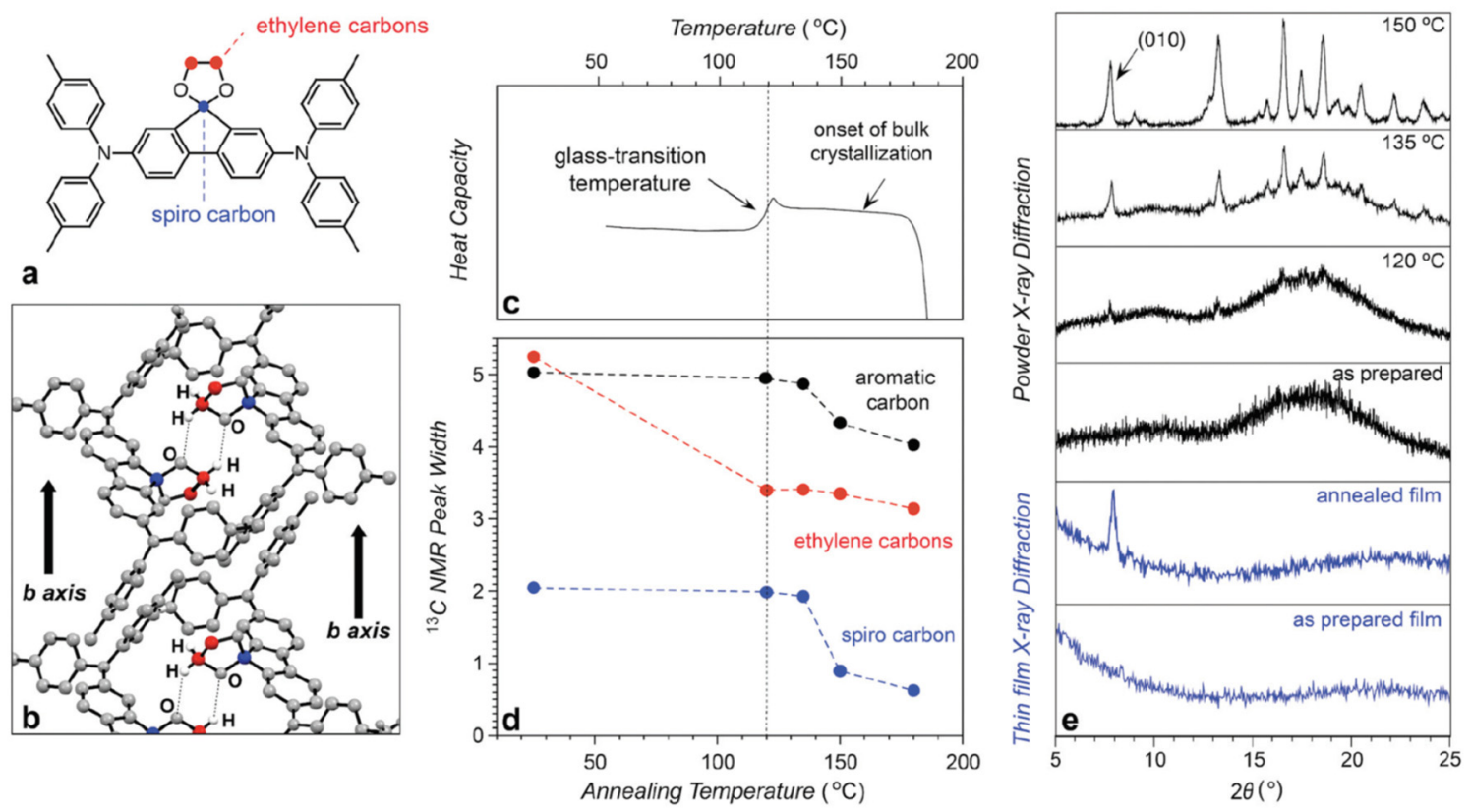

Figure 8. (a) Molecular structure of spiro HTM DFH; (b) X-ray crystalline structure showing the close C-H-O interactions. (c) DSC (Differential Scanning Calorimetry) showing the Glass Transition Temperature $\left(\mathrm{T}_{\mathrm{g}}\right)$ of DFH; (d) solid-state ${ }^{13} \mathrm{C}$ NMR line width for specific carbons of DFH, based on annealing temperature; (e) powder XRD diffractograms of DFH before and after annealing at different temperatures. Reproduced from Reference [118], with permission from The Royal Society of Chemistry.

Yin et al. recently published the synthesis of two bicarbazole-based HTMs, 3,6-BCzOMeTAD and 2,7-BCz-OMeTAD [118]. The only difference between the two HTMs was related to the substitution position on the carbazole core. The two HTMs showed excellent performances, with a PCE of $17.0 \%$ and $17.6 \%$ for 3,6-BCz-OMeTAD and 
2,7-BCz-OMeTAD, respectively, overcoming the undoped spiro-OMeTAD and being comparable with the doped one. These important results were related to interesting characteristics, mainly the natural attitude of this core structure to behave like spiro molecules, since the two sections of the core are perpendicularly twisted, like the $9,9^{\prime}$ 'spirobifluorene. They are transparent materials (absorption onset below $450 \mathrm{~nm}$ ), HOMO lying at -5.11 and $-5.15 \mathrm{eV}$, hole mobility of $1.13 \times 10^{-4}$ and $0.95 \times 10^{-4} \mathrm{~cm}^{2} \mathrm{~V}^{-1} \mathrm{~s}^{-1}$ for 3,6-BCz-OMeTAD and 2,7-BCz-OMeTAD (higher than for spiro-OMeTAD) respectively, Their cost is very low (8.55 \$/g and 14.00 \$/g for 3,6-BCz-OMeTAD and 2,7-BCz-OMeTAD, respectively) compared with the spiro-OMeTAD (92\$/g and commercial price around $170-475$ \$/g) [119] and the excellent PCE obtained is worth of competing with it. Besi, they show very good thermal stability. They were employed with the $\mathrm{Cs}_{0.05} \mathrm{FA}_{0.79} \mathrm{MA}_{0.16} \mathrm{PbI}_{2.49} \mathrm{Br}_{0.51}$ perovskite (valence band at $-5.56 \mathrm{eV}$ ). The HTM was deposited by spin-coating onto perovskite, and the film morphology was good and smooth, fully covering the perovskite. The 2,7-BCz-OMeTAD HTM gave smoother than the 3,6-BCz-OMeTAD, thus protecting the perovskite from moisture in a better way. This was confirmed in the stability tests, showing that under $30 \%$ humidity and not encapsulated devices, the PCE retention was $74 \%$ and $90 \%$ for 3,6-BCz-OMeTAD and 2,7-BCz-OMeTAD over 85 days (around $2000 \mathrm{~h}$ ), accordingly with the better film forming and protection ability of 2,7-BCz-OMeTAD. Under 65\% humidity and light soaking conditions, the 3,6-BCz-OMeTAD and 2,7-BCz-OMeTAD maintained $46 \%$ and $71 \%$ of the pristine PCE, after $150 \mathrm{~h}$.

Some other spiro-like compounds were prepared by attaching aromatic moieties onto a fluorene or a thieno[2,3-b]thiophene scaffold. While not being true "spiro" molecules, these behave like it since the high crowding caused by their specific structure. The first case is related to two fluorene-based HTMs, TPA-2,7-FLTPA-TPA and TPA-3,6-FLTPA-TPA [120]. Two triphenylamines were connected with the central fluorene $\mathrm{sp}^{3}$ carbon. The only difference between the two HTMs was the TPA substitution pattern on the 2,7- or 3,6-fluorene positions. The HOMO levels were lying quite low $(-5.45$ and $-5.57 \mathrm{eV}$, respectively) with respect to $\mathrm{MAPbI}_{3}(-5.46 \mathrm{eV})$. This made the TPA-3,6-FLTPA-TPA to be unfavorably aligned to receive holes from perovskite. The PSCs were built onto an $\mathrm{ITO} / \mathrm{MoO}_{3} / \mathrm{HTM} / \mathrm{MAPbI}_{3} / \mathrm{C}_{60} / \mathrm{BCP} / \mathrm{Ag}$ inverted architecture. The TPA-2,7-FLTPA-TPA gave a $17.1 \%$ PCE, overcoming the PCE $(15.9 \%)$ of the standard TaTm (here also reported as TPB, $\mathrm{N}^{4}, \mathrm{~N}^{4}, \mathrm{~N}^{4^{\prime \prime}}, \mathrm{N}^{4^{\prime \prime}}$-tetra([1,10-biphenyl]-4-yl)-[1, $1^{\prime}: 4^{\prime}, 1^{\prime \prime}$-terphenyl]-4, $4^{\prime \prime}$-diamine, see above for a lower PCE in mesoporous PSCs), while the TPA-3,6-FLTPA-TPA showed only a $13.9 \%$ efficiency.

The XY1 molecule was prepared from the scaffold thieno[2,3-b]thiophene, to which four TPA substituents were attached [121]. Since the crowding generated by four substituents on a small scaffold, a relevant twist of the different TPA groups was found, which makes the structure not planar, thus mimicking the spiro arrangement. The structure appeared to be not symmetric also from the electronic point of view. This made XY1 able to act as an HTM with good hole mobility $\left(3.76 \times 10^{-4} \mathrm{~cm}^{2} \mathrm{~V}^{-1} \mathrm{~s}^{-1}\right)$, higher than spiro-OMeTAD. The two sulfur atoms make the core electron rich and can effectively interact to passivate the $\mathrm{Pb}^{2+}$ surface traps. In the inverted PSC architecture and $\left(\mathrm{CsPbI}_{3}\right)_{0.05}\left[\left(\mathrm{FAPbI}_{3}\right)_{0.83}\left(\mathrm{MAPbBr}_{3}\right)_{0.17}\right]_{0.95}$ perovskite, the XY1 HTM gave an efficiency of $18.30 \%$ (18.78 for the best device). Besides, large area cells were prepared $\left(1 \mathrm{~cm}^{2}\right)$ for which an efficiency of $17.82 \%$ was obtained. The stability after $480 \mathrm{~h}$ at $25^{\circ} \mathrm{C}$ in a glove-box under constant illumination was determined by the retention of $86 \%$ of the pristine PCE. 
Table 3. Selected 3D-orthogonal dopant-free HTMs, based on performances exceeding 15\% (see legend for details).

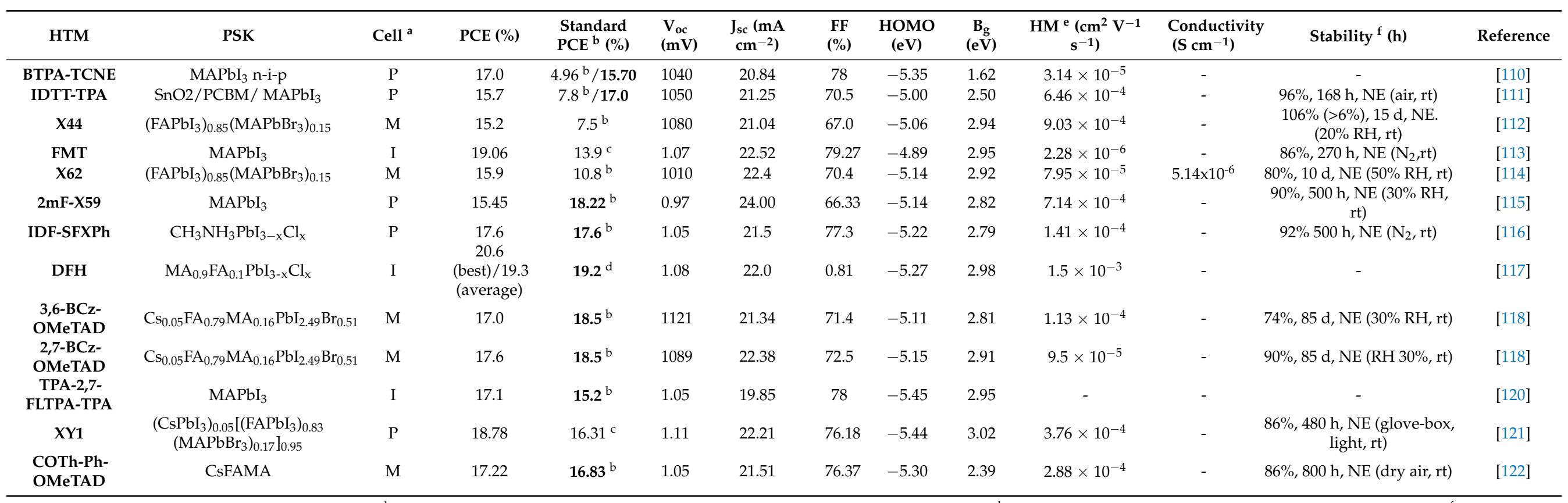

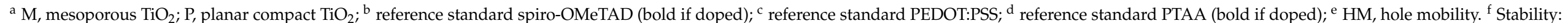

(1) $\%=$ PCE retained percentage; (2) time $-\mathrm{h}=$ hours, $\mathrm{d}=$ days, $\mathrm{m}=$ months; (3) NE = non-encapsulated devices; (4) $\mathrm{RH}=$ relative humidity; (5) $\mathrm{rt}=$ room temperature. 
A saddle shaped molecule, COTh-Ph-OMeTAD, was obtained by Lai et al. [122]. The central core was constituted by the cyclization of four thiophenes linked at their 2 and 3 positions and was further decorated with four dimethoxytriphenylamine arms (Figure 9) [122]. The HOMO was found at $5.30 \mathrm{eV}$, and the band-gap was $2.39 \mathrm{eV}$, while the thermal stability was good, however, at over $300^{\circ} \mathrm{C}$. The COTh-Ph-OMeTAD can pack quite easily, since the nearly $45^{\circ}$ dihedral angle between couples of thiophenes in the central core. This is a perfect example of the FCTC concept, discussed above for the DMZ HTM (see above for a better definition). This helps the molecule to behave as spiro-like structure and to obtain a good hole mobility $\left(2.88 \times 10^{-4} \mathrm{~cm}^{2} \mathrm{~V}^{-1} \mathrm{~s}^{-1}\right)$, well higher than the undoped spiro-OMeTAD but lower than the same doped standard HTM. When COTh-Ph-OMeTAD was used into a mesoporous PSC based on the $\left(\mathrm{CsPbI}_{3}\right)_{0.05}\left(\mathrm{FAPbI}_{3}\right)_{0.79}\left(\mathrm{MAPbBr}_{3}\right)_{0.16}$ perovskite, it reached a PCE of $17.22 \%$, higher than the spiro-OMeTAD (16.83\%). Stability test were performed on non-encapsulated devices at $25^{\circ} \mathrm{C}$, in dry air and in the dark for $800 \mathrm{~h}$, showing a retention of $86 \%$ of the pristine PCE for COTh-Ph-OMeTAD, while the spiro-OMeTAD retained around $20 \%$ after $600 \mathrm{~h}$.

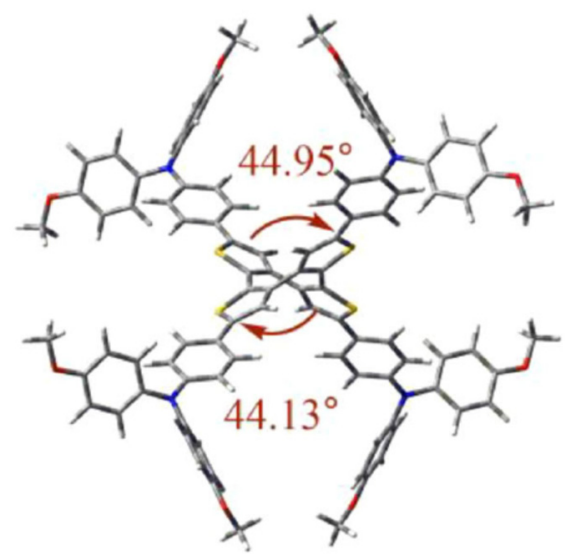

Figure 9. Example of tridimensional arrangement following the FTCT (Flexible Core with Tunable Conformation) concept, for COTh-Ph-OMeTAD (see text for FTCT concept and Scheme 3, for the chemical formula). Reprinted with permission from Reference [122]. Copyright 2019, John Wiley and Sons.

\section{Conclusions}

Dopant-free organic HTMs are molecular materials able to transport hole without any doping. Their story started in 2014 but gave impressive efficiencies in Perovskite Solar Cells in just a few years, achieving, up to now, efficiencies as high as $21.17 \%$ and very high hole mobilities (higher than $>10^{-4} \mathrm{~cm}^{2} \mathrm{~V}^{-1} \mathrm{~s}^{-1}$ ) in their undoped state (e.g., DOR3T-TBDT, $0.26 \mathrm{~cm}^{2} \mathrm{~V}^{-1} \mathrm{~s}^{-1}$ and DFH, $1.5 \times 10^{-3} \mathrm{~cm}^{2} \mathrm{~V}^{-1} \mathrm{~s}^{-1}$ ).

In this review, we collected all dopant-free small-molecule Hole Transporting Materials (HTMs) used in Perovskite Solar Cells (PSCs) exceeding the photovoltaic efficiency of $15 \%$. Several building blocks were detected as recurring cores used to prepare the HTMs. HTMs, based on benzodithiophene, dithienosilole, benzodipyrrole, dithienopyrrole, bithiophencarboximide, truxenes, spirobifluorene and spiro[fluorene-9, $9^{\prime}$-xanthene] cores, showed high efficiency, which attained efficiency exceeding 20-21\%. Truxene cores in general can promote the face-on organization on the perovskite surface, improving the performances. Some other molecules gave the same face-on arrangement due to tuning of structural elements. In general, the molecular planarity extended in two-dimension greatly helps the HTMs to adopt this behavior. Another important topic is the best compaction of molecules in the solid-state film. A reduced contact distance between packed molecules improves the hole mobility, especially when the minimum contact distances include the chemical centers which can be easily oxidized/reduced. Sometimes the fine-tuning of alkyl chain length can be used to optimize the HTM efficiency, since the steric hindrance and molecular crowding can hamper the conditions for a good hole mobility. As a general 
rule of thumb, all factors that promote the molecular planarity, such as (a) the presence of polinuclear aromatic or heteroaromatic groups, (b) the limited number on single rotatable bonds among those groups or (c) arrangements that limit the molecular tilting away from planarity (such as sulfur-oxygen interactions or hydrogen bonding, can help to improve the stacking and the close contact of molecules in the solid state and thus the photovoltaic performance. The complex interaction among all the above factors and the correct alignment of the HOMO energy level makes the HTM structure planning a real challenge and opportunity for organic chemists. However, it is essential to learn the lesson of the simplification of the HTM structure such as for DFH, which mimics the spiro-OMeTAD. This very simple structure can be produced with a three synthetic step path, attaining an exceptional PCE (20.6\%). Similarly, the MPA-BTTI, which possesses a complex $4 \mathrm{H}$-thieno[ $\left[2^{\prime}, 3^{\prime}: 4,5\right]$ thieno[3,2-c]thieno[ $\left.2^{\prime}, 3^{\prime}: 4,5\right]$ thieno[2,3-e]azepine-4,6(5H)-dione core capped by two TPA moieties, was shown to be truly linear and planar, attaining the exceptional PCE of $21.17 \%$.

Researchers still have to face several challenges to obtain better performance and stability for PSCs. At least in part, the organic chemistry can help to propose novel structures. The introduction of novel Donors and Acceptors and the judicious coupling of them can open the way to more performant HTMs, while the introduction of an alkyl chain having a specific length can improve the packing in the solid state and the HTM properties. The insertion in the HTM of passivating moieties (containing N, O or S atoms) already for the perovskite surface traps (often on the lead atoms) can help to increase the photovoltaic efficiency by improving the hole transfer at the interface, due to the suppression of perovskite surface traps. This was developed mainly in polymeric HTMs, but in some cases, one can forecast that also small-molecule HTMs containing specific passivating groups can be developed and used to create a thin layer to passivate the perovskite surface hole traps. This last topic is now very hot in the perovskite community since it was recognized that, while the electron and hole transfer in the perovskite are impressive, the presence of surface traps is hampering the device efficiency. A huge work is now under development also on the perovskite side, trying to use all possible small molecules to cover the perovskite surface to suppress the traps.

A lot of data were collected not only about the efficiency but also about the timestability of the PSCs made with dopant-free HTMs. In view of industrial preparation of PSCs, it is of utmost importance to guarantee the cell stability. Some of the reported materials showed the ability to save at least $80 \%$ of the initial efficiencies in tests performed for $1000 \mathrm{~h}$ or more, on not-encapsulated devices, which is a rough viable indication of an acceptable stability for potential commercialization.

In conclusion, in a few years, the efficiencies of PSCs based on organic dopant-free HTMs rose to values over $21 \%$. This suggests and confirms that there is still a lot of space for invention and imagination for organic chemists, just making bonds.

Author Contributions: Writing-Original Draft Preparation M.M.H.D., M.B. and P.Q.; WritingReview \& Editing, M.M.H.D., M.B., R.B., A.F., C.B., P.Q. and G.V.; Funding Acquisition, C.B., P.Q. and G.V. All authors have read and agreed to the published version of the manuscript.

Funding: This project has received funding from the European Union's Horizon 2020 Research and Innovation Programme under grant agreement no. 826013 (IMPRESSIVE).

Conflicts of Interest: The authors declare no conflict of interest.

\section{Acronyms}

$\begin{array}{ll}\text { ACE } & \text { acenaphthene } \\ \text { A-D-A } & \text { Acceptor-Donor-Acceptor } \\ \text { ANT } & \text { anthanthrone } \\ \text { BCP } & \text { bathocuproine } \\ \text { BDT } & \text { benzodithiophene }\end{array}$




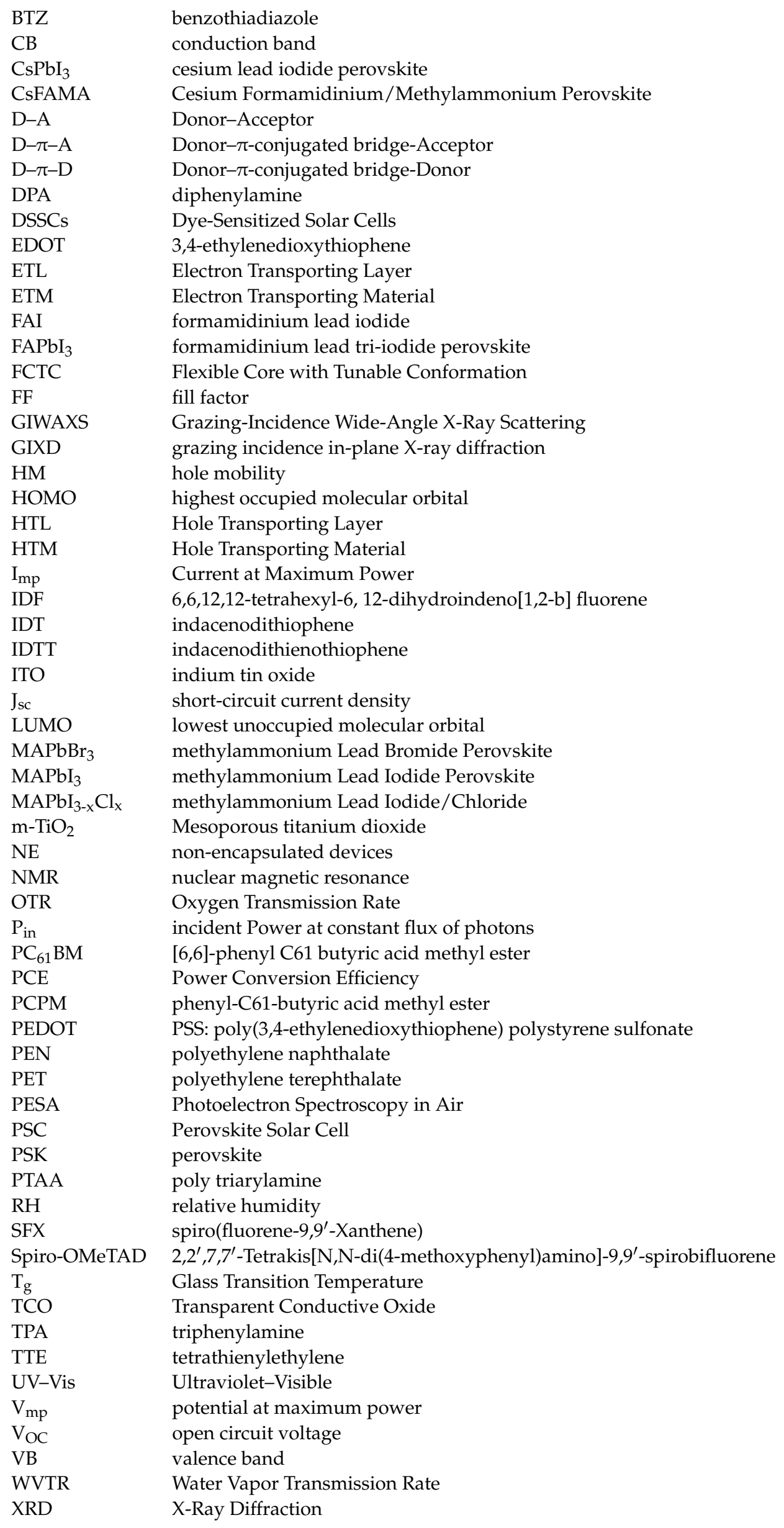




\section{References}

1. Chiang, C.K.; Fincher, C.R.; Park, Y.W.; Heeger, A.J.; Shirakawa, H.; Louis, E.J.; Gau, S.C.; MacDiarmid, A.G. Electrical Conductivity in Doped Polyacetylene. Phys. Rev. Lett. 1977, 39, 1098-1101. [CrossRef]

2. Chandrasekhar, P. Conducting Polymers, Fundamentals and Applications, 2nd ed.; Springer: Cham, Switzerland, 2018; 850p.

3. Foot, P.J.S.; Kaiser, A.B. Conducting polymers. In Kirk-Othmer Encyclopedia of Chemical Technology; John Wiley \& Sons, Inc.: Hoboken, NJ, USA, 2004; pp. 513-550.

4. Garnier, F. Functionalized conducting polymers-Towards intelligent materials. Angew. Chem. 1989, 101, 529-533. [CrossRef]

5. Wessling, B. Conductive polymers as organic nanometals. In Handbook of Nanostructured Materials and Nanotechnology; Academic Press: San Diego, CA, USA, 2000; Volume 5, pp. 501-575.

6. Chen, J.; Park, N.-G. Causes and Solutions of Recombination in Perovskite Solar Cells. Adv. Mater. 2019, 31, e1803019. [CrossRef] [PubMed]

7. Swayamprabha, S.S.; Nagar, M.R.; Yadav, R.A.K.; Gull, S.; Dubey, D.K.; Jou, J.-H. Hole-transporting materials for organic light-emitting diodes: An overview. J. Mater. Chem. C 2019, 7, 7144-7158.

8. Rakstys, K.; Paek, S.; Gao, P.; Gratia, P.; Marszalek, T.; Grancini, G.; Cho, K.T.; Genevicius, K.; Jankauskas, V.; Pisula, W.; et al. Molecular engineering of face-on oriented dopant-free hole transporting material for perovskite solar cells with 19\% PCE. J. Mater. Chem. A 2017, 5, 7811-7815. [CrossRef]

9. Nazeeruddin, M.K.; Snaith, H. Methylammonium lead triiodide perovskite solar cells: A new paradigm in photovoltaics. MRS Bull. 2015, 40, 641-645. [CrossRef]

10. Yang, W.S.; Park, B.-W.; Jung, E.H.; Jeon, N.J.; Kim, Y.C.; Lee, D.U.; Shin, S.S.; Seo, J.; Kim, E.K.; Noh, J.H.; et al. Iodide management in formamidinium-lead-halide-based perovskite layers for efficient solar cells. Science 2017, 356, 1376-1379. [CrossRef]

11. NREL. Available online: https:/ / www.nrel.gov/pv/cell-efficiency.html (accessed on 29 April 2020).

12. Li, M.-H.; Shen, P.-S.; Wang, K.-C.; Guo, T.-F.; Chen, P. Inorganic p-type contact materials for perovskite-based solar cells. J. Mater. Chem. A 2015, 3, 9011-9019. [CrossRef]

13. Cetin, C.; Chen, P.; Hao, M.; He, D.; Bai, Y.; Lyu, M.; Yun, J.-H.; Wang, L. Inorganic p-Type Semiconductors as Hole Conductor Building Blocks for Robust Perovskite Solar Cells. Adv. Sustain. Syst. 2018, 2, 1800032. [CrossRef]

14. Chen, J.; Park, N.-G. Inorganic Hole Transporting Materials for Stable and High Efficiency Perovskite Solar Cells. J. Phys. Chem. C 2018, 122, 14039-14063. [CrossRef]

15. Urieta-Mora, J.; García-Benito, I.; Molina-Ontoria, A.; Martín, N. Hole transporting materials for perovskite solar cells: A chemical approach. Chem. Soc. Rev. 2018, 47, 8541-8571. [CrossRef] [PubMed]

16. Zhou, W.; Wen, Z.; Gao, P. Less is More: Dopant-Free Hole Transporting Materials for High-Efficiency Perovskite Solar Cells. Adv. Energy Mater. 2018, 8, 1702512. [CrossRef]

17. Ummadisingu, A.; Seo, J.-Y.; Stojanovic, M.; Zakeeruddin, S.M.; Grätzel, M.; Hagfeldt, A.; Vlachopoulos, N.; Saliba, M. Additives, Hole Transporting Materials and Spectroscopic Methods to Characterize the Properties of Perovskite Films. Chim. Int. J. Chem. 2017, 71, 754-761. [CrossRef]

18. Calió, L.; Kazim, S.; Grätzel, M.; Ahmad, S. Hole-Transport Materials for Perovskite Solar Cells. Angew. Chem. Int. Ed. 2016, 55, 14522-14545. [CrossRef] [PubMed]

19. MacDiarmid, A.G. "Synthetic Metals": A Novel Role for Organic Polymers (Nobel Lecture). Angew. Chem. Int. Ed 2001, 40, 2581-2590. [CrossRef]

20. Heeger, A.J. Semiconducting and metallic polymers: The fourth generation of polymeric materials. Synth. Met. 2001, 125, 23-42. [CrossRef]

21. Jiang, Q.; Chu, Z.; Wang, P.; Pengyang, W.; Liu, H.; Wang, Y.; Yin, Z.; Wu, J.; Zhang, X.; You, J. Planar-Structure Perovskite Solar Cells with Efficiency beyond 21\%. Adv. Mater. 2017, 29, 1703852. [CrossRef]

22. Liu, D.; Yongsheng, L. Recent progress of dopant-free organic hole-transporting materials in perovskite solar cells. J. Semicond. 2017, 38, 011005. [CrossRef]

23. Sun, X.; Zhao, D.; Li, Z. Recent advances in the design of dopant-free hole transporting materials for highly efficient perovskite solar cells. Chin. Chem. Lett. 2018, 29, 219-231. [CrossRef]

24. Teh, C.H.; Daik, R.; Lim, E.L.; Yap, C.C.; Ibrahim, M.A.; Ludin, N.A.; Sopian, K.; Teridi, M.A.M. A review of organic small molecule-based hole-transporting materials for meso-structured organic-inorganic perovskite solar cells. J. Mater. Chem. A 2016, 4, 15788-15822. [CrossRef]

25. Kim, H.-S.; Lee, C.-R.; Im, J.-H.; Lee, K.-B.; Moehl, T.; Marchioro, A.; Moon, S.-J.; Humphry-Baker, R.; Yum, J.-H.; Moser, J.; et al. Lead Iodide Perovskite Sensitized All-Solid-State Submicron Thin Film Mesoscopic Solar Cell with Efficiency Exceeding 9\%. Sci. Rep. 2012, 2, 591. [CrossRef] [PubMed]

26. Wali, Q.; Elumalai, N.K.; Iqbal, Y.; Uddin, A.; Jose, R. Tandem perovskite solar cells. Renew. Sustain. Energy Rev. 2018, 84, 89-110. [CrossRef]

27. Grätzel, M. The light and shade of perovskite solar cells. Nat. Mater. 2014, 13, 838-842. [CrossRef] [PubMed]

28. Djurišić, A.B.; Liu, F.Z.; Tam, H.W.; Wong, M.K.; Ng, A.; Surya, C.; Chen, W.; He, Z.B. Perovskite solar cells-An overview of critical issues. Prog. Quantum Electron. 2017, 53, 1-37. [CrossRef]

29. Jung, H.S.; Han, G.S.; Park, N.-G.; Ko, M.J. Flexible Perovskite Solar Cells. Joule 2019, 3, 1850-1880. [CrossRef] 
30. De Rossi, F.; Renno, G.; Taheri, B.; Yaghoobi Nia, N.; Ilieva, V.; Fin, A.; Di Carlo, A.; Bonomo, M.; Barolo, C.; Brunetti, F. Modified P3HT materials as hole transport layers for flexible perovskite solar cells. J. Power Sources 2021, 494, 229735. [CrossRef]

31. Boyd, C.C.; Cheacharoen, R.; Leijtens, T.; McGehee, M.D. Understanding Degradation Mechanisms and Improving Stability of Perovskite Photovoltaics. Chem. Rev. 2019, 119, 3418-3451. [CrossRef] [PubMed]

32. De Quilettes, D.W.; Vorpahl, S.M.; Stranks, S.D.; Nagaoka, H.; Eperon, G.E.; Ziffer, M.E.; Snaith, H.J.; Ginger, D.S. Solar cells Impact of microstructure on local carrier lifetime in perovskite solar cells. Science 2015, 348, 683-686. [CrossRef]

33. Salim, T.; Sun, S.; Abe, Y.; Krishna, A.; Grimsdale, A.C.; Lam, Y.M. Perovskite-based solar cells: Impact of morphology and device architecture on device performance. J. Mater. Chem. A 2015, 3, 8943-8969. [CrossRef]

34. Yin, X.; Zhou, J.; Song, Z.; Dong, Z.; Bao, Q.; Shrestha, N.; Bista, S.S.; Ellingson, R.J.; Yan, Y.; Tang, W. Dithieno[3,2-b:2',3'd]pyrrol-cored hole transport material enabling over $21 \%$ efficiency dopant-free perovskite solar cells. Adv. Funct. Mater. 2019, 29, 1904300. [CrossRef]

35. Wang, Y.; Chen, W.; Wang, L.; Tu, B.; Chen, T.; Liu, B.; Yang, K.; Koh, C.W.; Zhang, X.; Sun, H.; et al. Dopant-Free SmallMolecule Hole-Transporting Material for Inverted Perovskite Solar Cells with Efficiency Exceeding 21\%. Adv. Mater. 2019, 31, e1902781. [CrossRef] [PubMed]

36. Huang, C.; Fu, W.; Li, C.-Z.; Zhang, Z.; Qiu, W.; Shi, M.; Heremans, P.; Jen, A.K.-Y.; Chen, H. Dopant-Free Hole-Transporting Material with a C3h Symmetrical Truxene Core for Highly Efficient Perovskite Solar Cells. J. Am. Chem. Soc. 2016, 138, 2528-2531. [CrossRef] [PubMed]

37. Meroni, S.M.P.; Worsley, C.; Raptis, D.; Watson, T.M. Triple-Mesoscopic Carbon Perovskite Solar Cells: Materials, Processing and Applications. Energies 2021, 14, 386. [CrossRef]

38. Berhe, T.A.; Su, W.-N.; Chen, C.-H.; Pan, C.-J.; Cheng, J.-H.; Chen, H.-M.; Tsai, M.-C.; Chen, L.-Y.; Dubale, A.A.; Hwang, B.-J. Organometal halide perovskite solar cells: Degradation and stability. Energy Environ. Sci. 2016, 9, 323-356. [CrossRef]

39. Conings, B.; Drijkoningen, J.; Gauquelin, N.; Babayigit, A.; D’Haen, J.; D’Olieslaeger, L.; Ethirajan, A.; Verbeeck, J.; Manca, J.; Mosconi, E.; et al. Intrinsic Thermal Instability of Methylammonium Lead Trihalide Perovskite. Adv. Energy Mater. 2015, 5, 1500477. [CrossRef]

40. Domanski, K.; Alharbi, E.A.; Hagfeldt, A.; Grätzel, M.; Tress, W. Systematic investigation of the impact of operation conditions on the degradation behaviour of perovskite solar cells. Nat. Energy 2018, 3, 61-67. [CrossRef]

41. Holzhey, P.; Saliba, M. A full overview of international standards assessing the long-term stability of perovskite solar cells. J. Mater. Chem. A 2018, 6, 21794-21808. [CrossRef]

42. Bonomo, M.; Taheri, B.; Bonandini, L.; Castro-Hermosa, S.; Brown, T.M.; Zanetti, M.; Menozzi, A.; Barolo, C.; Brunetti, F. Thermosetting Polyurethane Resins as Low-Cost, Easily Scalable, and Effective Oxygen and Moisture Barriers for Perovskite Solar Cells. ACS Appl. Mater. Interfaces 2020, 12, 54862-54875. [CrossRef]

43. Niu, G.; Guo, X.; Wang, L. Review of recent progress in chemical stability of perovskite solar cells. J. Mater. Chem. A 2015, 3, 8970-8980. [CrossRef]

44. Zhao, Z.; Gu, F.; Rao, H.; Ye, S.; Liu, Z.; Bian, Z.; Huang, C. Metal Halide Perovskite Materials for Solar Cells with Long-Term Stability. Adv. Energy Mater. 2019, 9, 1802671. [CrossRef]

45. Castro-Hermosa, S.; Top, M.; Dagar, J.; Fahlteich, J.; Brown, T.M. Quantifying Performance of Permeation Barrier-Encapsulation Systems for Flexible and Glass-Based Electronics and Their Application to Perovskite Solar Cells. Adv. Electron. Mater. 2019, 5, 1800978. [CrossRef]

46. Uddin, A.; Upama, M.B.; Yi, H.; Duan, L. Encapsulation of Organic and Perovskite Solar Cells: A Review. Coatings 2019, 9, 65. [CrossRef]

47. Schloemer, T.H.; Christians, J.A.; Luther, J.M.; Sellinger, A. Doping strategies for small molecule organic hole-transport materials: Impacts on perovskite solar cell performance and stability. Chem. Sci. 2019, 10, 1904-1935. [CrossRef]

48. Herz, L.M. Charge-Carrier Mobilities in Metal Halide Perovskites: Fundamental Mechanisms and Limits. ACS Energy Lett. 2017, 2, 1539-1548. [CrossRef]

49. Liu, J.; Wu, Y.; Qin, C.; Yang, X.; Yasuda, T.; Islam, A.; Zhang, K.; Peng, W.; Chen, W.; Han, L. A dopant-free hole-transporting material for efficient and stable perovskite solar cells. Energy Environ. Sci. 2014, 7, 2963-2967. [CrossRef]

50. Liu, Y.; Chen, Q.; Duan, H.-S.; Zhou, H.; Yang, Y.; Chen, H.; Luo, S.; Song, T.-B.; Dou, L.; Hong, Z.; et al. A dopant-free organic hole transport material for efficient planar heterojunction perovskite solar cells. J. Mater. Chem. A 2015, 3, 11940-11947. [CrossRef]

51. Kakiage, K.; Aoyama, Y.; Yano, T.; Oya, K.; Fujisawa, J.-I.; Hanaya, M. Highly-efficient dye-sensitized solar cells with collaborative sensitization by silyl-anchor and carboxy-anchor dyes. Chem. Commun. 2015, 51, 15894-15897. [CrossRef] [PubMed]

52. Cheng, M.; Aitola, K.; Chen, C.; Zhang, F.; Liu, P.; Sveinbjörnsson, K.; Hua, Y.; Kloo, L.; Boschloo, G.; Sun, L. AcceptorDonor-Acceptor type ionic molecule materials for efficient perovskite solar cells and organic solar cells. Nano Energy 2016, 30, 387-397. [CrossRef]

53. Chen, C.; Cheng, M.; Liu, P.; Gao, J.; Kloo, L.; Sun, L. Application of benzodithiophene based A-D-A structured materials in efficient perovskite solar cells and organic solar cells. Nano Energy 2016, 23, 40-49. [CrossRef]

54. Liu, Y.; Hong, Z.; Chen, Q.; Chen, H.; Chang, W.-H.; Yang, Y.; Song, T.-B. Perovskite Solar Cells Employing Dopant-Free Organic Hole Transport Materials with Tunable Energy Levels. Adv. Mater. 2016, 28, 440-446. [CrossRef] [PubMed] 
55. Chen, Y.; Xu, X.; Cai, N.; Qian, S.; Luo, R.; Huo, Y.; Tsang, S.-W. Rational Design of Dopant-Free Coplanar D- $\pi$-D HoleTransporting Materials for High-Performance Perovskite Solar Cells with Fill Factor Exceeding 80\%. Adv. Energy Mater. 2019, 9, 1901268. [CrossRef]

56. Salunke, J.; Guo, X.; Lin, Z.; Vale, J.R.; Candeias, N.R.; Nyman, M.; Dahlström, S.; Österbacka, R.; Priimagi, A.; Chang, J.; et al. Phenothiazine-Based Hole-Transporting Materials toward Eco-friendly Perovskite Solar Cells. ACS Appl. Energy Mater. 2019, 2, 3021-3027. [CrossRef]

57. Park, S.J.; Jeon, S.; Lee, I.K.; Zhang, J.; Jeong, H.; Park, J.-Y.; Bang, J.; Ahn, T.K.; Shin, H.-W.; Kim, B.-G.; et al. Inverted planar perovskite solar cells with dopant free hole transporting material: Lewis base-assisted passivation and reduced charge recombination. J. Mater. Chem. A 2017, 5, 13220-13227. [CrossRef]

58. Ameen, S.; Nazim, M.; Akhtar, M.S.; Nazeeruddin, M.K.; Shin, H.-S. A novel perovskite solar cell design using aligned TiO 2 nano-bundles grown on a sputtered Ti layer and a benzothiadiazole-based, dopant-free hole-transporting material. Nanoscale 2017, 9, 17544-17550. [CrossRef] [PubMed]

59. Kwon, H.; Reddy, S.S.; Arivunithi, V.M.; Jin, H.; Park, H.-Y.; Cho, W.; Song, M.; Jin, S.-H. A linear D- $\pi-A$ based hole transport material for high performance rigid and flexible planar organic-inorganic hybrid perovskite solar cells. J. Mater. Chem. C 2019, 7, 13440-13446. [CrossRef]

60. Heo, J.H.; Park, S.; Im, S.H.; Son, H.J. Development of Dopant-Free Donor-Acceptor-type Hole Transporting Material for Highly Efficient and Stable Perovskite Solar Cells. ACS Appl. Mater. Interfaces 2017, 9, 39511-39518. [CrossRef] [PubMed]

61. Lin, Q.; Armin, A.; Nagiri, R.C.R.; Burn, P.L.; Meredith, P. Electro-optics of perovskite solar cells. Nat. Photon. 2015, 9, 106-112. [CrossRef]

62. Hwang, H.; Park, S.; Heo, J.H.; Kim, W.; Ahn, H.; Kim, T.-S.; Im, S.H.; Son, H.J. Enhancing performance and stability of perovskite solar cells using hole transport layer of small molecule and conjugated polymer blend. J. Power Sources 2019, 418, 167-175. [CrossRef]

63. Zhang, J.; Xu, L.J.; Huang, P.; Zhou, Y.; Zhu, Y.Y.; Yuan, N.Y.; Ding, J.N.; Zhang, Z.G.; Li, Y.F. A simple and dopant-free hole-transporting material based on (2-ethylhexyl)-9H-carbazole for efficient planar perovskite solar cells. J. Mater. Chem. C 2017, 5, 12752-12757. [CrossRef]

64. Qiu, J.; Liu, H.; Li, X.; Wang, S.; Zhang, F. Impact of 9-(4-methoxyphenyl) Carbazole and Benzodithiophene Cores on Performance and Stability for Perovskite Solar Cells Based on Dopant-Free Hole-Transporting Materials. Sol. RRL 2019, 3, 1900202. [CrossRef]

65. Wang, S.-Y.; Chen, C.-P.; Chung, C.-L.; Hsu, C.-W.; Hsu, H.-L.; Wu, T.-H.; Zhuang, J.-Y.; Chang, C.-J.; Chen, H.M.; Chang, Y.J. Defect Passivation by Amide-Based Hole-Transporting Interfacial Layer Enhanced Perovskite Grain Growth for Efficient $\mathrm{p}-\mathrm{i}-\mathrm{n}$ Perovskite Solar Cells. ACS Appl. Mater. Interfaces 2019, 11, 40050-40061. [CrossRef] [PubMed]

66. Cai, B.; Yang, X.; Jiang, X.; Yu, Z.; Hagfeldt, A.; Sun, L. Boosting the power conversion efficiency of perovskite solar cells to 17.7\% with an indolo[3,2-b]carbazole dopant-free hole transporting material by improving its spatial configuration. J. Mater. Chem. A 2019, 7, 14835-14841. [CrossRef]

67. Shang, R.; Zhou, Z.; Nishioka, H.; Halim, H.; Furukawa, S.; Takei, I.; Ninomiya, N.; Nakamura, E. Disodium Benzodipyrrole Sulfonate as Neutral Hole-Transporting Materials for Perovskite Solar Cells. J. Am. Chem. Soc. 2018, 140, 5018-5022. [CrossRef] [PubMed]

68. Liu, F.; Wu, F.; Ling, W.; Tu, Z.; Zhang, J.; Wei, Z.; Zhu, L.; Li, Q.; Li, Z. Facile-Effective Hole-Transporting Materials Based on Dibenzo[a,c]carbazole: The Key Role of Linkage Position to Photovoltaic Performance of Perovskite Solar Cells. ACS Energy Lett. 2019, 4, 2514-2521. [CrossRef]

69. Azmi, R.; Nam, S.Y.; Sinaga, S.; Akbar, Z.A.; Lee, C.-L.; Yoon, S.C.; Jung, I.H.; Jang, S.-Y. High-performance dopant-free conjugated small molecule-based hole-transport materials for perovskite solar cells. Nano Energy 2018, 44, 191-198. [CrossRef]

70. Bharath, D.; Sasikumar, M.; Chereddy, N.R.; Vaidya, J.R.; Pola, S. Synthesis of new 2-((5-(4-alkyl-4H-dithieno[3,2-b:2' ,3'-d]pyrrol2-yl)thiophen-2-yl)methylene)malononitrile: Dopant free hole transporting materials for perovskite solar cells with high power conversion efficiency. Sol. Energy 2018, 174, 130-138. [CrossRef]

71. Zhou, J.; Yin, X.; Dong, Z.; Ali, A.; Song, Z.; Shrestha, N.; Bista, S.S.; Bao, Q.; Ellingson, R.J.; Yan, Y.; et al. Dithieno[3,2-b:2',3'd]pyrrole Cored p-Type Semiconductors Enabling 20\% Efficiency Dopant-Free Perovskite Solar Cells. Angew. Chem. Int. Ed. 2019, 58, 13717-13721. [CrossRef]

72. Tu, B.; Wang, Y.; Chen, W.; Liu, B.; Feng, X.; Zhu, Y.; Yang, K.; Zhang, Z.; Shi, Y.; Guo, X.; et al. Side-Chain Engineering of Donor-Acceptor Conjugated Small Molecules as Dopant-Free Hole-Transport Materials for Efficient Normal Planar Perovskite Solar Cells. ACS Appl. Mater. Interfaces 2019, 11, 48556-48563. [CrossRef] [PubMed]

73. Li, Y.; Scheel, K.R.; Clevenger, R.G.; Shou, W.; Pan, H.; Kilway, K.V.; Peng, Z. Highly Efficient and Stable Perovskite Solar Cells Using a Dopant-Free Inexpensive Small Molecule as the Hole-Transporting Material. Adv. Energy Mater. 2018, 8, 1801248. [CrossRef]

74. Pham, H.D.; Do, T.T.; Kim, J.; Charbonneau, C.; Manzhos, S.; Feron, K.; Tsoi, W.C.; Durrant, J.R.; Jain, S.M.; Sonar, P. Molecular Engineering Using an Anthanthrone Dye for Low-Cost Hole Transport Materials: A Strategy for Dopant-Free, High-Efficiency, and Stable Perovskite Solar Cells. Adv. Energy Mater. 2018, 8, 1703007. [CrossRef]

75. Sun, X.; Xue, Q.; Zhu, Z.; Xiao, Q.; Jiang, K.; Yip, H.-L.; Yan, H.; Li, Z. Fluoranthene-based dopant-free hole transporting materials for efficient perovskite solar cells. Chem. Sci. 2018, 9, 2698-2704. [CrossRef]

76. Sun, X.; Wu, F.; Zhong, C.; Zhu, L.; Li, Z. A structure-property study of fluoranthene-cored hole-transporting materials enables 19.3\% efficiency in dopant-free perovskite solar cells. Chem. Sci. 2019, 10, 6899-6907. [CrossRef] 
77. Zhang, D.; Xu, P.; Wu, T.; Ou, Y.; Yang, X.; Sun, A.; Cui, B.; Sun, H.; Hua, Y. Cyclopenta[hi]aceanthrylene-based dopantfree hole-transport material for organic-inorganic hybrid and all-inorganic perovskite solar cells. J. Mater. Chem. A 2019, 7, 5221-5226. [CrossRef]

78. Qiu, J.; Liu, H.; Li, X.; Wang, S. Position effect of arylamine branches on pyrene-based dopant-free hole transport materials for efficient and stable perovskite solar cells. Chem. Eng. J. 2020, 387, 123965. [CrossRef]

79. Pham, H.D.; Jain, S.M.; Li, M.; Manzhos, S.; Feron, K.; Pitchaimuthu, S.; Liu, Z.; Motta, N.; Wang, H.; Durrant, J.R.; et al. Dopant-free novel hole-transporting materials based on quinacridone dye for high-performance and humidity-stable mesoporous perovskite solar cells. J. Mater. Chem. A 2019, 7, 5315-5323. [CrossRef]

80. Lin, Y.-S.; Abate, S.Y.; Lai, K.-W.; Chu, C.-W.; Lin, Y.-D.; Tao, Y.-T.; Sun, S.-S. New Helicene-Type Hole-Transporting Molecules for High-Performance and Durable Perovskite Solar Cells. ACS Appl. Mater. Interfaces 2018, 10, 41439-41449. [CrossRef] [PubMed]

81. Qin, P.; Paek, S.; Dar, M.I.; Pellet, N.; Ko, J.; Grätzel, M.; Nazeeruddin, M.K. Perovskite Solar Cells with $12.8 \%$ Efficiency by Using Conjugated Quinolizino Acridine Based Hole Transporting Material. J. Am. Chem. Soc. 2014, 136, 8516-8519. [CrossRef]

82. Zhao, X.; Zhang, F.; Yi, C.; Bi, D.; Bi, X.; Wei, P.; Luo, J.; Liu, X.; Wang, S.; Li, X.; et al. A novel one-step synthesized and dopant-free hole transport material for efficient and stable perovskite solar cells. J. Mater. Chem. A 2016, 4, 16330-16334. [CrossRef]

83. Zhang, F.; Liu, X.; Yi, C.; Bi, D.; Luo, J.; Wang, S.; Li, X.; Xiao, Y.; Zakeeruddin, S.M.; Grätzel, M. Dopant-Free Donor (D) $-\pi-D-\pi-D$ Conjugated Hole-Transport Materials for Efficient and Stable Perovskite Solar Cells. ChemSusChem 2016, 9 , 2578-2585. [CrossRef] [PubMed]

84. Zhang, F.; Yi, C.; Wei, P.; Bi, X.; Luo, J.; Jacopin, G.; Wang, S.; Li, X.; Xiao, Y.; Zakeeruddin, S.M.; et al. A Novel Dopant-Free Triphenylamine Based Molecular "Butterfly" Hole-Transport Material for Highly Efficient and Stable Perovskite Solar Cells. Adv. Energy Mater. 2016, 6, 1600401. [CrossRef]

85. Zhang, F.; Zhao, X.; Yi, C.; Bi, D.; Bi, X.; Wei, P.; Liu, X.; Wang, S.; Li, X.; Zakeeruddin, S.M.; et al. Dopant-free star-shaped hole-transport materials for efficient and stable perovskite solar cells. Dye. Pigment. 2017, 136, 273-277. [CrossRef]

86. Qi, P.; Zhang, F.; Zhao, X.; Liu, X.; Bi, X.; Wei, P.; Xiao, Y.; Li, X.; Wang, S. Efficient, Stable, Dopant-Free Hole-Transport Material with a Triphenylamine Core for CH3 NH3 PbI3 Perovskite Solar Cells. Energy Technol. 2017, 5, 1173-1178. [CrossRef]

87. Liu, X.; Zhang, F.; Liu, Z.; Xiao, Y.; Wang, S.; Li, X. Dopant-free and low-cost molecular "bee" hole-transporting materials for efficient and stable perovskite solar cells. J. Mater. Chem. C 2017, 5, 11429-11435. [CrossRef]

88. Paek, S.; Qin, P.; Lee, Y.; Cho, K.T.; Gao, P.; Grancini, G.; Oveisi, E.; Gratia, P.; Rakstys, K.; Al-Muhtaseb, S.A.; et al. Dopant-Free Hole-Transporting Materials for Stable and Efficient Perovskite Solar Cells. Adv. Mater. 2017, 29, 1606555. [CrossRef]

89. Goodby, J.W.; Collings, P.J.; Kato, T.; Tschierske, C.; Gleeson, H.; Raynes, P. Handbook of Liquid Crystals; Wiley-VCH: Weinheim, Germany, 1998.

90. Cao, J.; Liu, Y.-M.; Jing, X.; Yin, J.; Li, J.; Xu, B.; Tan, Y.-Z.; Zheng, N. Well-Defined Thiolated Nanographene as Hole-Transporting Material for Efficient and Stable Perovskite Solar Cells. J. Am. Chem. Soc. 2015, 137, 10914-10917. [CrossRef]

91. Sun, C.; Wu, Z.; Yip, H.-L.; Zhang, H.; Jiang, X.-F.; Xue, Q.; Hu, Z.; Hu, Z.; Shen, Y.; Wang, M.; et al. Amino-Functionalized Conjugated Polymer as an Efficient Electron Transport Layer for High-Performance Planar-Heterojunction Perovskite Solar Cells. Adv. Energy Mater. 2016, 6, 1501534. [CrossRef]

92. Kim, Y.H.; Cho, H.; Heo, J.H.; Kim, T.S.; Myoung, N.; Lee, C.L.; Im, S.H.; Lee, T.W. Multicolored organic/inorganic hybrid perovskite light-emitting diodes. Adv. Mater. 2015, 27, 1248-1254. [CrossRef]

93. Calió, L.; Momblona, C.; Gil-Escrig, L.; Kazim, S.; Sessolo, M.; Sastre-Santos, Á.; Bolink, H.J.; Ahmad, S. Vacuum deposited perovskite solar cells employing dopant-free triazatruxene as the hole transport material. Sol. Energy Mater. Sol. Cells 2017, 163, 237-241. [CrossRef]

94. Wang, B.; Zeng, Q.; Sun, Z.; Xue, S.; Liang, M. Molecularly engineering of truxene-based dopant-free hole-transporting materials for efficient inverted planar perovskite solar cells. Dye. Pigment. 2019, 165, 81-89. [CrossRef]

95. Molina-Ontoria, A.; Zimmermann, I.; Garcia-Benito, I.; Gratia, P.; Roldán-Carmona, C.; Aghazada, S.; Graetzel, M.; Nazeeruddin, M.K.; Martín, N. Benzotrithiophene-Based Hole-Transporting Materials for 18.2 \% Perovskite Solar Cells. Angew. Chem. Int. Ed. 2016, 55, 6270-6274. [CrossRef]

96. Peng, Y.-K.; Lee, K.-M.; Ting, C.-C.; Hsu, M.-W.; Liu, C.-Y. Making benzotrithiophene derivatives dopant-free for perovskite solar cells: Step-saving installation of $\pi$-spacers by a direct $\mathrm{C}-\mathrm{H}$ arylation strategy. J. Mater. Chem. A 2019, 7, 24765-24770. [CrossRef]

97. Chen, H.; Fu, W.; Huang, C.; Zhang, Z.; Li, S.; Ding, F.; Shi, M.; Li, C.-Z.; Jen, A.K.-Y.; Chen, H. Molecular Engineered HoleExtraction Materials to Enable Dopant-Free, Efficient p-i-n Perovskite Solar Cells. Adv. Energy Mater. 2017, 7, 1700012. [CrossRef]

98. Xue, Y.; Wu, Y.; Li, Y. Readily synthesized dopant-free hole transport materials with phenol core for stabilized mixed perovskite solar cells. J. Power Sources 2017, 344, 160-169. [CrossRef]

99. Zhang, Y.; Heng, P.; Su, H.; Li, J.; Guo, J.; Ning, P.; Wu, W.; Ren, T.; Wang, L.; Zhang, J. Star-Shaped Molecules as Dopant-Free Hole Transporting Materials for Efficient Perovskite Solar Cells: Multiscale Simulation. Chem. Rec. 2018, 938-946. [CrossRef]

100. Liu, N.; Zong, X.; Wang, Z.; Cui, T.; Liang, M.; Zhang, Y.; Xue, S. LiTFSI/TBP-free hole transport materials with nonlinear $\pi$-conjugation for efficient inverted perovskite solar cells. Electrochim. Acta 2019, 296, 283-293. [CrossRef]

101. Duan, L.; Chen, Y.; Yuan, J.; Zong, X.; Sun, Z.; Wu, Q.; Xue, S. Dopant-free X-shaped D-A type hole-transporting materials for p-i-n perovskite solar cells. Dye. Pigment. 2020, 178, 108334. [CrossRef]

102. Duan, L.; Chen, Y.; Jia, J.; Zong, X.; Sun, Z.; Wu, Q.; Xue, S. Dopant-Free Hole-Transport Materials Based on 2,4,6-Triarylpyridine for Inverted Planar Perovskite Solar Cells. ACS Appl. Energy Mater. 2020, 3, 1672-1683. [CrossRef] 
103. Bi, C.; Wang, Q.; Shao, Y.; Yuan, Y.; Xiao, Z.; Huang, J. Non-wetting surface-driven high-aspect-ratio crystalline grain growth for efficient hybrid perovskite solar cells. Nat. Commun. 2015, 6, 7747. [CrossRef] [PubMed]

104. Cui, B.-B.; Han, Y.; Yang, N.; Yang, S.; Zhang, L.; Wang, Y.; Jia, Y.; Zhao, L.; Zhong, Y.-W.; Chen, Q. Propeller-Shaped, TriarylamineRich, and Dopant-Free Hole-Transporting Materials for Efficient n-i-p Perovskite Solar Cells. ACS Appl. Mater. Interfaces 2018, 10, 41592-41598. [CrossRef] [PubMed]

105. Meng, F.; Jia, Y.; Wang, J.; Huang, X.; Gui, Z.; Huang, L.; Li, R.; Chen, R.; Xu, J.; Chen, W.; et al. Dopant-Free Hole Transporting Molecules for Highly Efficient Perovskite Photovoltaic with Strong Interfacial Interaction. Sol. RRL 2019, 3, 1900319. [CrossRef]

106. Chen, Y.-C.; Li, Y.-H.; Chung, C.-L.; Hsu, H.-L.; Chen, C.-P. Triphenylamine dibenzofulvene-derived dopant-free hole transporting layer induces micrometer-sized perovskite grains for highly efficient near $20 \%$ for p-i-n perovskite solar cells. Prog. Photovolt. 2020, 28, 49-59. [CrossRef]

107. Lai, X.; Du, M.; Meng, F.; Li, G.; Li, W.; Kyaw, A.K.K.; Wen, Y.; Liu, C.; Ma, H.; Zhang, R.; et al. High-Performance Inverted Planar Perovskite Solar Cells Enhanced by Thickness Tuning of New Dopant-Free Hole Transporting Layer. Small 2019, 15, e1904715. [CrossRef] [PubMed]

108. Shen, C.; Wu, Y.; Zhang, H.; Li, E.; Zhang, W.; Xu, X.; Wu, W.; Tian, H.; Zhu, W.-H. Semi-Locked Tetrathienylethene as a Building Block for Hole-Transporting Materials: Toward Efficient and Stable Perovskite Solar Cells. Angew. Chem. Int. Ed. 2019, 58, 3784-3789. [CrossRef] [PubMed]

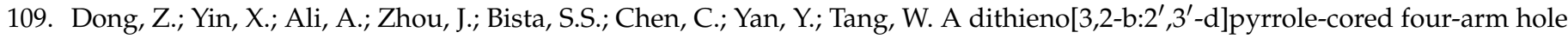
transporting material for over 19\% efficiency dopant-free perovskite solar cells. J. Mater. Chem. C 2019, 7, 9455-9459. [CrossRef]

110. Li, Z.; Zhu, Z.; Chueh, C.-C.; Jo, S.B.; Luo, J.; Jang, S.-H.; Jen, A.K.-Y. Rational Design of Dipolar Chromophore as an Efficient Dopant-Free Hole-Transporting Material for Perovskite Solar Cells. J. Am. Chem. Soc. 2016, 138, 11833-11839. [CrossRef] [PubMed]

111. Liu, X.; Zheng, X.; Wang, Y.; Chen, Z.; Yao, F.; Zhang, Q.; Fang, G.; Chen, Z.-K.; Huang, W.; Xu, Z.-X. Dopant-Free Hole-Transport Materials Based on Methoxytriphenylamine-Substituted Indacenodithienothiophene for Solution-Processed Perovskite Solar Cells. ChemSusChem 2017, 10, 2833-2838. [CrossRef] [PubMed]

112. Zhang, J.; Xu, B.; Yang, L.; Mingorance, A.; Ruan, C.; Hua, Y.; Wang, L.; Vlachopoulos, N.; Lira-Cantú, M.; Boschloo, G.; et al Incorporation of Counter Ions in Organic Molecules: New Strategy in Developing Dopant-Free Hole Transport Materials for Efficient Mixed-Ion Perovskite Solar Cells. Adv. Energy Mater. 2017, 7, 1602736. [CrossRef]

113. Zhang, J.; Sun, Q.; Chen, Q.; Wang, Y.; Zhou, Y.; Song, B.; Yuan, N.; Ding, J.; Li, Y. High efficiency planar p-i-n perovskite solar cells using low-cost fluorene-based hole transporting material. Adv. Funct. Mater. 2019, 29, 1900484. [CrossRef]

114. Wang, L.; Zhang, J.; Liu, P.; Xu, B.; Zhang, B.; Chen, H.; Inge, A.K.; Li, Y.; Wang, H.; Cheng, Y.-B.; et al. Design and synthesis of dopant-free organic hole-transport materials for perovskite solar cells. Chem. Commun. 2018, 54, 9571-9574. [CrossRef]

115. Guo, K.; Wu, M.; Yang, S.; Wang, Z.; Li, J.; Liang, X.; Zhang, F.; Liu, Z.; Wang, Z. Introduction of fluorine into spiro[fluorene-9,9'xanthene]-based hole transport material to obtain sensitive-dopant-free, high efficient and stable perovskite solar cells. Sol. $R R L$ 2019, 3, 1800352. [CrossRef]

116. Liu, F.; Wu, F.; Tu, Z.; Liao, Q.; Gong, Y.; Zhu, L.; Li, Q.; Li, Z. Hole Transport Materials Based on 6,12-Dihydroindeno[1,2b]fluorine with Different Periphery Groups: A New Strategy for Dopant-Free Perovskite Solar Cells. Adv. Funct. Mater. 2019, 29, 1901296. [CrossRef]

117. Cao, Y.; Li, Y.; Morrissey, T.; Lam, B.; Patrick, B.O.; Dvorak, D.J.; Xia, Z.; Kelly, T.L.; Berlinguette, C.P. Dopant-free molecular hole transport material that mediates a $20 \%$ power conversion efficiency in a perovskite solar cell. Energy Environ. Sci. 2019, 12, 3502-3507. [CrossRef]

118. Yin, C.; Lu, J.; Xu, Y.; Yun, Y.; Wang, K.; Li, J.; Jiang, L.; Sun, J.; Scully, A.D.; Huang, F.; et al. Low-Cost N,N'-Bicarbazole-Based Dopant-Free Hole-Transporting Materials for Large-Area Perovskite Solar Cells. Adv. Energy Mater. 2018, 8, 1800538. [CrossRef]

119. Petrus, M.L.; Bein, T.; Dingemans, T.J.; Docampo, P. A low cost azomethine-based hole transporting material for perovskite photovoltaics. J. Mater. Chem. A 2015, 3, 12159-12162. [CrossRef]

120. Pham, H.D.; Gil-Escrig, L.; Feron, K.; Manzhos, S.; Albrecht, S.; Bolink, H.J.; Sonar, P. Boosting inverted perovskite solar cell performance by using 9,9-bis(4-diphenylaminophenyl)fluorene functionalized with triphenylamine as a dopant-free hole transporting material. J. Mater. Chem. A 2019, 7, 12507-12517. [CrossRef]

121. Yang, X.; Xi, J.; Sun, Y.; Zhang, Y.; Zhou, G.; Wong, W.-Y. A dopant-free twisted organic small-molecule hole transport material for inverted planar perovskite solar cells with enhanced efficiency and operational stability. Nano Energy 2019, 64, 103946. [CrossRef]

122. Lai, X.; Meng, F.; Zhang, Q.-Q.; Wang, K.; Li, G.; Wen, Y.; Ma, H.; Li, W.; Li, X.; Kyaw, A.K.K.; et al. A Bifunctional Saddle-Shaped Small Molecule as a Dopant-Free Hole Transporting Material and Interfacial Layer for Efficient and Stable Perovskite Solar Cells. Sol. RRL 2019, 3, 1900011. [CrossRef] 